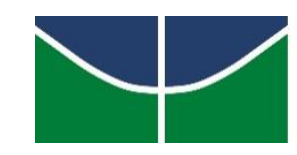

UNIVERSIDADE DE BRASÍLIA

INSTITUTO DE FÍSICA

\title{
ESTUDO SERS DE CARREADORES NANOPARTICULADOS DE FÁRMACOS BASEADOS EM NANOPARTÍCULAS MAGNÉTICAS E POLIMÉRICAS
}

\author{
QUEILA DA SILVA FERREIRA \\ ORIENTADOR: Prof. Dr. SEBASTIÃO W. DA SILVA
}

Brasília/DF

Maio 2015 


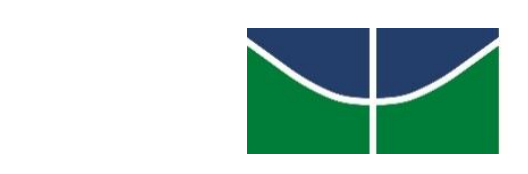

UNIVERSIDADE DE BRASÍLIA

INSTITUTO DE FÍSICA

\section{ESTUDO SERS DE CARREADORES NANOPARTICULADOS DE FÁRMACOS BASEADOS EM NANOPARTÍCULAS MAGNÉTICAS E POLIMÉRICAS}

Tese apresentada ao programa de Pós-Graduação em Física da Universidade de Brasília como parte dos requisitos à obtenção do título de DOUTOR em Física.

QUEILA DA SILVA FERREIRA

ORIENTADOR: Prof. Dr. SEBASTIÃO W. DA SILVA

Maio 2015 


\section{BANCA EXAMINADORA}

Prof. Dr. Sebastião William da Silva - Orientador

(Instituto de Física/Universidade de Brasília)

Prof. Dr. Junio Márcio Rosa Cruz

(Instituto de Física/Universidade de Brasília)

Prof. Dr. João Paulo Longo

(Instituto de Biologia/Universidade de Brasília)

Prof. Dr. Marcelo Henrique de Souza

(Instituto de Química/UnB-Ceilândia)

Prof. Dr. Noélio de Oliveira DAntas

(Departamento de Física/Universidade Federal de Uberlândia) 


\section{Índice}

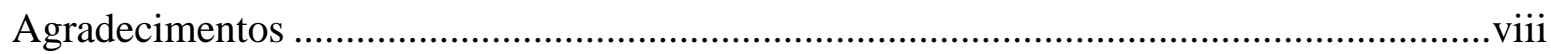

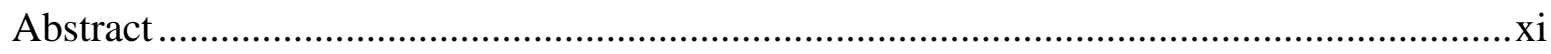

Lista de Símbolos e abreviaturas ................................................................................

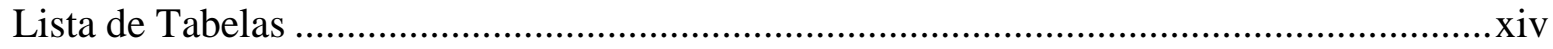

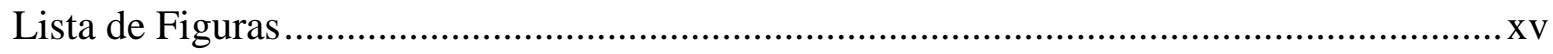

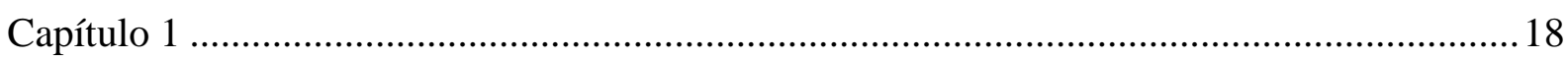

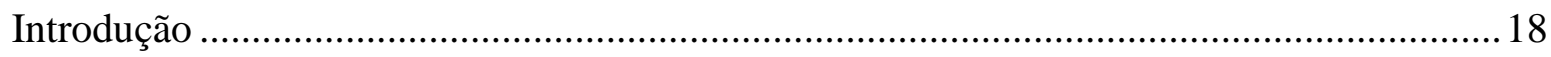

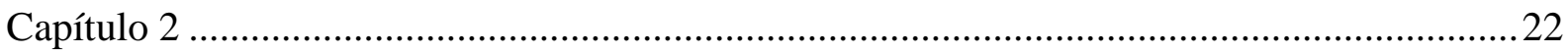

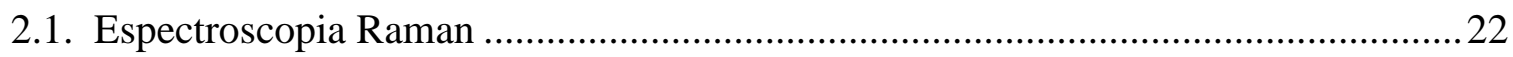

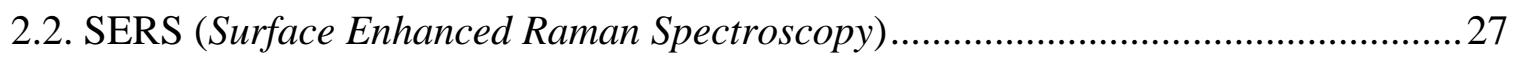

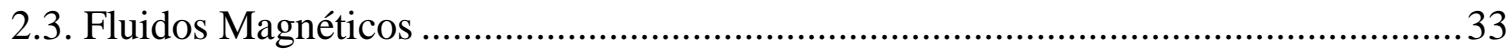

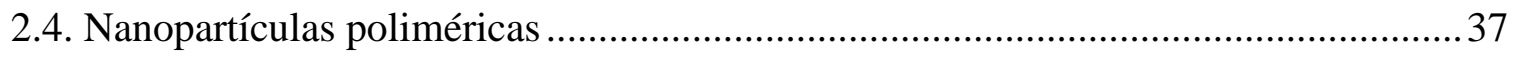

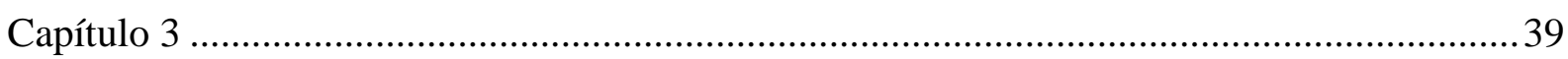

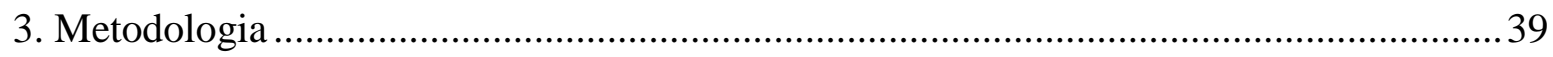

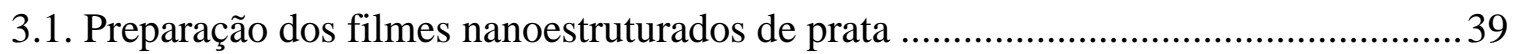

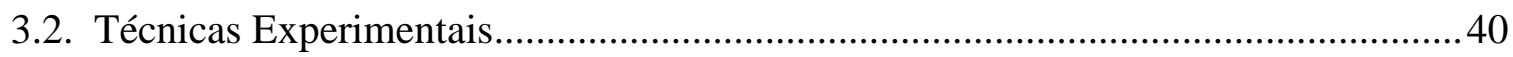


Capítulo 4 42

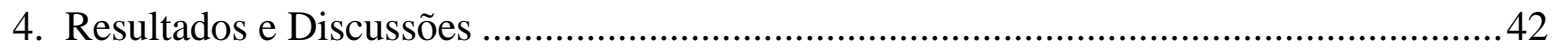

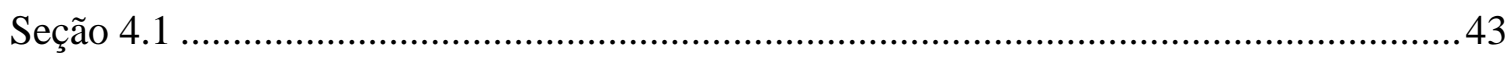

Estudo do arranjo de moléculas de Rifampicina adsorvidas sobre a superfície das nanopartículas e o efeito da luz nas propriedades físico-químicas.

Seção 4.2 61

Estudo do ancoramento do SELOL sobre nanopartículas magnéticas e da estabilidade após aquecimento. 61

Seção 4.3 71

Estudo do carregamento de Itraconazol em Nanopartículas de PLGA. 71

Capítulo 5 84

5.1. Conclusões Gerais. 84

5.2. Perspectivas Futuras. 87

Bibliografia 88 
Acredite em você mesmo, pois é só você que pode se alto julgar.

Ouse, arrisque e nunca se arrependa.

Não desista jamais e saiba valorizar quem te ama, esses sim merecem seu respeito. Quanto ao resto, bom, ninguém nunca precisou de restos para ser feliz. 
Dedico este trabalho a toda minha família.

Em especial aos meus pais Antônio e Elidia, e aos meus irmãos Wesley e Thainá. Que são meu alicerce e porto seguro. 


\section{Agradecimentos}

A jornada foi grande para que eu chegasse aqui, são muitos que passaram pela minha vida não somente nesses quatro anos, mas por toda minha vida acadêmica, por isso tentarei aqui retribuir o carinho que todos tiveram comigo. Gostaria de agradecer:

Primeiro a Deus pela minha vida e todas as realizações.

A minha família, primos, tios que mesmo estando longe nunca deixaram de me apoiar e incentivar para que assim eu alcançasse meus objetivos.

Ao meu namorado Jussiglê, que mesmo estando longe se fez presente.

Ao meu orientador Prof. Dr. Sebastião William da Silva, pela orientação, por todas as discussões, apoio, paciência, credibilidade a mim depositados e principalmente pela amizade ao longo desses quatro anos. A minha gratidão lhe será eterna.

A Prof ${ }^{a}$. Dr ${ }^{\mathrm{a}}$. Luciana R. Guilherme da Universidade Federal de Goiás pelas amostras de Rifampicina.

A Prof ${ }^{\mathrm{a}}$ Dr $^{\mathrm{a}}$ Emília Celma de Oliveira Lima, do Instituto de Química/UFG pela preparação das amostras de Selol.

A $\operatorname{Dr}^{\mathrm{a}}$ Livia C. M. Avelino do Instituto de Biologia/UnB pelas medidas de MET e aquecimento de campo magnético alternado das amostras de Selol.

A Dr $^{\mathrm{a}}$ Jaqueline Rodrigues da Silva do Instituto de Biologia/UnB pelas amostras de nanopartículas de PLGA carregadas com Itraconazol.

Ao Prof. Dr. Ricardo Gargano por ser mais que um professor, ser amigo.

A Prof. ${ }^{a}$ Dr. ${ }^{a}$ Letícia Coelho pela orientação do projeto REUNI.

A Camila Messias, por compartilhar seu conhecimento em SERS e sempre disposta a ajudar, e pela amizade que continua mesmo a distância.

A Letícia Massa, por ter me recebido de braços abertos em sua casa quando cheguei em Brasília, sem nem me conhecer, isso é uma atitude rara. 
A minha amiga Nádia, que com seu jeito muito danado e expansivo sempre dava um jeito de tornar aqueles dias cansativos, divertidos. Agradeço também á sua mãe e irmã, dona Terezinha e Mágda, que me acolheram como sua família.

A Aline que sempre foi tão atenciosa e carinhosa comigo, admiro sua força.

A Liz e ao Marco, pelos almoços peruanos.

Ao Turista, por ter me recebido esses últimos meses em sua "república", e aos seus filhos Caio e Vitor por terem me ensinado a jogar Catan, e pelas tentativas de me explicarem os “judsos" de Naruto.

A Lauri pela paciência nesses últimos dias, e a Mônica pelos chás.

Ao Mário pelas incansáveis assistências com os computadores.

As minhas amigas de graduação Geovana e Daniela pelo companheirismo e amizade durante esses longos anos.

A Ísis pelo jeito sempre carismático em conversar e a Grazi pelos deliciosos bolos que sua mãe fez para nós.

Aos meus demais "irmãos" e "primos" de coração: Tiago, Fábio Nakagomi, Lucélia, Roberto, Camila Letti, Antônia, Luís, Ana Paula, Leandro, Valdeir, Cléver.

A todos os grandes amigos que fiz ao longo desses anos: Pedro Dias, Keila, Rhuiago, Igo, Rodolpho, Eri, Júnior, Marcelão e Will meu muito obrigado a todos pela amizade.

Aos professores do Instituto de Física pelo aprendizado durante esses anos.

Aos funcionários da secretaria do Instituto de Física, Sandra e Thalles, pela disponibilidade e simpatia.

A CAPES pela bolsa a mim concedida.

E a todos aqueles que direta ou indiretamente contribuíram para a execução deste trabalho. 


\section{Resumo}

Neste trabalho a técnica de espalhamento Raman intensificado por superfície (Surface Enhanced Raman Spectroscopy - SERS) foi utilizada no estudo de carreadores nanoparticulados de fármacos baseados em nanopartículas magnéticas (NPMs) e poliméricas. Para isso, filmes nanoestruturados de prata, obtidos por eletrodeposição, foram usados como substratos SERS ativos. Os fármacos utilizados foram: Rifampicina (RIF) e Selol, adsorvidos à superfície das NPs de magnetita e Itraconazol (ITZ) carregado em nanopartículas de PLGA (ITZ@PLGA-nano). A estabilidade fotoquímica da RIF assim como a estabilidade do ancoramento das moléculas de Selenitotriglicerídeos (Selol) após aquecimento por campo magnético alternado também foram investigados. Além da técnica SERS as técnicas de MET, MEV, FTIR, Uv/Vis, potencial Zeta $(\zeta)$ e Espalhamento de Luz Dinâmico (DLS) foram empregadas na caracterização das amostras. Os dados SERS mostraram que o ancoramento das moléculas de RIF e de Selol à superfície das NPs de magnetita, pré-cobertas com uma bicamada de Ácido Láurico (AL), ocorre em ambos os casos por meio da ligação do grupo carboxilato externa à bicamada de $\mathrm{AL}$ com o grupo $\mathrm{OOSeO}$, para caso da molécula de Selol e, com o nitrogênio piperazina adjacente ao nitrogênio imina para o caso da molécula de RIF. Adicionalmente, foi verificado que a molécula de RIF é menos susceptível a degradação fotoquímica enquanto adsorvida sobre a superfície das NPs e que em torno de $50 \%$ do teor inicial das moléculas de Selol permanecem ancoradas à superfície das NPs após aquecimento por campo magnético alternado. Com relação ao sistema ITZ@PLGA-nano, verificou-se, que diferentemente do ITZ livre (ITZ+PLGA-nano), o ITZ carregada pelas NPs de PLGA não se adsorve à superfície do filme de prata em virtude do impedimento estérico provocado pelo PLGA. Por outro lado, as mudanças espectrais observadas entre o espectro Raman do ITZ pó e espectro SERS da amostra ITZ+PLGA-nano estão associadas com a adsorção da molécula de ITZ à superfície do filme de prata nanoestruturado por meio da interação do nitrogênio heterocíclico do ITZ com os átomos de Ag do substrato. Além do mais, as evidências espectrais mostraram que, ao ser adsorvida à superfície do filme prata, a molécula de ITZ se orienta paralelamente à superfície de prata.

Palavras-chave: SERS, Raman, Nanopartículas Magnéticas, Carreadores de Fármacos, Polímeros. 


\section{Abstract}

In this work, the technique of Surface-Enhanced Raman Spectroscopy (SERS) was used in the study of nanoparticle drug carriers based on magnetic nanoparticles (MNPs) and polymeric nanoparticles. For this purpose, silver nanostructured films obtained by electrodeposition were used as SERS active substrates. The drugs used were: Rifampicin (RIF) and Selol, adsorbed onto the surface of the magnetite NPs, and Itraconazole (ITZ) loaded in PLGA nanoparticles (ITZ@PLGA-nano). The photochemical stability of the RIF and the stability of the anchoring of Selol molecules after heating with an alternating magnetic field were investigated. In additional to the SERS technique, TEM, SEM, FTIR, UV/Vis , Zeta potential $(\zeta)$ and Dynamic Light Scattering (DLS) techniques were used to characterize the samples. The SERS data showed that the anchoring of the RIF and Selol molecules onto the surface of the magnetite NPs, pre-coated with a bilayer of Lauric Acid (LA) occurs in both cases with the binding of the external carboxylate group of LA-bilayer with the $O O S e O$ group in the case of Selol molecule and with the piperazine nitrogen adjacent to the imine nitrogen in the case of RIF molecule. Additionally it, has been found that the RIF molecule is less susceptible to photochemical degradation while adsorbed onto the surface of the NPs and around $50 \%$ of the initial content of Selol molecules remain anchored to the surface of the NPs, after heating by an alternating magnetic field. In respect to the ITZ@PLGA-nano system it was verified that, unlike free ITZ (ITZ+PLGA-nano), ITZ loaded PLGA NPs do not adsorb to the silver film surface due to the steric hindrance caused by the PLGA. On the other hand, the spectral changes observed between the Raman spectra of the ITZ powder and SERS spectrum of the ITZ+PLGA-nano sample, were associated with the adsorption of an ITZ molecule onto the surface of the nanostructured silver film through interaction of the ITZ heterocyclic nitrogen with Ag atoms from the substrate. Moreover, spectral evidence demonstrated that when an ITZ molecule is adsorbed onto the surface of the silver film, it is oriented parallel to the silver surface.

Keywords: SERS, Raman, Magnetic Nanoparticles, Drug Carriers, Polymer 


\section{Lista de Símbolos e abreviaturas}

E

Campo Eletromagnético

$\mathbf{E}_{\mathbf{0}}$

Amplitude

$\omega_{\mathrm{E}}$

Frequência incidente

$\alpha$

Polarizabilidade

$\mathbf{p}$

Momento de dipolo

$\mathrm{t}$

Tempo

q

Coordenada generalizada

$\omega_{v}$

Frequência vibracional

$\Psi$

Função de onda

$\omega_{1}$

Frequência espalhada

I

Intensificação

$\varepsilon_{1}$

Constante dielétrica do metal

$\varepsilon_{2}$

Constante dielétrica do ambiente

$\delta$

Modo bending

$v$

Modo stretching

$v_{\mathrm{s}}$

Modo stretching simétrico

$v_{\text {as }}$

Modo stretching assimétrico

$\omega$

Modo wagging

$\tau$

Modo twisting

$\varsigma$

Modo scissoring

$\rho$

Modo rocking

$\zeta$

Zeta

$\beta$

Modo bending no plano

$\gamma$

Modo bending fora do plano 
$\theta$

MET

MEV

DLS

NPMs

RIF

DMSO

$\mathrm{AgNO}_{3} \quad$ Nitrato de prata

SELOL Selenitotriglicerídeos

ITZ

PLGA

PLA

PGA

PVA

Modo respiração

Nanopartículas magnéticas

Rifampicina

Dimetilsulfóxido

Itraconazol

Poli(lático-co-glicólico)

Poli (ácido lático)

Poli (ácido glicólico)

Poli (acetato de vinilo)

Microscopia eletrônica de transmissão

Microscopia eletrônica de varredura

Espalhamento de luz dinâmico 


\section{Lista de Tabelas}

Tabela 4.1: Tabela com a posição dos modos vibracionais obtidos a partir da técnica SERS para RIF livre, FMBL e FMBL/RIF.

Tabela 4.2: Tabela com a posição dos modos vibracionais obtidos a partir da técnica SERS e Raman normal para bicamada de AL, Selol puro e FMS.

Tabela 4.3: Razão entre as intensidades dos picos de Selol ( $\left.I_{\text {selol }}\right)$ e da bicamada de AL $\left(I_{A L}\right)$. 70

Tabela 4.4: Posição dos modos vibracionais obtidos a partir da técnica SERS para o ITZ pó, ITZ+PLGA-nano,ITZ@PLGA-nanoeITZ@PLGA-nano sonicada. 79 


\section{Lista de Figuras}

Figura 2.1: Representação esquemática de espectros Rayleigh e de espectros Raman Stokes e Raman anti-Stokes (Fonte: Ref. [9]).

Figura 2.2 : Mecanismo de espalhamento de um fóton ao interagir com uma molécula (Adaptado da referência [10])..... 26

Figura 2.3: Espectro de absorção no UV-VIS de colóide de prata preparado pelo método de (a) Creighton et al. e (b) Lee-Meisel.(Fonte Refs. [17] e [18] )

Figura 2.4: Diagrama ilustrando o mecanismo de intensificação SERS pelo modelo químico(Adaptado da Ref. [4]).

Figura 2.5: Modelo de fluido magnético surfactado. 34

Figura 2.6: Modelo de fluido magnético iônico.

Figura 2.7: Representação esquemática dos tipos de nanopartículas poliméricas e possíveis disposições do fármaco nas mesmas: a) Fármaco dissolvido dentro da nanocápsula. b) Fármaco adsorvido à superfície da nanocápsula. c) Fármaco retido na matriz polimérica da nanoesfera. d) Fármaco adsorvido ou disperso na matriz polimérica da nanoesfera (Fonte: Ref. [33]). 38

Figura 4.1 - Estrutura química da molécula de Rifampicina. 44

Figura 4.2: Micrografia MET (a) e histograma da distribuição do tamanho das partículas (b) obtidos a partir da amostra FMBL.

Figura 4.3: Espectros de Infravermelho das amostras (i) RIF livre, (ii) FMBL e (iii) $F M B L / R I F$, antes (linha preta) e após (linha vermelha) à exposição a luz.

Figura 4.4: Espectros SERS da amostra de (i) RIF livre (ii) FMBL e (iii) FMBL/RIF, antes (a) e após (b) exposição a luz. Para facilitar as análises os modos vibracionais foram destacados. As cores em vermelho, verde e azul são usadas para indicar os modos vibracionais provenientes do DMSO, Rifampicina e da bicamada de AL, respectivamente. ..51 
Figura 4.5: Espectros SERS da RIF livre (linha vermelha) e FMBL/RIF (linha preta). 55

Figura 4.6: Representação esquemática para o ancoramento da Rifampicina nas nanopartículas de magnetita recobertas com ácido láurico. 58

Figura 4.7: Estrutura do Selol. 62

Figura 4.8: Micrografias MET, das amostras FMS (a) e FMBL (b). 65

Figura 4.9: Espectros SERS das amostras FMBL (a) FMS (b) FMSD (c). E em (d) tem-se o espectro Raman normal do Selol puro. 68

Figura 4.10: Representação das moléculas de Itraconazol (a) e do polímero PLGA (b), respectivamente. Sendo que o PLGA é composto por outros dois polímeros, o poli (ácido lático) - PLA e o poli (ácido glicólico) - PGA. .72

Figura 4.11: Micrografias MEV para as amostras de nanopartículas de PLGA pura (a) e ITZ@PLGA-nano $(b)$. .74

Figura 4.12: Espectro FTIR da amostra ITZ pó (i), mistura física de ITZ com nanopartículas de PLGA (ITZ+PLGA-nano) (ii),nanopartículas de PLGA carregadas com ITZ (ITZ@PLGAnano) (iii) e nanopartículas de PLGA (iv). 75

Figura 4.13: Espectro SERS da amostra ITZ pó (i), nanopartículas de PLGA (ii) mistura física de ITZ e nanopartículas de PLGA (iii), nanopartículas de PLGA carregadas com ITZ após sonicação (iv) nanopartículas de PLGA carregadas com ITZ (iv). 78

Figura 4.14: Esquema do arranjo espacial proposto para a adsorção do ITZ sobre a superfície de prata. 


\section{Capítulo 1}

\section{Introdução}

Na última década, acompanhando o desenvolvimento acelerado da nanotecnologia, o uso de sistemas nanoparticulados no tratamento das mais diversas enfermidades tem se destacado. O interesse crescente da área biomédica nos sistemas nanoparticulados é justificado por suas características peculiares, tais como: (i) alta proporção na relação superfície/volume e consequente aumento de reatividade biológica, (ii) possível proteção dos compostos da inativação antes de atingirem o local da ação e o possível aumento da penetração intracelular, (iii) capacidade de serem conduzidas e retidas em alvos selecionados por meio de gradiente de campo magnético externo, (iv) comportamento como partículas superparamagnéticas, não retendo o magnetismo após a remoção do campo magnético. Neste sentido, a medicina atual vem desenvolvendo esforços para o diagnóstico, tratamento e cura 
dos mais variados tipos de enfermidade. Para isto, têm-se recorrido ao desenvolvimento de sensores biológicos, marcação e separação de células tumorais, sistemas de entrega de drogas (drug delivery) e quimioterápicos cada vez mais eficientes. Neste contexto, este trabalho se insere no âmbito do "Instituto Nacional de Tecnologia (INCT): Nanobiotecnologia" o qual tem por objetivo o desenvolvimento, caracterização e aplicação de complexos nanoestruturados em saúde humana e veterinária. Estes complexos nanoestruturados são geralmente construídos a partir do acoplamento de drogas ou biomoléculas a materiais nanoestruturados (magnéticos e não-magnéticos).

No entanto, para tornar essas aplicações (marcadores biológicos e sistema para entrega de drogas, por exemplo) tão eficazes quanto possível, é essencial conhecer as propriedades físico-químicas da interface partículas/cobertura. Nesse contexto a espectroscopia Raman tem se apresentado com uma técnica muito útil [1].

O efeito Raman consiste no espalhamento inelástico da luz pela matéria. Nesse processo, um quantum de radiação incidente é aniquilado e outro quantum espalhado é criado. Isso ocorre com a criação (no processo Stokes) ou aniquilação (anti-Stokes) de uma excitação no meio. Estas excitações (fônons, plasmons, éxcitons) atuam como "sondas" internas do material, tornando a espectroscopia Raman sensível às suas características químicas e estruturais. Por fornecer informações sobre as energias vibracionais de moléculas e cristais, a espectroscopia Raman tem se mostrado uma poderosa ferramenta na identificação e quantificação de espécies químicas presentes em uma determinada amostra, uma vez que o conjunto dos modos vibracionais da amostra está univocamente relacionado à sua identidade química [2]. Deste modo a espectroscopia Raman proporciona, em poucos segundos, importantes informações a respeito das propriedades químicas, eletrônicas e estruturais de compostos orgânicos ou inorgânicos, nas fases sólidas, líquidas ou gasosas. 
Embora a espectroscopia Raman convencional forneça importantes informações a respeito das propriedades químicas e estruturais de um grande número de macromoléculas biológicas, o seu uso no estudo destes sistemas ainda é limitado, pois muitas vezes eles apresentam pequena seção de choque Raman, baixa concentração de moléculas ou efeitos de fluorescência. Neste contexto, a técnica SERS emerge como uma ferramenta poderosa e inovadora no estudo destes sistemas em particular [3].

O efeito SERS, consiste na intensificação do sinal Raman, por fatores que podem ser maiores que $10^{6}$, de moléculas adsorvidas ou nas proximidades de superfícies metálicas nanoestruturadas (geralmente metais como prata, ouro ou cobre) [4]. A existência desse efeito permite o uso da espectroscopia Raman de forma muito mais abrangente, abrindo possibilidades da aplicação da espectroscopia vibracional para detecção de até uma única molécula [5].

Assim, o presente trabalho tem por objetivo principal a utilização da técnica SERS no estudo de carreadores nanoparticulados de fármacos baseado em nanoparticulas magnéticas e poliméricas. Para isso, filmes nanoestruturados de prata, obtidos por eletrodeposição, foram usados como substratos SERS ativo. Os fármacos utilizados foram: Rifampicina (RIF) e Selol, adsorvidos à superfície das NPs de magnetita e Itraconazol (ITZ) carregado em nanopartículas de PLGA.

Esta tese está assim organizada: no Capítulo 2 temos uma breve revisão da literatura sobre os efeitos Raman normal e SERS. No Capítulo 3 são apresentadas as metodologias empregadas na elaboração e caracterização das amostras. No Capítulo 4 são expostos os resultados e discussões obtidos ao longo deste trabalho, os quais foram divididos em três seções: O trabalho apresentado na Seção 4.1 tem como objetivo estudar o ancoramento e a degradação fotoquímica das moléculas de Rifampicina adsorvidas à nanopartículas de 
magnetita, pré-cobertas com uma bicamada de Ácido Láurico. Na Seção 4.2 é apresentado o estudo do ancoramento de moléculas de Selol, também adsorvidas à nanopartículas de magnetita e pré-cobertas com uma bicamada de Ácido Láurico. A estabilidade do ancoramento das moléculas de Selol após aquecimento por campo alternado também é investigada e apresentada. Por último, na Seção 4.3 o trabalho apresentado tem como objetivo investigar o carregamento do fármaco Itraconazol por nanopartículas do polímero PLGA. E por fim, no Capítulo 5 podem ser encontradas as conclusões finais e as perspectivas futuras deste trabalho de tese. 


\section{Capítulo 2}

Este capítulo tem como objetivo fazer uma breve revisão de alguns conceitos que srão úteis ao longo da tese. Inicialmente serão discutidos os efeitos Raman e SERS. Posteriormente, considerações relativas a fluidos magnéticos e nanopartículas poliméricas serão abordadas.

\subsection{Espectroscopia Raman}

As primeiras investigações sobre espalhamento de luz foram feitas em 1868 por John Tyndall. Em 1899, Lord Rayleigh comprovou as investigações de Tyndall mostrando que a intensidade da luz espalhada é inversamente proporcional à quarta potência do comprimento de onda, o que ficou conhecido como lei de Rayleigh [6]. 
Em 1923, o físico alemão Adolf Smekal postulou a existência do efeito Raman, onde em 1928 o mesmo foi comprovado experimentalmente pelo físico indiano Chandrasekhara V. Raman [7], sendo que em 1930 recebeu o prêmio Nobel pela sua descoberta e o estudo sobre o fenômeno. Ele observou em seus experimentos que quando um feixe de radiação eletromagnética monocromática atravessa um meio material, uma pequena parte da radiação espalhada tem frequência diferente da radiação incidente.

O espalhamento Rayleigh da radiação eletromagnética pode ser visto, como uma colisão elástica entre o fóton e os átomos do meio, na qual o fóton muda a direção de propagação do mesmo, mas conserva sua energia. No espalhamento Raman, o fóton sofre uma colisão inelástica, sendo então espalhado com energia diferente de seu valor inicial.

Considere uma onda eletromagnética $\mathbf{E}$ de amplitude $\mathbf{E}_{\mathbf{0}}$ e de frequência $\omega_{E}$, incidindo em uma molécula de polarizabilidade $\propto$ e criando um momento de dipolo induzido $\mathbf{p}=\propto \boldsymbol{E}$, podemos escrever[8]:

$$
\boldsymbol{E}=\boldsymbol{E}_{\mathbf{0}} \cos \left(\omega_{E} t\right)
$$

O momento de dipolo p gerado pelo campo elétrico, em primeira ordem é dado por:

$$
\boldsymbol{p}=\propto . \boldsymbol{E}=\propto . \boldsymbol{E}_{\mathbf{0}} \cos \left(\omega_{E} t\right)
$$

A luz incidente induz vibrações moleculares no sistema, afetando a polarizabilidade, que pode ser escrita como série da coordenada interna $q$ como:

$$
\propto=\propto_{0}+\left(\frac{d \propto}{d q}\right)_{0} q+\cdots
$$

onde $q$ é dado por:

$$
q=q_{0} \cos \left(\omega_{v} t\right)
$$


Substituindo as Eqs (2.3) e (2.4) em (2.2) o momento de dipolo induzido ficará:

$$
p=\propto_{0} \cdot E_{0} \cos \left(\omega_{E} t\right)+\left(\frac{d \propto}{d q}\right)_{0} q_{0} \cdot E_{0} \cos \left(\omega_{E} t\right) \cos \left(\omega_{v} t\right)
$$

sendo $\omega_{E}$ e $\omega_{v}$ as frequências da onda incidente e vibracional, respectivamente.

Levando em conta que $\cos (A) \cos (B)=\frac{1}{2}[\cos (A+B)+\cos (A-B)]$, a Eq.(2.5) assume a forma:

$$
\begin{aligned}
\boldsymbol{p}= & \propto_{0} \cdot \boldsymbol{E}_{0} \cos \left(\omega_{E} t\right) \\
& +\frac{1}{2}\left(\frac{d \propto}{d q}\right)_{0} q_{0} \cdot \boldsymbol{E}_{0}\left\{\cos \left[\left(\omega_{E}+\omega_{v}\right) t\right]+\cos \left[\left(\omega_{E}-\omega_{v}\right) t\right]\right\} .
\end{aligned}
$$

O primeiro termo corresponde ao espalhamento elástico (espalhamento Rayleigh). Para que haja contribuição do segundo termo é necessário que $\left(\frac{d \propto}{d q}\right)_{0} \neq 0$, ou seja se $\alpha$ for igual a uma constante o efeito Raman não pode existir, pois, nesse caso, as componentes de frequência Raman teriam amplitude zero. Assim para que o espalhamento Raman ocorra é necessário que haja variação da polarizabilidade com o deslocamento da coordenada $q$ em torno da posição de equilíbrio. Desse modo, a luz espalhada com frequência $\omega_{E}+\omega_{v}$ corresponde ao chamado espalhamento Raman anti-Stokes e a luz com frequência espalhada $\omega_{E}-\omega_{v}$ ao espalhamento Raman Stokes.

No espectro Raman tem-se, simetricamente em relação à linha Rayleigh, uma banda do lado de frequências mais baixas, a Stokes, e uma do lado de frequências mais altas, antiStokes, veja Figura 2.1. 

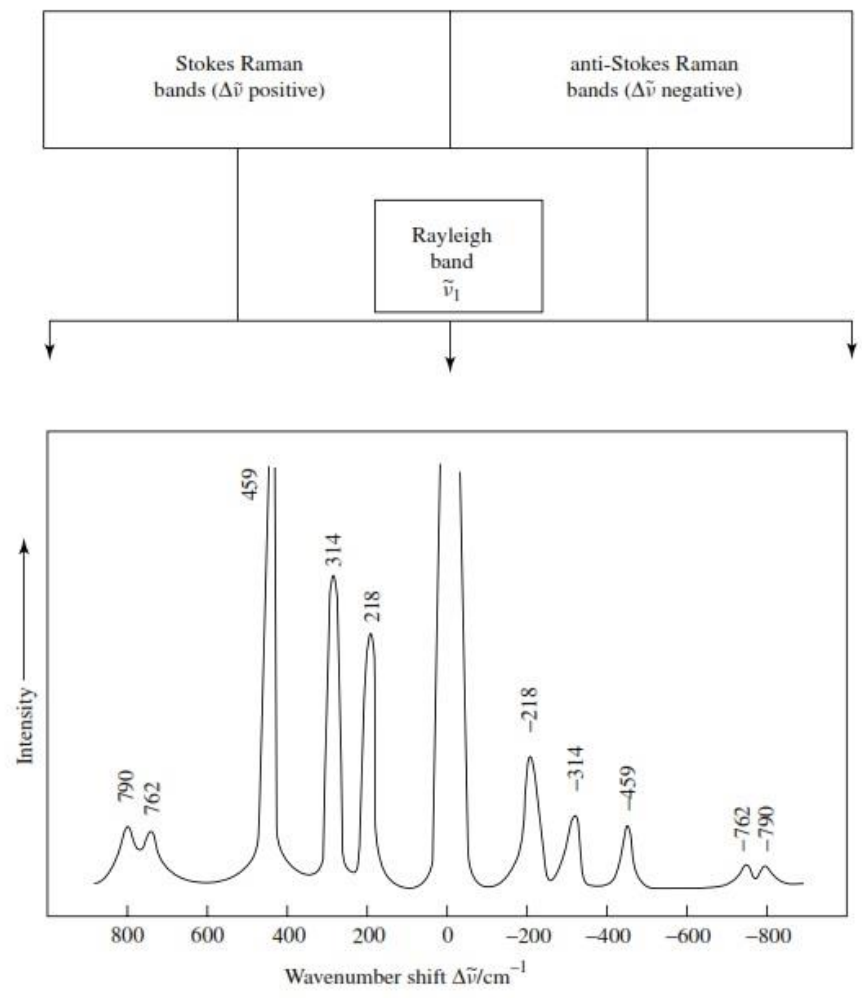

Figura 2.1: Representação esquemática de espectros Rayleigh e de espectros Raman Stokes e Raman anti-Stokes (Fonte: Ref. [9]).

Utilizando-se da descrição quântica do espalhamento Raman, pode-se escrever a polarizabilidade como [8]:

$$
\propto_{m n}=\int \psi_{m} \propto \psi_{n} d \tau,
$$

onde $\psi_{m}$ e $\psi_{n}$ são as funções de onda para os estados $m$ e $n$. Substituindo a Eq.(2.3) em (2.7), assim:

$$
\propto_{m n}=\propto_{0} \int \psi_{m} \psi_{n} d \tau+\left(\frac{d \propto}{d q}\right)_{0} \int \psi_{m} q \psi_{n} d \tau
$$

A primeira integral do lado direito da Eq.(2.8) é zero, devido à ortogonalidade das funções $\psi_{m}$ e $\psi_{n}$ já que no espalhamento Raman Stokes e anti-Stokes os estados vibracionais $m$ e $n$ 
são diferentes. Desta forma para que o segundo termo seja diferente de zero, ou seja, para que ocorra o espalhamento Raman é necessário que sejam satisfeitas as seguintes condições:

- $\left(\frac{d \propto}{d q}\right)_{0} \neq 0$, ou seja, que haja variação da polarizabilidade;

- $\int \psi_{m} q \psi_{n} d \tau \neq 0$, o produto $\psi_{m} q \psi_{n}$ deve ser par. Para que isso ocorra é necessário que o produto $\psi_{m} \psi_{n}$ seja ímpar, visto que $q$ é uma função ímpar.

Este mecanismo pode ser melhor compreendido no esquema da Fig.2.2.

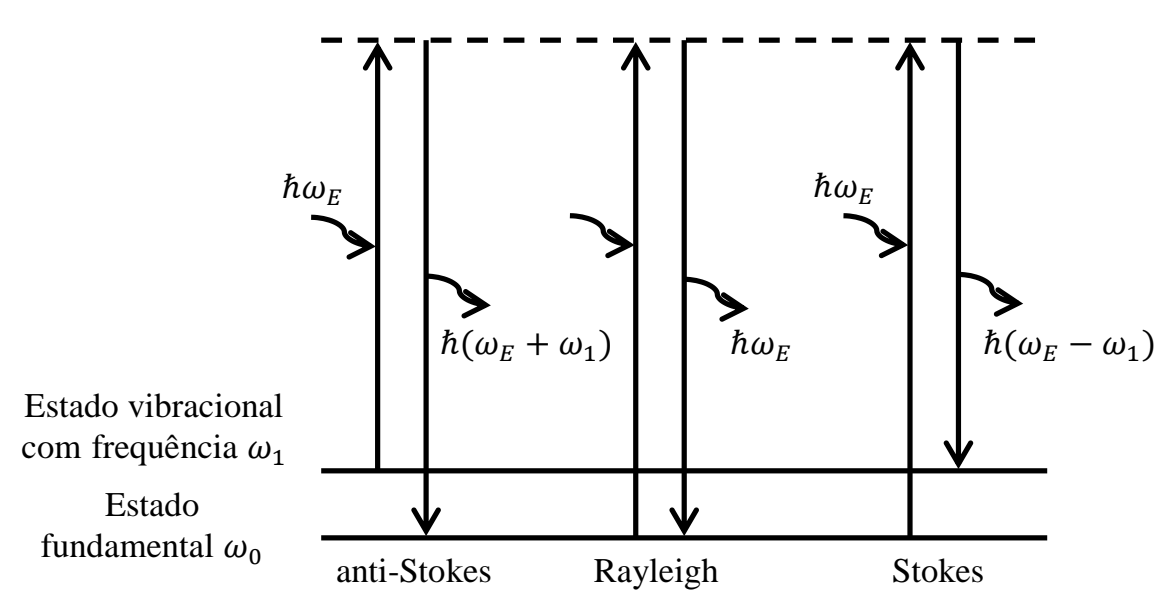

Figura 2.2 : Mecanismo de espalhamento de um fóton ao interagir com uma molécula (Adaptado da referência [10])

O espalhamento Raman anti-Stokes ocorre quando o fóton interage com uma molécula já num estado excitado $\hbar \omega_{1}$ e que, ao retornar para o estado fundamental $\hbar \omega_{0}$, emite um fóton com energia $\hbar \omega_{E}+\hbar \omega_{1}$. No caso do espalhamento Rayleigh após a interação do fóton com a molécula, esta volta ao mesmo nível de energia inicial e o fóton é espalhado sem modificação de frequência. Já o espalhamento Stokes é caracterizado pela excitação da molécula quando esta encontra-se em seu estado fundamental $\hbar \omega_{0}$ e, após ser excitada para o 
estado virtual, emite um fóton com energia $\hbar \omega_{E}-\hbar \omega_{1}$, e decai em seguida para um estado de energia maior que o fundamental.

\subsection{SERS (Surface Enhanced Raman Spectroscopy)}

O efeito SERS é um fenômeno no qual a intensidade do espalhamento Raman de moléculas adsorvidas ou próximas à superfície de certos metais (geralmente prata, ouro e cobre) é melhorada por fatores maiores que $10^{6}$ vezes. A baixa sensibilidade inerente do Raman normal limita sua aplicabilidade, mas o aumento da sensibilidade por meio do SERS resultou em aplicações mais generalizadas [11].

O primeiro trabalho relatando o fenômeno foi realizado por Fleischmann e colaboradores [12] em 1974, em que eles observaram um forte sinal Raman da piridina, ao ser adsorvida à superfície de eletrodos de prata. O objetivo do trabalho de Fleischamann era aumentar a seção de choque eletroquimicamente por meio da aplicação de vários ciclos oxirredução, o que permitiria a adsorção de um número maior de moléculas. A justificativa para o trabalho de Fleischmann decorre do fato de que a espectroscopia Raman normal não apresenta sensibilidade para analisar amostras distribuídas em monocamadas, uma vez que a seção de choque para o espalhamento Raman é de aproximadamente $10^{-30} \mathrm{~cm}^{-2} \cdot \mathrm{Sr}^{-1} \cdot$ molécula ${ }^{1}$ [10] e a densidade de moléculas adsorvidas era da ordem de $10^{14}-10^{15}$ moléculas por centímetro quadrado [4]. Assim através da técnica SERS observou-se uma relação sinal/ruído muito boa.

Dois trabalhos posteriores ao de Fleischmann mostraram que a intensificação de sinal por ele obtido (aproximadamente $10^{6}$ ) não poderia ser atribuída somente a área do eletrodo. No primeiro trabalho, Jeanmaire e Van Duyne [13] propuseram um mecanismo de 
intensificação do campo eletromagnético sobre a superfície nanoestruturada do eletrodo, enquanto no segundo trabalho, Albrecht e Creighton [14], propuseram que o espalhamento ressonante dos fótons Raman era devido à modificação dos estados eletrônicos moleculares através da interação com a superfície metálica, assim um novo efeito foi descoberto: SERS (Surface Enhanced Raman Spectroscopy) - espalhamento Raman intensificado por superfície.

Nestes quarenta anos da descoberta do efeito vários tipos de substratos foram testados, sendo que os mais empregados são: coloides, eletrodos e filmes. Tanto coloides como eletrodos oferecem vantagem de serem facilmente preparados.

- Eletrodos metálicos: consiste na ativação da superfície metálica dos eletrodos através da oxidação-redução do metal, por meio da variação do potencial aplicado ao eletrodo. Eletrodos metálicos preparados com nanopartículas de prata para investigação de moléculas são constantemente utilizados [15];

- UHV (ultra high vacuum): filmes de prata são preparados por deposição de quantidades adequadas de vapor do metal em pressões da ordem de $10^{-8}$ bar, sendo que a espessura da camada depositada é usualmente controlada por uma balança de quartzo [4];

- Coloides metálicos: metais em suspensão são preparados pela redução dos sais de metais dissolvidos na presença de um agente redutor apropriado, em um meio aquoso ou não. Os coloides de prata são os mais comuns por serem de fácil preparação, podendo ser bem caracterizados e requerem um mínimo de manipulação da amostra [16]. Os métodos mais empregados de preparação de coloides são os de Creighton et al. [17] e o de Lee-Meisel [18]. 
O método de Creighton et al. consiste no uso de borohidreto de sódio como agente redutor. A solução preparada tem coloração que varia do amarelo intenso ao marrom e seu espectro ótico apresenta banda centrada em torno de $390 \mathrm{~nm}$. Já o procedimento de LeeMeisel, emprega redução com citrato e as dispersões possuem coloração amareloesverdeadas, e apresentam máximo de absorção em torno de $410 \mathrm{~nm}$. A diferença entre os dois métodos de sintetização do coloide pode ser visto no espectro de absorção da Fig.2.3.

Conforme mencionado nos trabalhos citados, o efeito SERS pode ser explicado por meio de dois mecanismos, o eletromagnético e o químico. Sabe-se que a intensidade da luz espalhada na espectroscopia Raman normal, é proporcional ao quadrado do momento de dipolo induzido ( $\boldsymbol{p}$ ) pela radiação incidente. Logo, para uma molécula adsorvida na superfície de um eletrodo metálico, o momento de dipolo induzido é descrito como na Eq. 2.2. Assim tem-se que a contribuição química está relacionada com a modificação da polarizabilidade da molécula $(\propto)$ devido à transferência de carga entre a molécula e o metal. Já o efeito eletromagnético considera a intensificação do campo eletromagnético próximo à superfície do metal devido à ressonância com os plasmons de superfície [4].

Os dois mecanismos constituem-se fenômenos independentes e de efeito multiplicativo sobre a intensificação total, de modo que:

$$
I_{S E R S}=I_{M E} \cdot I_{M Q},
$$

onde $I_{S E R S}$ é a intensificação total observada, $I_{M E}$ é a intensificação devido ao Mecanismo Eletromagnético e $I_{M Q}$ é a intensificação devido ao Mecanismo Químico. 

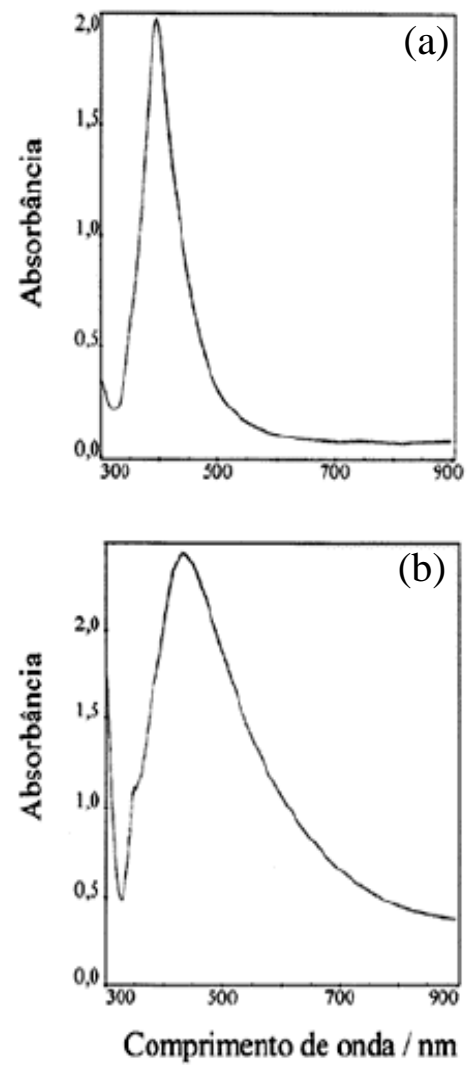

Figura 2.3: Espectro de absorção no UV-VIS de colóide de prata preparado pelo método de (a) Creighton et al. e (b) Lee-Meisel.(Fonte Refs. [17] e [18] )

\subsubsection{Mecanismo Eletromagnético}

O mecanismo eletromagnético para o efeito SERS é baseado na intensificação do campo elétrico na superfície do eletrodo devido à ressonância dos plasmons de superfície. A intensidade do espalhamento Raman é proporcional ao momento de dipolo induzido do sistema metal-molécula. A relação entre o momento de dipolo induzido e a intensidade do campo elétrico incidente é dada pela Eq.2.2.

O campo atuante no caso de uma molécula adsorvida depende da interação do campo elétrico da radiação incidente com o campo elétrico dos plasmons de superfície. Uma 
superfície metálica pode ser vista como um plasmon, isto é, formado por um conjunto de cargas negativas oscilantes. A oscilação coletiva dessas cargas é chamada de plasmons de superfície [19], a qual tem uma frequência característica dependente da natureza do metal e da rugosidade da superfície. Em uma superfície metálica lisa, a oscilação dos plasmons ocorre ao longo do plano da superfície de modo que pode ocorrer absorção, mas não espalhamento. Para haver espalhamento é preciso ter oscilação do plasmons perpendicularmente ao plano da superfície metálica e isto é conseguido quando se tem uma rugosidade na superfície.

Quando a frequência da radiação incidente se aproxima da frequência dos plasmons superficiais, ocorre ressonância, e por consequência a absorção da radiação. Neste caso, o campo elétrico na superfície devido à ressonância dos plasmons de superfície é muito mais intenso que o campo elétrico da radiação incidente, levando a intensificação do espalhamento.

Para compreendermos melhor o mecanismo eletromagnético podemos analisar o comportamento de uma esfera metálica com raio muito menor do que o comprimento de onda da luz, de modo que a esfera fica submetida a um campo elétrico uniforme. Assim o campo induzido na esfera pode ser escrito como [20]:

$$
E_{\text {induzido }}=\left[\frac{\varepsilon_{1}(\omega)-\varepsilon_{2}(\omega)}{\varepsilon_{1}(\omega)+2 \varepsilon_{2}(\omega)}\right] E_{\text {laser }}
$$

onde $\varepsilon_{1}(\omega)$ é complexo, e também função dielétrica do metal dependente da frequência; e $\varepsilon_{2}(\omega)$ é a do ambiente. Esta função é ressonante quando $\operatorname{Re}\left[\varepsilon_{1}(\omega)\right]=-2 \varepsilon_{2}(\omega)$ e quando a parte $\operatorname{Im}\left[\varepsilon_{1}(\omega)\right]$ for pequena [21]. A excitação dos plasmons de superfície aumenta consideravelmente o campo local experimentado por uma molécula adsorvida na superfície da partícula. 
Vale salientar que a utilização de metais como prata, ouro e cobre ou outros metais alcalinos na utilização dos substratos SERS deve-se ao fato da ressonância ocorrer na frequência do visível.

Pelo mecanismo eletromagnético pode-se chegar a uma intensificação do espalhamento Raman maior que $10^{6}$ vezes. Segundo esse modelo o espectro observado é fundamentalmente igual ao Raman normal, uma vez que não é necessária uma interação forte com a superfície. No entanto, o elevado fator de intensificação muitas vezes observado em vários sistemas, evidencia a existência de outro mecanismo paralelo de intensificação, o Mecanismo Químico.

\subsubsection{Mecanismo Químico}

O mecanismo químico do efeito SERS é assim chamado devido à sua dependência com a estrutura eletrônica da molécula adsorvida. Diferente do modelo eletromagnético, onde a intensificação do momento de dipolo induzido se deve a intensificação do campo elétrico na superfície do metal, no mecanismo químico a intensificação se deve ao aumento da polarizabilidade, gerada pela interação da molécula espalhadora com a superfície.

O surgimento de novos estados eletrônicos entre a molécula e o metal é o que intensifica o sinal nesse o mecanismo. Estes novos estados servem como intermediários ressonantes no espalhamento Raman. A radiação incidente, com energia $\hbar \omega_{0}$, é absorvida pelo metal numa região ativa SERS, local onde a molécula está quimio-adsorvida. Como consequência pode haver a formação de pares elétron-buraco no metal. O elétron ou buraco tunela para a molécula e, se permanecer nela o suficiente para que a molécula mude seu estado vibracional, o elétron ao retornar para o metal levará essa informação. Quando então, o 
par elétron-buraco for aniquilado um fóton é liberado com energia diferente da inicial, $h \omega_{1}$ [22]. A Fig. 2.4 ilustra o esquema descrito.

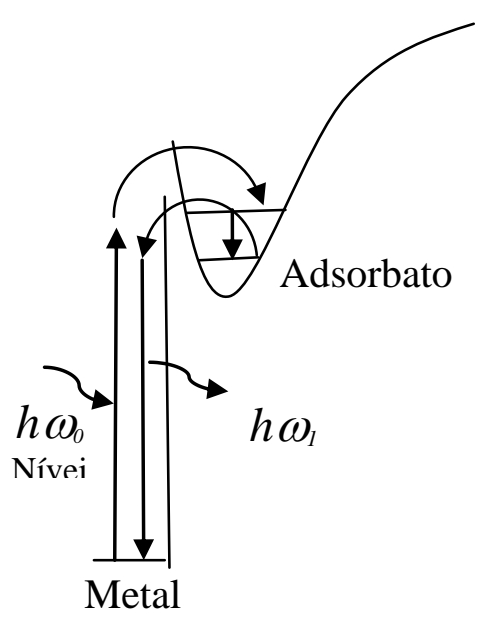

Figura 2.4: Diagrama ilustrando o mecanismo de intensificação SERS pelo modelo químico(Adaptado da Ref. [4]).

O mecanismo químico para o efeito SERS corresponde a uma intensificação experimental da ordem de $10^{2}$. Embora não corresponda a maior parte da intensificação, ela é altamente dependente da natureza química do adsorbato, da geometria de absorção da molécula, de sua variação ao longo dos experimentos e do potencial aplicado, fornecendo uma enorme quantidade de informações experimentais [23].

\subsection{Fluidos Magnéticos}

Ferrofluidos ou fluidos magnéticos são sistemas coloidais estáveis, consistindo de nanopartículas magnéticas (NPMs) dispersas em um líquido carreador orgânico ou inorgânico [24]. Para manter a estabilidade e impedir a formação de agregados entre as nanopartículas é essencial que elas sejam suficientemente pequenas, de modo que o movimento browniano impessa a precipitação ou a aglomeração das nanopartículas [25]. 
Neste contexto, um fluido magnético pode ser surfactado ou iônico, dependendo de como as nanopartículas são mantidas em suspensão. Nos fluidos magnéticos surfactados, a superfície da nanopartícula é recoberta por uma camada molecular da ordem de 1 a $3 \mathrm{~nm}$ de espessura apresentando uma terminação polar (hidrofílica) e outra apolar (hidrofóbica) (Fig.2.5).

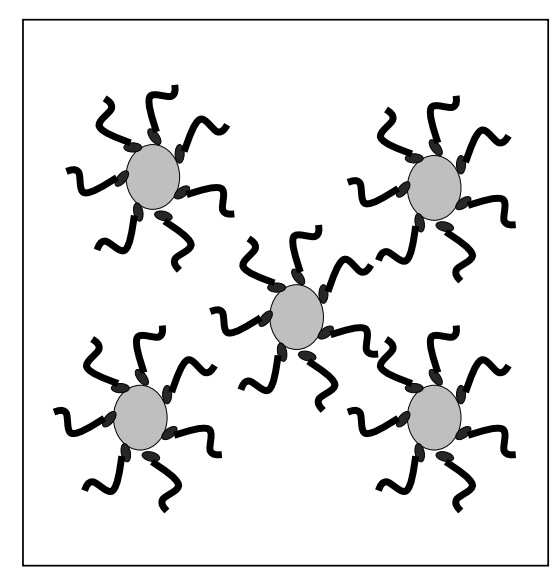

Figura 2.5: Modelo de fluido magnético surfactado.

Assim, um fluido magnético surfactado pode ser miscível tanto em lipídios e solventes orgânicos quanto em água, dependendo de como o surfactante recobre a nanopartícula. No primeiro caso, a parte polar se liga as partículas formando uma monocamada, já no segundo caso, deve-se obter uma estrutura que torne a parte mais externa da cobertura da nanopartícula polar. Para isso adiciona-se mais uma camada surfactante, na qual a parte apolar da nova camada se liga a apolar da partícula recoberta, formando uma dupla camada com uma terminação polar solúvel em água.

No caso do fluido iônico, as nanopartículas são separadas por repulsão eletrostática. O solvente é tipicamente água e a nanopartícula é carregada com uma densidade superficial de carga (Fig.2.6). A densidade superficial de carga das nanopartículas é uma função do pH do meio; as superfícies das nanopartículas são carregadas positivamente em meio ácido $(\mathrm{pH}<7)$ e 
negativamente em meio básico $(\mathrm{pH}>7)$ [26], assim os fluidos magnéticos iônicos são coloides iônicos dispersos em soluções aquosas com pH alto ou baixo.

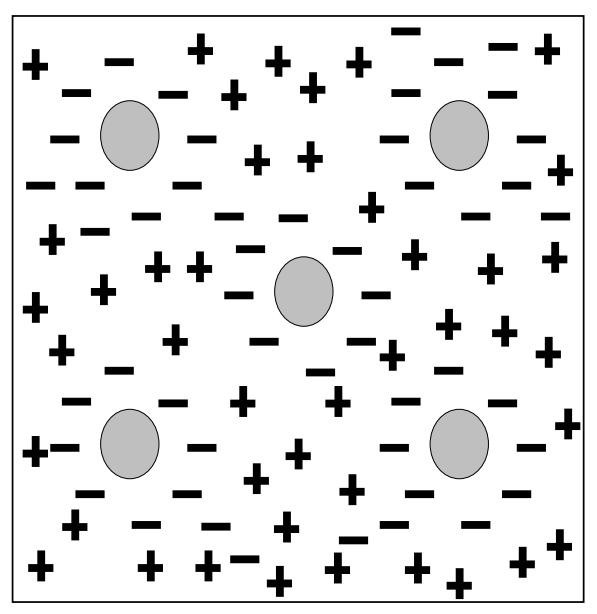

Figura 2.6: Modelo de fluido magnético iônico.

\subsubsection{Utilização da espectroscopia Raman em fluidos magnéticos}

A espectroscopia Raman é uma poderosa técnica na caracterização de ferrofluidos [26, 27]. A utilização da mesma para a análise de fluidos magnéticos é de grande interesse, visto que tal técnica permite investigar os detalhes microscópicos da camada sobre a superfície da nanopartícula, isto é, a interface da nanopartícula e líquido carreador [27, 28, 29, 30]. No caso de fluidos magnéticos procura-se conhecer o comportamento das coberturas dos fluidos magnéticos, onde tal informação é de grande importância para diversas aplicações. Por exemplo, os fluidos magnéticos biocompatíveis vem sendo estudados com vários propósitos, entre eles o uso como carreadores de drogas para melhorar a liberação controlada de fármacos. No entanto para que os fluidos sejam compatíveis com o meio biológico é necessária uma adequação do pH $(7,4)$ e salinidade fisiológica.

Um estudo mais detalhado sobre fluidos magnéticos com o objetivo de aplicações biológicas é muitas vezes discutido na literatura [24, 28]. A proposta é a utilização da 
espectroscopia Raman para investigar as propriedades químicas e estruturais dos ferrofluidos tanto na fase líquida quanto sólida [28].

Nos trabalhos de Morais et al. [24, 29] foram estudados fluidos magnéticos iônicos de ferrita de zinco e cobre através da espectroscopia Raman, com o objetivo de investigar a interface da superfície da nanopartícula e o meio carreador. Verificou-se que a supressão dos modos stretching simétricos, sendo uma forte indicação que os grupos $O H$ quimio-sorvidos dominam o processo de espalhamento de luz em fluidos magnéticos iônicos.

Fluido magnético de maguemita com superfície recoberta por ácido oleico, com a quantidade deste ácido sendo variada, foi estudado por Soler et al. [30], utilizando entre outras técnicas a espectroscopia Raman. Concluíram que a superfície das nanopartículas de maghemita contém moléculas de ácido oleico associadas por meio das ligações de hidrogênio e as espécies de oleato covalentemente ligados aos íons de ferro por meio de diferentes coordenações.

Existem limitações nos estudos Raman das camadas que recobrem as nanopartículas, como por exemplo, a cor escura dos fluidos magnéticos, as baixas concentrações de moléculas adsorvidas e de intensas fluorescências. Assim, para contornar estas limitações, abordagens experimentais mais avançadas se fazem necessárias. Neste contexto, a técnica SERS (Surface Enhanced Raman Spectroscopy) emerge como uma ferramenta poderosa e inovadora para estudar esta questão em particular. Alguns trabalhos recentes [31,32] têm abordado o uso da técnica SERS para a análise de fluidos magnéticos biocompatíveis. Santos et al. [32] estudaram Anfotericina B adsorvida na superfície de NPMs revestidas com uma bicamada de ácido láurico (AL). Entre outras técnicas, a utilização a técnica SERRS (Surface-enhanced Resonance Raman Scatering), empregando coloides de prata, provou que a Anfotericina B foi adsorvida à superfície das nanopartículas por meio da interação entre a cadeia poliênica do 
anel macrolactone da Anfotericina B com a cadeia $\left(\mathrm{CH}_{2}\right)_{10}$ da bicamada de AL. Em outro trabalho Paz et al. [31] utilizaram a técnica SERS no estudo da conjugação do anticorpo antiCEA (antígeno carcinoembrionário) na superfícies de NPMs recobertas com DMSA (ácido dimercaptosuccínico). A conjugação do anticorpo anti-CEA com as moléculas de DMSA adsorvidas na superfície das nanopartículas foi comprovada por meio das alterações energéticas dos modos vibracionais referentes ao carboxilato do DMSA adsorvido e, pelo surgimento do modo stretching associado à ligação $C=O$ no espectro SERS do sistema conjugado.

\subsection{Nanopartículas poliméricas}

Nanopartículas poliméricas são sistemas carreadores com diâmetros entre 10 e 1000 $\mathrm{nm}(1 \mu \mathrm{m})$ e denominadas nanocápsulas ou nanoesferas de acordo com sua composição: as nanocápsulas são formadas por uma camada polimérica disposta ao redor de um núcleo geralmente oleoso, podendo o fármaco estar disposto no núcleo e/ou adsorvido à parede polimérica. As nanoesferas, por outro lado, são sistemas matriciais constituídos apenas por polímeros [33] (veja Fig. 2.7). Neste sistema o fármaco pode estar retido ou adsorvido na matriz polimérica. As nanopartículas constituídas de polímeros biodegradáveis têm sido largamente utilizados nas áreas médica, como biomateriais, e farmacêutica, como sistemas carreadores e de liberação de fármacos. Dentre eles, destacam-se derivados do ácido lático e glicólico. 


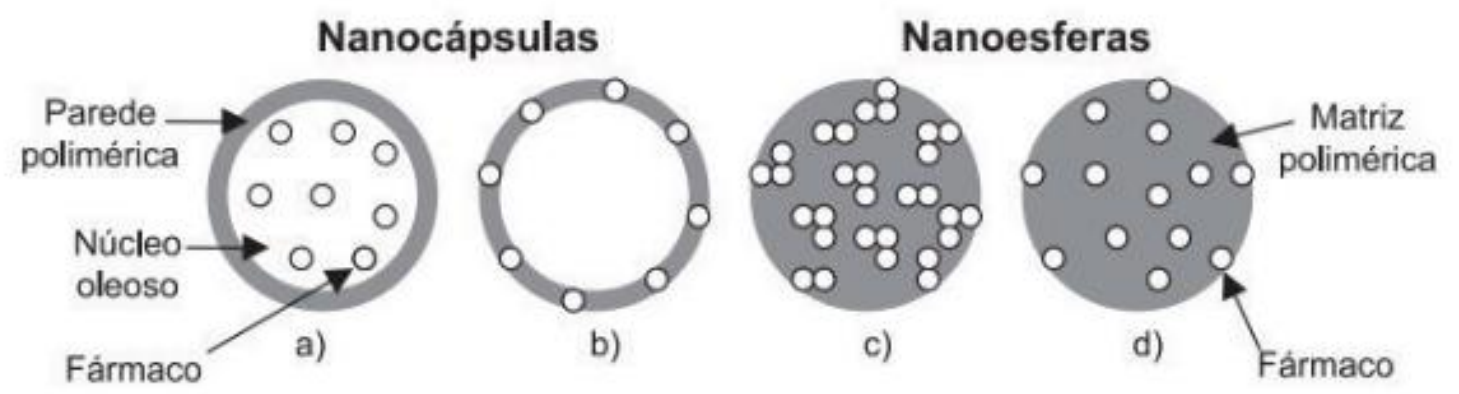

Figura 2.7: Representação esquemática dos tipos de nanopartículas poliméricas e possíveis disposições do fármaco nas mesmas: a) Fármaco dissolvido dentro da nanocápsula. b) Fármaco adsorvido à superfície da nanocápsula. c) Fármaco retido na matriz polimérica da nanoesfera. d) Fármaco adsorvido ou disperso na matriz polimérica da nanoesfera (Fonte: Ref. [33]).

A utilização de nanopartículas poliméricas como sistemas de liberação de fármacos vem atraindo a atenção por proporcionar uma alternativa às terapias de longo prazo. Estes sistemas oferecem diversas vantagens em relação a outras vias de administração, como proteção do fármaco e sua liberação em um sítio específico, de forma contínua e sustentada; alta capacidade de atravessar barreiras fisiológicas e redução de administrações repetidas do fármaco - consequentemente reduzindo os efeitos colaterais sistêmicos [34]. Através destes sistemas, a concentração do fármaco no sítio de ação é mantida na faixa terapêutica por um período maior de tempo, utilizando-se menor número de doses. 


\section{Capítulo 3}

\section{Metodologia}

\subsection{Preparação dos filmes nanoestruturados de prata}

Filmes nanoestruturados de prata foram preparados pela deposição de nanopartículas de prata sobre substrato de prata pelo método de eletrólise [22]. Para isso, duas placas de prata foram imersas no eletrólito $\left(\mathrm{AgNO}_{3}\right.$ diluído em água), uma como ânodo e outra como cátodo. Esta mistura consiste em uma solução de nitrato de prata à $6 \times 10^{-4} \mathrm{~mol} / \mathrm{L}$. Para se obter a deposição da prata, foi aplicada uma diferença de potencial de $3 \mathrm{~V}$ entre os eletrodos de modo que uma corrente contínua foi mantida por $1 \mathrm{~h}$. Após este período as placas foram removidas e secas com fluxo de nitrogênio. 


\subsection{Técnicas Experimentais}

\subsubsection{Medidas SERS}

Os espectros SERS foram obtidos à temperatura ambiente em um espectrômetro triplo Jobin Yvon modelo T64000, acoplado a uma CCD. Para evitar aquecimento das amostras e garantir a reprodutibilidade dos espectros SERS o feixe de um laser de íon argônio foi focalizado na amostra por meio de uma lente cilíndrica, a qual forneceu uma densidade de pontência de $0,1 \mathrm{~W} / \mathrm{cm}^{2}$.

Para o estudo SERS as amostras foram diluídas em água destilada e $20 \mu 1$ da solução foi depositada sobre o filme, que em seguida foi seco com fluxo de nitrogênio. A luz espalhada foi coletada na configuração de macro-Raman. A linha utilizada foi de 514,5 nm do laser de íon argônio com potência ótica na amostra de 200 mW.

\subsubsection{Microscopia Eletrônica de Transmissão (MET)}

As medidas de microscopia foram realizadas no Laboratório de Microscopia Eletrônica do Instituto de Biologia - Universidade de Brasília. Para a microscopia de transmissão foi utilizado o equipamento da JEOL modelo 1011 com $100 \mathrm{kV}$. As micrografias foram obtidas a partir de uma gota da amostra depositada sob uma tela de cobre de 300 mesh, preparada primeiramente com uma película do polímero Formvar. 


\subsubsection{Microscopia Eletrônica de Varredura (MEV)}

As medidas de microscopia eletrônica de varredura foram realizadas no Laboratório de Microscopia Eletrônica do Instituto de Biologia - Universidade de Brasília. As medidas de MEV foram obtidas em equipamento da JEOL JEM modelo 840 A.

\subsubsection{FTIR (Fourier Transform Infrared Spectroscopy)}

As medidas de FTIR foram realizadas no Laboratório de Nanociência e Nanobiotecnolgia do Instituto de Física - Universidade de Brasília. Para a obtenção dos espectros foi utilizado Espectrômetro de Infravermelho Bruker Vertex 70. Os espectros foram obtidos a partir de uma pastilha de brometo de potássio $(\mathrm{KBr})$ com $\sim 1 \%$ da amostra a ser estudada.

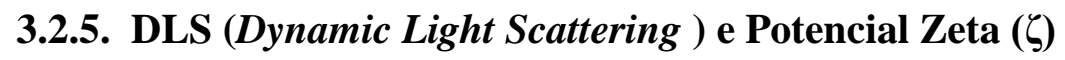

As medidas de DLS e Potencial Zeta foram realizadas no Laboratório do Instituto de Biologia/UnB. Os diâmetros hidrodinâmicos e potenciais Zeta foram obtidos utilizando-se do equipamento Malvern modelo Zetasizer nanoseries Nano Z590. Para efetuar as medidas, foi utilizado o volume de $1 \mathrm{~mL}$ de amostra. 


\section{Capítulo 4}

\section{Resultados e Discussões}

Os resultados obtidos durante o período de doutorado serão expostos neste capítulo. Inicialmente será apresentado um estudo referente à adsorção do fármaco Rifampicina (RIF) à superfície de NPMs pré-cobertas com ácido láurico. Neste trabalho também é investigado a fotodegração da RIF quando exposta à luz branca. Em seguida será apresentado um estudo da adsorção do fármaco Selol também em NPMs pré-cobertas com ácido láurico. A estabilidade do ancoramento das moléculas de Selol após o aquecimento por campo magnético alternado também é investigada e apresentada. Por último, a investigação do carregamento do fármaco Itraconazol por nanopartículas do polímero PLGA será apresentado. 


\section{Seção 4.1}

\section{Estudo do arranjo de moléculas de Rifampicina adsorvidas sobre à superfície das nanopartículas e o efeito da luz nas propriedades físico- químicas.}

Rifampicina (RIF) é um dos fármacos mais populares no tratamento da tuberculose (TB), e pertence à família dos antibióticos das ansamicinas [35]. Este nome (ansamicina) foi dado devido à arquitetura molecular desses antibióticos ser parecida com uma cesta, compreendida por uma porção aromática ligada a cadeias alifáticas em posições não adjacentes (veja Fig.4.1).A RIF atua inibindo a RNA polimerase dependente de DNA nas células procarióticas pela formação de um complexo estável enzima-fármaco no qual resulta na supressão da formação da cadeia de RNA [36]. Em geral, a RIF inibe o crescimento de muitas bactérias, tanto Gram-positivas quanto Gram-negativas. A associação da Rifampicina com a isoniazida é muito utilizada para o tratamento da tuberculose. No entanto, o tratamento convencional contra a TB usando RIF requer altas doses combinada com terapia por longos períodos de tempo [37]. Além disso, alguns estudos anteriores mostram que a RIF livre apresenta algumas desvantagens, tais como limitada solubilidade aquosa, baixa biodisponibilidade, solubilidade dependente do $\mathrm{pH}$ e baixa estabilidade quando exposta a luz [38, 39, 40, 41]. Para superar as desvantagens apresentadas pela RIF, diferentes sistemas de entrega de drogas (drug delivery system-DDS) baseados em nanopartículas tem sido propostos seguindo diferentes protocolos de administração, entre eles podemos citar os lipossomas [42], nanopartículas baseadas em lipídio sólido e sílica [43, 44]. Recentemente, em um trabalho publicado pelo nosso grupo, foi mostrado que a Anfotericina B adsorvida à superfície de 
NPMs pode ser usada com sucesso no tratamento de infecções em pulmão de rato [32, 45]. Portanto, o sistema de entrega de drogas compreendendo a conjugação da RIF com NPMs parece ser muito promissora no tratamento contra turbeculose. Nesse tipo de sistema seria possível um tratamento localmente eficiente utilizando menor dose do fármaco, o que levaria à redução dos efeitos tóxicos. A partir destes sistemas é possível, pela aplicação de um gradiente de campo magnético, concentrar o fármaco no local desejado e controlar a liberação da droga. No contexto de se avaliar a conjugação do fármaco às NPMs e o desempenho terapêutico do sistema de entrega de drogas, a técnica SERS surge como uma poderosa e inovadora ferramenta.

São poucos os trabalhos encontrados na literatura envolvendo o efeito SERS utilizando Rifampicina. Howes et al. [35], por exemplo, estudou o efeito SERRS para a família ansamicinas (Rifamicina SV, Rifampicina e Rifaximina) utilizando coloides de prata e verificou que tanto a Rifampicina quanto a Rifaximina foram adsorvidas sobre a superfície da prata, o que já não ocorreu com Rifamicina SV. Em outro trabalho Howes et al. [46] abordou a influência da variação do $\mathrm{pH}$ da solução de Rifampicina com coloide de prata observando uma progressiva mudança nas intensidades a partir da variação do $\mathrm{pH}$.

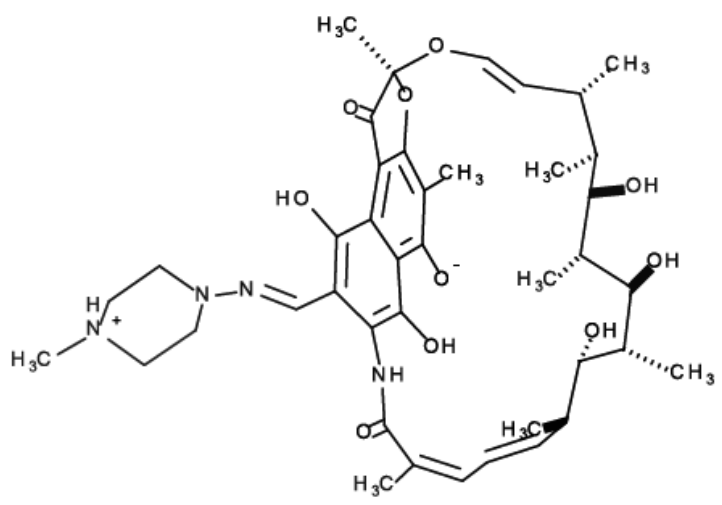

Figura 4.1 - Estrutura química da molécula de Rifampicina. 
Nesta seção será apresentado um estudo sobre a aplicação bem sucedida da técnica SERS na avaliação da adsorção da molécula de RIF adsorvidas à superfície de NPs de magnetita, pré-cobertas com uma bicamada de AL. Com o propósito de investigar cuidadosamente o efeito da luz sobre a estabilidade da RIF adsorvida, as amostras foram divididas em dois grupos: o primeiro grupo foi mantido no escuro e o segundo grupo foi sujeito a iluminação por luz branca durante 12 horas.

\subsubsection{Metodologia}

\section{Preparação das amostras}

Nanopartículas de magnetita $\left(\mathrm{Fe}_{3} \mathrm{O}_{4}\right)$ foram preparadas pelo método de coprecipitação química de íons $\mathrm{Fe}^{+2} \mathrm{e} F e^{+3}$ em meio alcalino, seguindo o procedimento descrito na literatura [47]. O precipitado de NPMs foi então lavado com água destilada e separado por um imã permanente. O precipitado preto foi recoberto com uma bicamada de AL e submetido à agitação e aquecimento $\left(90^{\circ} \mathrm{C}\right)$, resultando em uma dispersão espontaneamente suspensa em meio aquoso, rendendo uma amostra de FM estável por vários dias (FMBL). Após este passo a amostra FMBL produzida foi dividida em duas partes: a primeira parte (uma alíquota de 1 $\mathrm{mL}$ ) foi misturada com $2 \mathrm{ml}$ de dimetilsulfóxido puro (DMSO) enquanto que a segunda alíquota foi tratada com RIF usando o protocolo descrito na literatura [32]. De acordo com a protocolo descrito em [32], a solução de RIF em DMSO $(10 \mathrm{mg} / \mathrm{ml})$ foi adicionada à amostra FMBL sob agitação, na ausência de luz. As nanopartículas magnéticas contendo RIF adsorvida foram separadas do sobrenadante por separação magnética e re-dispersas em água deionizada produzindo a amostra FMBL/RIF. O conteúdo de RIF adsorvido foi indiretamente determinado pela quantificação do excesso de fármaco em suspensão (droga livre) usando medidas de UV-Vis (Perkin Elmer Lambda 25) registrado em $414 \mathrm{~nm}$. A quantidade medida 
de RIF na amostra FMBL/RIF foi de $0,2 \mathrm{mg} / \mathrm{ml}$. Para referência uma solução de RIF livre foi preparada pela dispersão de RIF em uma mistura de DMSO/água (1:4).

Com o objetivo de examinar a estabilidade após exposição à luz, as amostras (FMBL, FMBL/RIF e RIF livre) foram irradiadas com uma lâmpada de tungstênio com intensidade de $0,1 \mathrm{~W} / \mathrm{cm}^{2}$ por 12 horas. As temperaturas das amostras foram monitoradas e não excederam $28^{\circ} \mathrm{C}$.

\subsubsection{Resultados e Discussões}

\section{Microscopia eletrônica de transmissão, Diâmetro hidrodinâmico e Potencial $\zeta$}

Uma micrografia representativa de MET das nanopartículas utilizadas neste trabalho, bem como o histograma das nanopartículas suspensas são mostrados nas Figs. 4.2 (a) e (b), respectivamente. Foi observado que as NPMs são quase esféricas, com um diâmetro médio de aproximadamente $8,5 \mathrm{~nm}$ e uma polidispersão em torno de 0,19 .
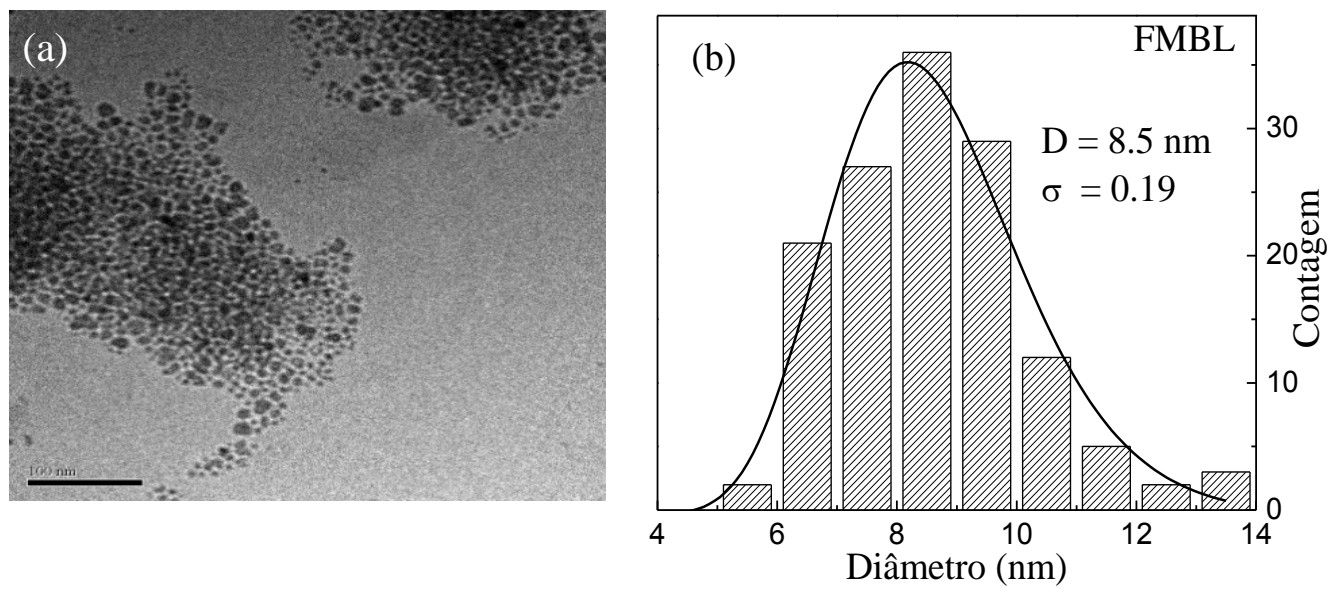

Figura 4.2: Micrografia MET (a) e histograma da distribuição do tamanho das partículas (b) obtidos a partir da amostra FMBL. 
A estabilidade coloidal destas nanopartículas foi avaliada por Espalhamento de Luz Dinâmico (Dynamic Light Scattering-DLS) e o potencial $\zeta$. Por meio destes dados foi verificado que os valores do diâmetro médio obtido por MET são menores do que os valores obtidos por DLS, que foram de 68,7 e 54,0 nm para as amostras FMBL e FMBL/RIF, respectivamente. O fato de os diâmetros hidrodinâmicos das NPs serem maiores, quando comparados com os valores obtidos pelo MET, é principalmente devido a agregação das nanopartículas ocasionado pela interação dipolar magnética entre as unidades em suspensão, mesmo na ausência de qualquer campo aplicado. Estes resultados sugerem que a agregação é maior no FM recoberto somente com uma bicamada de AL (amostra FMBL). No entanto, foi encontrado o valor do potencial $\zeta$ para a amostra FMBL/RIF $(-20 \mathrm{mV})$ é menor do que o observado para a amostra FMBL (-30 mV).

\section{FTIR}

Os espectros de FTIR das nanopartículas de magnetita recobertas tanto com bicamada de AL (FMBL) quanto com RIF (FMBL/RIF), antes (linha preta) e após (linha vermelha) exposição à luz são mostrados nas Figs.4.3 (ii) e (iii). Para efeito de comparação, os espetros FTIR da RIF livre, antes (linha preta) e após (linha vermelha) exposição a luz podem ser visto na Fig.4.3 (i). Os espectros da RIF livre (antes de expor a luz) apresentam uma banda larga em torno de 3150 - $3600 \mathrm{~cm}^{-1}$, devido a absorção da cadeia ansa-OH e dois picos bem definidos em 1644 e $1725 \mathrm{~cm}^{-1}$ são devidos ao furanona e $C=O$ acetil, respectivamente. Contribuições do $\mathrm{CH}$ stretching e dos grupos e $\mathrm{CH}_{3}$ a partir das pontes alifáticas ansa podem ser observadas na região $2850-2950 \mathrm{~cm}^{-1}$, enquanto o modo vibracional do $\mathrm{N}-\mathrm{CH}_{3}$ pode ser encontrado em $2883 \mathrm{~cm}^{-1}[48,49,50]$. Adicionalmente, os 
modos de deformação do equeleto bem como os modos stretching do anel do cromóforo naftohidroquinona podem ser observados nas regiões de $400-1300 \mathrm{~cm}^{-1}$ e $1300-1600 \mathrm{~cm}^{-1}$, respectivamente.

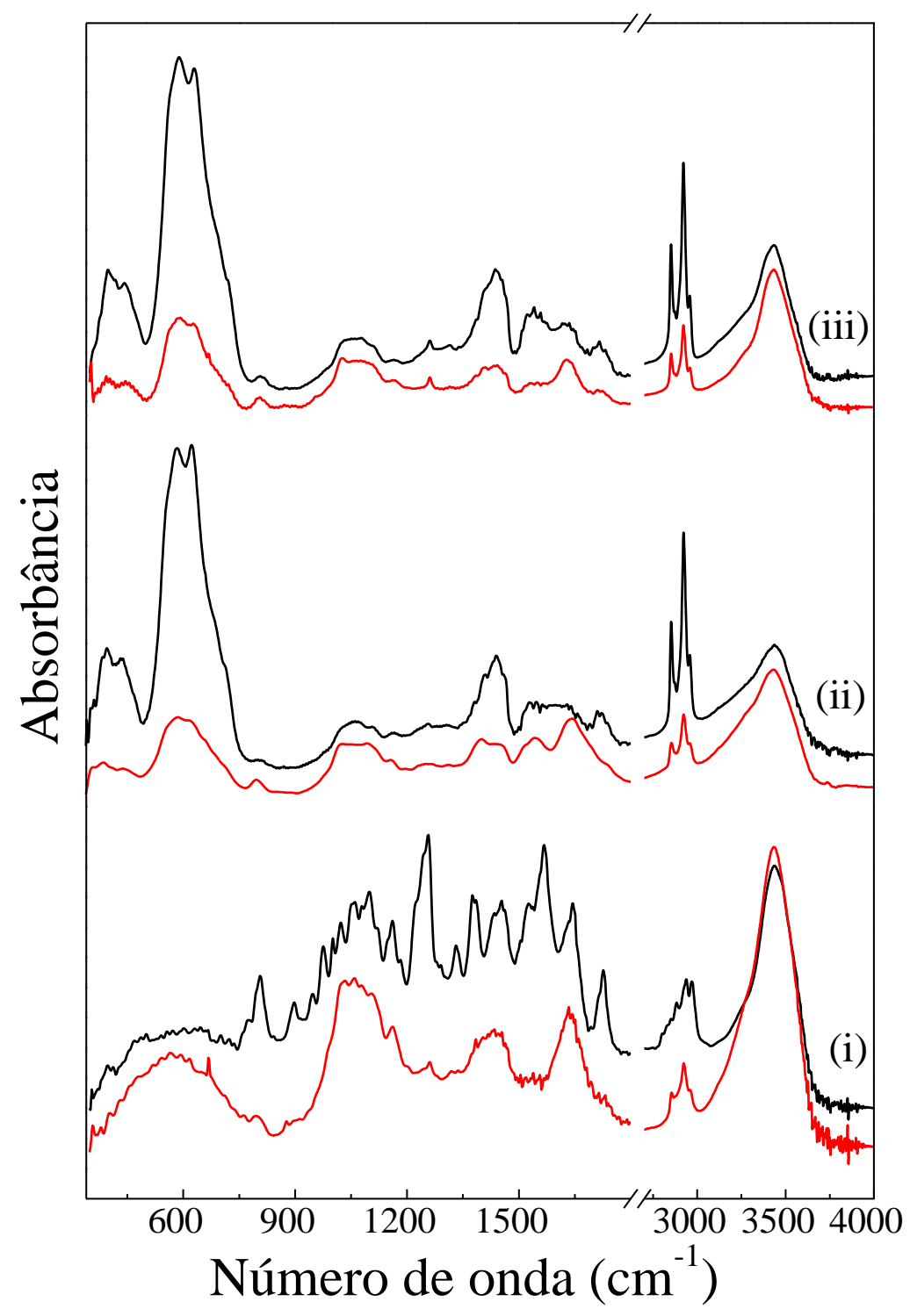

Figura 4.3: Espectros de Infravermelho das amostras (i) RIF livre, (ii) FMBL e (iii) FMBL/RIF, antes (linha preta) e após (linha vermelha) à exposição a luz.

Como observado na Fig. 4.3 (i), a RIF livre após exposição à luz branca (espectro em vermelho) mostra substanciais mudanças espectrais. As principais mudanças resultantes da exposição da RIF à luz estão relacionadas ao desaparecimento das bandas em torno de 800, 
1250, 1560 e $1725 \mathrm{~cm}^{-1}$, os quais são atribuídos aos modos $\delta(C-C), \delta(O H), v(C-N)$ e $v(C=O)$, respectivamente. Este comportamento provavelmente está associado à degradação das moléculas de RIF induzida pela exposição à luz branca.

Os espectros FTIR (linhas preta e vermelha) das amostras FMBL (veja Fig. 4.3 (ii)) mostram as assinaturas das bandas das ligações $\mathrm{Fe}-\mathrm{O}$ do caroço da magnetita em torno de 600 $\mathrm{cm}^{-1}$, do grupo carboxílico do $\operatorname{AL}\left(v_{s}\right.$ e $v_{a s}$ do (-COO-) na região em $\left.1400-1690 \mathrm{~cm}^{-1}\right)$ e contribuição da ligação $\mathrm{CH}_{2} \mathrm{em} 1440 \mathrm{~cm}^{-1}$. Também é possível observar o pico de absorção do $v(C=O)$ em $1720 \mathrm{~cm}^{-1}$. É interessante notar que a exposição a luz leva a um decréscimo na intensidade relativa da banda em torno de $1440 \mathrm{~cm}^{-1}$ e uma forte redução no pico de absorção do $v(C=O)\left(1720 \mathrm{~cm}^{-1}\right)$.

Ao contrário do espectro da RIF livre (Fig. 4.3 (i) linha preta), onde é observada a presença de bandas de absorção bem resolvidas, o espectro FTIR da RIF adsorvida à superfície das nanopartículas (Fig. 4.3 (iii)) exibem amplas bandas, similares ao espectro da amostra FMBL (Fig. 4.3 (ii)) inclusive com a ausência da banda referente à ligação $\mathrm{N}-\mathrm{CH}_{3}$ em $2883 \mathrm{~cm}^{-1}$. Este resultado sugere que o FTIR não é sensível o suficiente para detectar a baixa quantidade de RIF adsorvida sobre a superfície das nanopartículas de magnetita. A evidência da presença da molécula de RIF adsorvida é o aumento da intensidade relativa das bandas em torno de 1250 e $1560 \mathrm{~cm}^{-1}$, onde estão provavelmente associadas aos modos stretching $O H$ e $C-N$ referentes a molécula de Rifampicina. Por outro lado, nota-se que após a exposição a luz branca (Fig. 4.3 (iii) linha vermelha) a intensidade relativa das bandas associadas às ligações $C-N$ e $C=O$ são extremamente reduzidas, o que sugere que estas ligações são quebradas pelos fótons incidentes, levando à degradação da molécula de RIF. 


\section{SERS}

Os espectros SERS das amostras de RIF livre, FMBL e FMBL/RIF foram registrados com o objetivo de obter uma compreensão mais profunda de como a molécula RIF adsorve à bicamada de AL da nanopartículas de magnetita. Adicionalmente, com o objetivo de acessar informações a respeito do efeito da luz nas moléculas de RIF adsorvidas, os experimentos de SERS foram realizados antes e depois de expor todas as amostras investigadas à luz branca utilizando o protocolo descrito na seção 4.1.1. Para facilitar a análise dos diferentes espectros, modos vibracionais foram destacados de acordo com a sua origem; os componentes de cores vermelho, verde e azul mostrados na Fig. 4.4 foram tentativamente usados para indicar os modos de vibração do DMSO, Rifampicina e a bicamada de AL, respectivamente. 

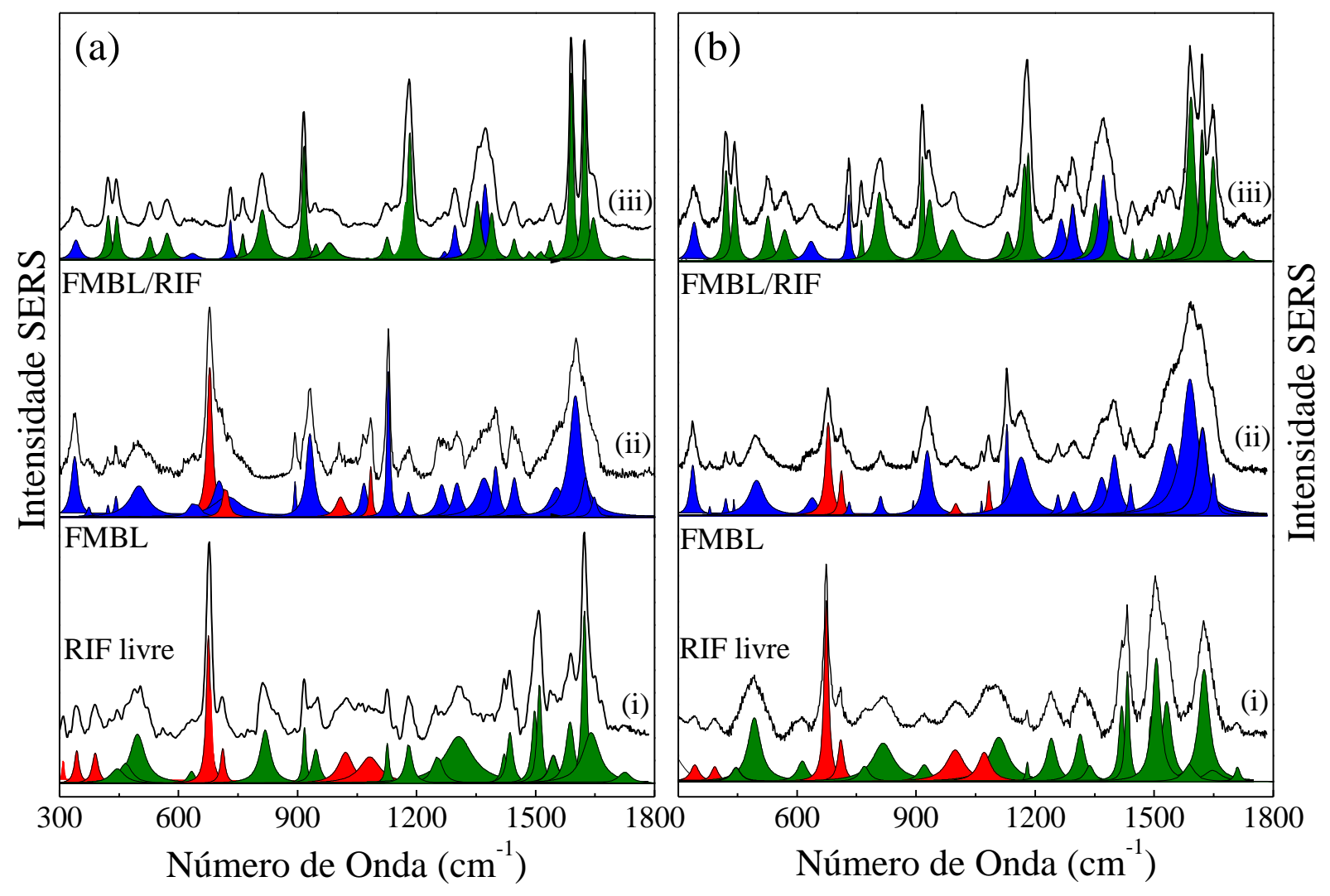

Figura 4.4: Espectros SERS da amostra de (i) RIF livre (ii) FMBL e (iii) FMBL/RIF, antes (a) e após (b) exposição a luz. Para facilitar as análises os modos vibracionais foram destacados. As cores em vermelho, verde e azul são usadas para indicar os modos vibracionais provenientes do DMSO, Rifampicina e da bicamada de $A L$, respectivamente.

Os espectros SERS da RIF livre antes e após exposição a luz (Fig. 4.4 (i) (a) e (b)) apresentam características similares as observadas no trabalho de Howes et al. [35], ao estudar a adsorção da RIF sobre nanopartículas de prata, em forma coloidal. Os espectros SERS da RIF são caracterizados por uma forte banda na região de $1400-1670 \mathrm{~cm}^{-1}$. As três bandas de mais alta energia 1623, 1640 e $1725 \mathrm{~cm}^{-1}$, são atribuídos aos modos $v(C=N)$ da piperazina substituinte na posição três do anel do cromóforo, $v\left(C-O^{-}\right)$e $v(C=O)$, respectivamente. O fato do modo $v(C=N)$ estar em $1623 \mathrm{~cm}^{-1}$ indica que não existe interação entre este grupo e a superfície da prata. Este resultado difere do observado na referência [35], onde foi verificado que a adsorção da RIF sobre a superfície da prata produz um 
deslocamento do modo $v(C=N)$, de 1623 para $1604 \mathrm{~cm}^{-1}$. Esta diferença no comportamento provavelmente está relacionada com a maneira que o experimento SERS foi conduzido no presente estudo, oposto ao experimento reportado na ref. [35]. No trabalho da ref. [35], os espectros SERS foram obtidos em o meio aquoso o que provavelmente contribuiu para o processo de adsorção à superfície de prata. Diferentemente no presente estudo os espectros SERS foram obtidos em meio não aquoso o que por sua vez impediu a adsorção química da RIF sobre a superfície do filme nanoestruturado de prata. Os correspondentes modos $\delta\left(C-O^{-}\right)$ e $\delta(C=O)$ são atribuídos às bandas em 466 e $496 \mathrm{~cm}^{-1}$, respectivamente. Os modos de deformação esquelética, assim como os modos stretching associados ao anel do cromóforo naftohidroquinona podem ser observados nas regiões de $400-1000 \mathrm{~cm}^{-1}$ e $1300-1600 \mathrm{~cm}^{-1}$, respectivamente. Nos espectros SERS da RIF livre (em solução de DMSO/água) também estão presentes os modos do DMSO em 342 e $390 \mathrm{~cm}^{-1}$ associados à ligação $C-S=O\left(v_{a s}\right.$ e $v_{s}$, respectivamente), $677\left(v_{a s}\right)$ e $715 \mathrm{~cm}^{-1}\left(v_{s}\right)$ atribuídos à ligação $C-S-C$ e, por último, em 1020 $\left(v_{a s}\right)$ e $1080 \mathrm{~cm}^{-1}\left(v_{s}\right)$, assinaturas para a ligação $S=O$. Uma listagem completa das energias vibracionais dos modos SERS e suas atribuições podem ser encontradas na Tabela 4.1.

Como esperado os espectros SERS da amostra FMBL (Fig. 4.4 (ii)), mostram os modos vibracionais associados ao DMSO e à bicamada de AL. Como observado na amostra de RIF livre as bandas em 677, 715, 1008 e $1080 \mathrm{~cm}^{-1}$ são referentes ao DMSO. Os demais modos vibracionais são referentes à bicamada de AL adsorvida sobre a superfície das nanopartículas. Os modos vibracionais observados na região $300-1400 \mathrm{~cm}^{-1}$ estão associados ao esqueleto das moléculas da bicamada de AL (veja Tabela 4.1). Adicionalmente, o pico em $893 \mathrm{~cm}^{-1}$ é devido ao $\rho\left(\mathrm{CH}_{3}\right)$ e as bandas SERS localizadas em torno de 1263, 1306 e $1445 \mathrm{~cm}^{-1}$ estão associadas com os modos wangging, twisting e scissoring do $\mathrm{CH}_{2}$, respectivamente (também relacionados ao esqueleto da molécula). Finalmente, em 1402 e $1600 \mathrm{~cm}^{-1}$ são observados os modos stretching simétrico e assimétrico do carboxilato (- 
$\mathrm{COO}^{-}$). A presença dessas bandas é uma evidência da formação da bicamada de AL em torno da nanopartículas, pois, se uma única camada de AL tivesse sido formada em torno das nanopartículas o grupo carboxilato deveria se ligar a superfície das nanopartículas e portanto, os dois modos stretchings do carboxilato (simétrico e assimétrico) deveriam estar ausentes no espectro SERS. 
Tabela 4.1: Tabela com a posição dos modos vibracionais obtidos a partir da técnica SERS para RIF livre, FMBL e FMBL/RIF.

\begin{tabular}{|c|c|c|c|c|c|c|}
\hline \multicolumn{2}{|c|}{ RIF livre } & \multicolumn{2}{|c|}{ FMBL } & \multicolumn{2}{|c|}{ FMBL/RIF } & \multirow[t]{2}{*}{ Atribuições } \\
\hline Antes & Depois & Antes & Depois & Antes & Depois & \\
\hline & & 340 & & 340 & & $\delta(\mathrm{C}-\mathrm{C})$ \\
\hline 342 & 342 & & & & & $* v_{\mathrm{as}}(\mathrm{C}-\mathrm{S}=\mathrm{O})$ \\
\hline 390 & 390 & & & & & $* v_{\mathrm{s}}(\mathrm{C}-\mathrm{S}=\mathrm{O})$ \\
\hline 422 & 422 & & & 422 & 422 & $\delta(\mathrm{C}-\mathrm{C})$ \\
\hline 445 & 445 & & & 445 & 445 & $\delta(\mathrm{C}-\mathrm{C})$ \\
\hline 466 & 466 & & & & & $\delta\left(\mathrm{C}^{-} \mathrm{O}^{-}\right)$ \\
\hline \multirow[t]{4}{*}{496} & 496 & 499 & 499 & & & $\delta(\mathrm{C}=\mathrm{O})$ \\
\hline & & & & 527 & 526 & $\delta(\mathrm{C}-\mathrm{C})$ \\
\hline & & & & 571 & 568 & $\delta(\mathrm{C}-\mathrm{OH})$ \\
\hline & & 635 & 635 & 635 & 635 & $(\mathrm{C}-\mathrm{C})$ \\
\hline \multirow[t]{2}{*}{677} & & 677 & 677 & & & $* v_{\mathrm{as}}(\mathrm{C}-\mathrm{S}-\mathrm{C})$ \\
\hline & & 703 & & & & $v(\mathrm{C}-\mathrm{C})$ \\
\hline \multirow[t]{3}{*}{715} & & 715 & 715 & & & $* v_{\mathrm{s}}(\mathrm{C}-\mathrm{S}-\mathrm{C})$ \\
\hline & & 730 & & 730 & 730 & $\rho(C-C)$ \\
\hline & & & & 762 & 762 & $\delta(\mathrm{C}-\mathrm{C})$ \\
\hline \multirow[t]{2}{*}{815} & 815 & & & 815 & 815 & $\delta(\mathrm{C}-\mathrm{C})$ \\
\hline & & 893 & & & & $\rho\left(\mathrm{CH}_{3}\right)$ \\
\hline \multirow[t]{2}{*}{915} & & & & 915 & 915 & $\delta(C-C)$ \\
\hline & & 930 & & 930 & & $v(\mathrm{C}-\mathrm{C})$ \\
\hline \multirow[t]{2}{*}{945} & 945 & & & 945 & 945 & $\delta(C-C)$ \\
\hline & & & & 980 & 990 & $\delta(\mathrm{C}-\mathrm{C})$ \\
\hline \multirow[t]{2}{*}{1020} & & 1008 & 1008 & 1008 & & $* v_{\text {as }}(\mathrm{S}=\mathrm{O})$ \\
\hline & & 1067 & 1067 & & & $v_{\mathrm{as}}(\mathrm{C}-\mathrm{C})$ \\
\hline \multirow[t]{2}{*}{1080} & & 1082 & 1082 & & & $* v_{\mathrm{s}}(\mathrm{S}=\mathrm{O})$ \\
\hline & & 1127 & 1127 & 1127 & 1127 & $v_{\mathrm{s}}(\mathrm{C}-\mathrm{C})$ \\
\hline 1125 & 1125 & & & & & $v(\mathrm{C}-\mathrm{C})$ \\
\hline 1180 & & & & 1180 & & $\mathrm{C}-\mathrm{O}-\mathrm{O}-\mathrm{C}$ \\
\hline \multirow[t]{3}{*}{1247} & & & & 1247 & & $\delta(\mathrm{OH})$ \\
\hline & & 1263 & 1263 & & & $\omega\left(\mathrm{CH}_{2}\right)$ \\
\hline & & 1306 & 1306 & 1306 & 1206 & $\tau\left(\mathrm{CH}_{2}\right)$ \\
\hline \multirow{5}{*}{1309} & 1309 & & & 1297 & 1297 & $v$ do anel \\
\hline & & & & 1353 & 1353 & $v(\mathrm{C}-\mathrm{OH})$ \\
\hline & & 1370 & 1370 & & & $v(\mathrm{C}-\mathrm{C})$ \\
\hline & & & & 1390 & 1390 & $v(\mathrm{C}-\mathrm{C})$ \\
\hline & & 1402 & & & & $v_{\mathrm{s}}\left(-\mathrm{COO}^{-}\right)$ \\
\hline 1420 & 1420 & & & & & $v$ do anel \\
\hline 1435 & 1435 & & & & & $v$ do anel \\
\hline & & 1445 & 1445 & & & $\varsigma\left(\mathrm{CH}_{2}\right)$ \\
\hline 1509 & 1509 & & & & & $v(\mathrm{C}-\mathrm{C})$ \\
\hline 1540 & 1540 & & & 1540 & 1540 & $v$ do anel \\
\hline 1586 & 1586 & & & 1586 & 1586 & $v(\mathrm{C}-\mathrm{C})$ \\
\hline & & 1600 & & & & $v_{\mathrm{as}}\left(-\mathrm{COO}^{-}\right)$ \\
\hline 1623 & 1623 & & & 1623 & 1623 & $v(\mathrm{C}=\mathrm{N})$ \\
\hline 1640 & 1640 & & & 1645 & 1645 & $v\left(\mathrm{C}^{-} \mathrm{O}^{-}\right)$ \\
\hline 1725 & & 1649 & 1649 & 1725 & 1725 & $v(\mathrm{C}=\mathrm{O})$ \\
\hline
\end{tabular}

* modos associados ao DMSO; v: modo stretching; $v_{s}$ : stretching simétrico; $v_{a s}$ : stretching assimétrico; $\delta$ : modo bending; $\omega$ : modo wagging; $\tau$ : modo twisting; $\varsigma$, modo scissoring; $\rho$, modo rocking. 
A Fig. 4.4 (iii)-(a) e (b) mostra os espectros da amostra FMBL/RIF. Note que, com relação aos espectros da RIF livre (Figs 4.4 (i)), os espectros SERS da amostra FMBL/RIF estão consideravelmente alterados; maiores detalhes podem ser vistos na Fig. 4.5, onde, para facilitar a comparação das intensidades relativas, os espectros SERS na Fig. 4.5 foram normalizados, dividindo ambos os espectros pela sua área integrada na região de $300-1800$ $\mathrm{cm}^{-1}$. As mudanças mais óbvias são o desaparecimento dos picos SERS referentes ao DMSO e, como esperado, o aparecimento das bandas associadas à bicamada de AL. É importante notar que as energias vibracionais dos modos Raman relacionadas à cadeia carbônica da bicamada de AL permanecem quase inalteradas em todo o espectro (veja Tabela 4.1). No entanto, as bandas relacionadas com as vibrações do grupo carboxilato (esperados em $1402 \mathrm{e}$ $1600 \mathrm{~cm}^{-1}$ ), assim como a ligação $\mathrm{CH}_{3}$ (esperada em $893 \mathrm{~cm}^{-1}$ ) estão ausentes. Estes resultados sugerem que a interação da molécula de RIF com a bicamada de AL ocorre via grupo carboxilato.

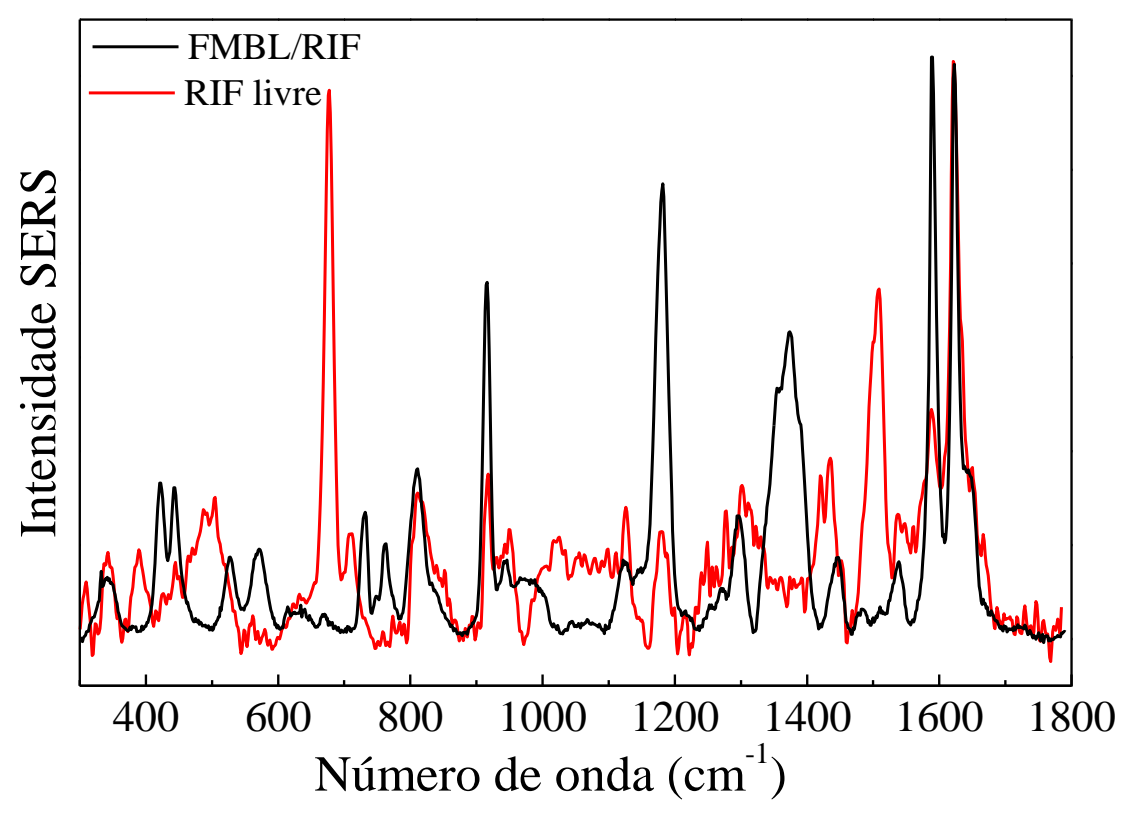

Figura 4.5: Espectros SERS da RIF livre (linha vermelha) e FMBL/RIF (linha preta). 
É possível notar na Fig. 4.5 que, quando as moléculas de RIF estão adsorvidas sobre a superfície das nanopartículas (amostra FMBL/RIF) as energias vibracionais associadas ao anel naftohidroquinona (modos de deformação esquelética no plano em 422, 445, 815, 915 e $945 \mathrm{~cm}^{-1}$ e modos stretching do anel em 1540 e $1586 \mathrm{~cm}^{-1}$ ) e a ligação $C=N$ em $1623 \mathrm{~cm}^{-1}$ permanecem praticamente inalteradas quando comparadas ao espectro SERS da RIF livre. Além do mais, é importante ressaltar que embora adsorvida sobre a superfície das nanopartículas de magnetita, os modos fora do plano da RIF não são observados nos espectros SERS. Adicionalmente, quando comparado com a RIF livre o espectro SERS da amostra FMBL/RIF mostra o surgimento de cinco novas bandas em 527, 571, 762, 1353 e $1390 \mathrm{~cm}^{-1}$. As bandas em 571 e $1353 \mathrm{~cm}^{-1}$ são respectivamente atribuídas a $\delta(C-O H)$ e $v(C-O H)$, enquanto as bandas em 527, 762 e $1390 \mathrm{~cm}^{-1}$ estão associadas aos modos vibracionais do anel $(\delta(C-C)$ e $v(C-C)$, respectivamente) $[35,51]$. Além do mais, é observado que quando as moléculas de RIF estão adsorvidas à superfície das NPMS as bandas associadas a $\delta\left(C-O^{-}\right)$em $466 \mathrm{~cm}^{-1}, \delta(\mathrm{C}=\mathrm{O})$ em $496 \mathrm{~cm}^{-1}$ e os modos stretching do anel em 1435 e $1509 \mathrm{~cm}^{-1}$ estão ausentes. Finalmente, é também observado (veja Fig.4.5) que os modos vibracionais associados com as moléculas de RIF adsorvidas à superfície das NPMs, em 422, 445, 915, 1180 e $1586 \mathrm{~cm}^{-1}$ têm suas intensidades aumentadas. O pico em $1180 \mathrm{~cm}^{-1}$ foi atribuído à ligação $C-O-O-C$.

Neste ponto, vale ressaltar que a molécula de RIF é uma molécula com estrutura zwiteriônica [52] com valores de $\mathrm{pK}_{\mathrm{a}}$ de 1,7 e 7,9. Em recente estudo, foi demonstrado que em $\mathrm{pH} \sim 7,7$ (valor próximo do $\mathrm{pK}_{\mathrm{a}}=7,9$ ) a adsorção da RIF sobre as nanopartículas de prata é favorecida pela forma zwiteriônica neutra mais do que pela forma aniônica da molécula [35]. De acordo com os autores, este comportamento está relacionado à interação da forma neutra da RIF com o potencial negativo da superfície da prata, promovida pela estrutura química da molécula de RIF, onde o nitrogênio imina foi identificado como a espécie mais 
provável de se ligar diretamente à superfície metálica. De fato, como a amostra FMBL/RIF foi preparada em $\mathrm{pH}=7,0$, um comportamento similar deve ser esperado aqui, uma vez que as nanopartículas magnéticas recobertas com bicamada de AL também apresentam um potencial negativo devido ao grupo carboxilato. Como mencionado na referência [35] as condições químicas impostas ao estudo faz o nitrogênio imina ou o nitrogênio piperazina adjacente ao nitrogênio imina ter uma maior probabilidade de se ligar ao grupo carboxilato exterior a bicamada de AL. Contudo, o fato de o modo vibracional Raman do nitrogênio imina não sofrer nenhuma variação na energia indica que o ancoramento da RIF sobre a superfície das nanopartículas não é devido a interação química direta deste grupo molecular. $\mathrm{Na}$ verdade, nossa análise indica que a porção mais provável para se ligar ao grupo carboxilato da bicamada do AL é o nitrogênio piperazina adjacente ao nitrogênio imina (veja na Fig.4.6 esquema proposto para o ancoramento da RIF nas NPs recobertas com uma bicamada de AL). Esta hipótese é corroborada pelos dados de FTIR, onde foi verificado a ausência do modo vibracional da ligação $\mathrm{N}-\mathrm{CH}_{3}$ da molécula de RIF após a adsorção sobre a bicamada de AL. Acredita-se que o ancoramento da molécula de RIF acarreta uma diminuição na flexibilidade conformacional da molécula, o qual pode explicar as mudanças espectrais observadas. A hipótese é que o enrijecimento da molécula de RIF favorece a ligação do oxigênio proveniente do grupo hidroquinona com o oxigênio do grupo carbonil, produzindo a ligação $C-O-O-C$ e consequentemente a quebra da dupla ligação do oxigênio. Como resultado, é verificado um decréscimo da intensidade das bandas Raman associadas com as ligações $C-O^{-}\left(466 \mathrm{~cm}^{-1}\right)$ e $C=O\left(496 \mathrm{~cm}^{-1}\right)$ e um aumento na intensidade dos picos em 571 e $1353 \mathrm{~cm}^{-1}$ (ligação $C-O H$ ) e $1180 \mathrm{~cm}^{-1}$ atribuído ao $v(C-O-O-C$ ). 


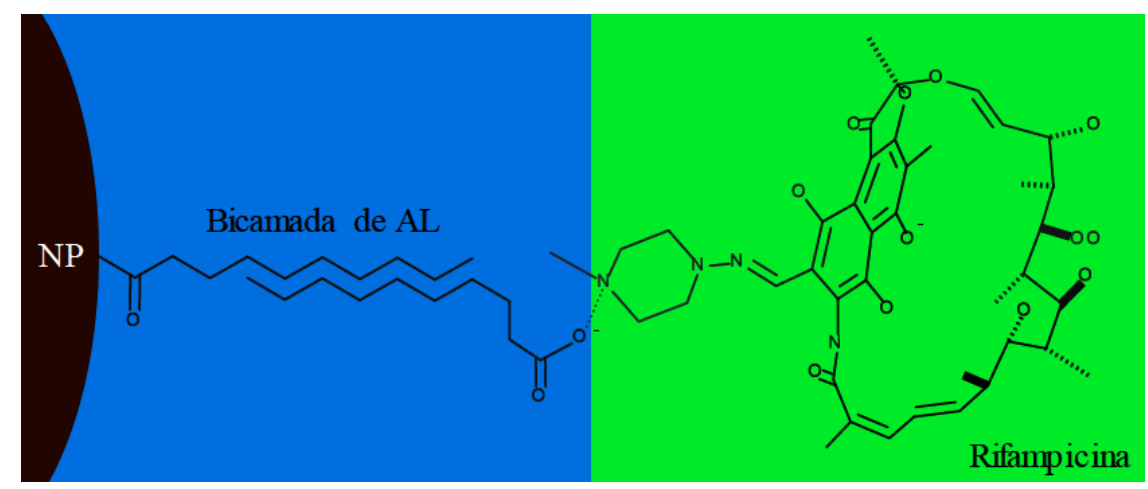

Figura 4.6: Representação esquemática para o ancoramento da Rifampicina nas nanopartículas de magnetita recobertas com ácido láurico.

Uma explicação para o aparecimento das bandas SERS extras em 527, 762 e 1390 $\mathrm{cm}^{-1}$ e o desaparecimento das bandas em 1435 e $1509 \mathrm{~cm}^{-1}$ nos espectros SERS da amostra FMBL/RIF ainda não é muito claro. Fazendo uma analogia com a molécula de naftaleno podemos inferir que essas bandas estão associadas com o modo stretching no plano do anel do cromóforo naftohidroquinona $[51,53]$. Mais especificamente, os modos vibracionais que surgiram apresentaram simetria $\mathrm{A}_{1 \mathrm{~g}}$ enquanto que aqueles que desapareceram apresentaram simetrias $\mathrm{B}_{1 \mathrm{u}}$ e $\mathrm{B}_{2 \mathrm{u}}$. Provavelmente, este comportamento está relacionado ao enrijecimento da molécula de RIF após a adsorção sobre a superfície da nanopartícula. A ausência dos modos esqueléticos totalmente simétricos $\left(\operatorname{modos} \mathrm{A}_{1 \mathrm{~g}}\right.$ ) e a presença dos modos vibracionais proibidos nos espectros SERS da amostra RIF livre podem estar associados com a orientação aleatória adquirida pela molécula ao ser depositada sobre o filme de prata, no qual quebra a simetria do anel, levando ao desaparecimento de modos totalmente simétricos e ao aparecimento de modos proibidos. Por outro lado, quando adsorvida sobre a superfície das nanopartículas, a molécula de Rifampicina torna-se rígida e as regras de seleção são restabelecidas. Assim, os modos simétricos aparecem e os proibidos desaparecem. Além disso, se levarmos em conta a ausência dos modos fora do plano e a grande melhora dos 
modos stretching no plano do anel nos espectros SERS, pode-se sugerir que o anel está verticalmente orientado com relação à superfície do metal [54].

Uma comparação entre os espectros SERS da amostra RIF livre, antes e após à exposição à luz (Figs. 4.4 (i) - (a) e (b)) mostra que apesar das mesmas características gerais, algumas diferenças podem ser observadas, particularmente com relação aos modos vibracionais do anel naftohidroquinona e sua vizinhança. Como afirmado anteriormente, antes da exposição a luz, o espectro SERS da amostra RIF livre mostra a presença de um modo vibracionai com simetria $\mathrm{A}_{1 \mathrm{~g}}\left(\mathrm{em} 1586 \mathrm{~cm}^{-1}\right.$ ) e dois modos vibracionais proibidos (em $1435 \mathrm{e}$ $1509 \mathrm{~cm}^{-1}$ ). No entanto, após a exposição a luz foi verificado que a banda em $1586 \mathrm{~cm}^{-1}$ quase desapareceu, enquanto que modos vibracionais proibidos tiveram suas intensidades relativas aumentadas. Além disso, também foi observado que a banda em $1623 \mathrm{~cm}^{-1}$ tornou-se mais larga e menos intensa. Uma vez que o pico de alta energia $\left(\mathrm{em} 1586 \mathrm{~cm}^{-1}\right)$ está associado com modos totalmente simétricos do esqueleto do anel naftohidroquinona e a intensidade relativa dos modos vibracionais proibidos aumentaram, pode-se admitir que a exposição a luz branca leva a uma redução da simetria dos modos do anel, o qual distorce a ligação $C=N$, explicando assim o decréscimo na intensidade e o alargamento do pico em $1623 \mathrm{~cm}^{-1}$. Desta maneira, todas estas alterações são responsáveis pelas mudanças observadas na coloração da amostra após a mesma ser exposta a luz branca, mudando da cor avermelhada para alaranjada.

Finalmente, como pode ser observado nas Figs. 4.4 (iii) - (a) e (b), o efeito de exposição a luz na amostra FMBL/RIF é bem menor do que o observado na amostra RIF livre. As diferenças espectrais são restritas ao aumento nas intensidades relativas referentes aos modos do esqueleto e da ligação $C-O^{-}$em $1645 \mathrm{~cm}^{-1}$. Estes dados indicam que a molécula de RIF é menos susceptível a degradação fotoquímica quando adsorvida sobre a superfície das nanopartículas. 


\subsubsection{Conclusões}

Em resumo, o estudo reporta a aplicação bem sucedida da técnica de espalhamento Raman intensificado por superfície (SERS) para investigar a adsorção e a estabilidade fotoquímica da molécula de Rifampicina (RIF) enquanto ancorada sobre a superfície das nanopartículas de magnetita recobertas com uma bicamada de ácido láurico (AL). Para comparação, a molécula de RIF livre também foi investigada pela técnica SERS. As significativas mudanças nos espectros SERS tanto da RIF livre e da RIF adsorvida na superfície das NPs permitiu avaliar informações fundamentais sobre a interação da molécula de RIF com o substrato SERS e com as NPMs. De fato, com base nos dados SERS foi proposto neste trabalho que o ancoramento da molécula de RIF à superfície das NPs ocorre por meio da ligação do grupo carboxilato externo proveniente da bicamada de AL e o nitrogênio piperazina adjacente ao nitrogênio imina da RIF. Adicionalmente, os dados SERS indicaram que a molécula de RIF é menos susceptível a degradação fotoquímica enquanto adsorvida à superfície das nanopartículas. 


\section{Seção 4.2}

\section{Estudo do ancoramento do SELOL sobre nanopartículas magnéticas e da sua estabilidade após aquecimento.}

Selol é um derivado orgânico semissintético do Se (IV), é uma mistura de selenitotriglicerídeos [55] preparados a partir do óleo de girassol. O Selol (Figura 4.7) foi sintetizado e patenteado por um grupo de pesquisa da Universidade de Varsóvia na Polônia [56]. Como contém o elemento selênio em sua estrutura, suspeita-se de exibir atividade quimiopreventiva e anticâncer [57]. No entanto, sua característica hidrofóbica tem sido empecilho para sua aplicação in vivo. Neste contexto, com o intuito de potencializar o tratamento e reduzir os efeitos hidrofóbicos do Selol, estudos contendo Selol associado à nanopartículas magnéticas são encontrados na literatura, em que as NPMs foram associadas ao Selol e em seguida foram carregados em polímero PLGA [58, 59]. Uma das principais características das NPMs é a capacidade de serem manipuladas sob a presença de um campo magnético externo. Devido a esse fenômeno, uma das principais aplicações das NPMs é a magnetohipertermia, uma terapia antitumoral muito utilizada na área biomédica. Magnetohipertermia é a elevação da temperatura provocada pelas NPMs que respondem a um campo alternado [60]. Quando as NPMs são submetidas a este campo, seus domínios magnéticos se alinham com o campo aplicado e uma vez que esse campo é alternado, os domínios magnéticos do material também se alternam com o campo. A constante mudança de orientação faz com que as nanopartículas dissipem energia na forma de calor, gerando assim o aquecimento necessário ao tratamento do tumor [61], uma vez que as células tumorais são menos resistentes a aumentos bruscos de temperatura do que as células sadias. 
Devido a estas considerações, nesta seção será investigada a eficiência da associação do Selol com nanopartículas magnéticas de magnetita e a estabilidade desta associação após o sistema ser submetido a aquecimento por campo magnético alternado. Estas condições foram criadas com o intuito de estudar o efeito antitumoral das nanopartículas magnéticas quando utilizadas para o tratamento de câncer com magnetohipertermia.

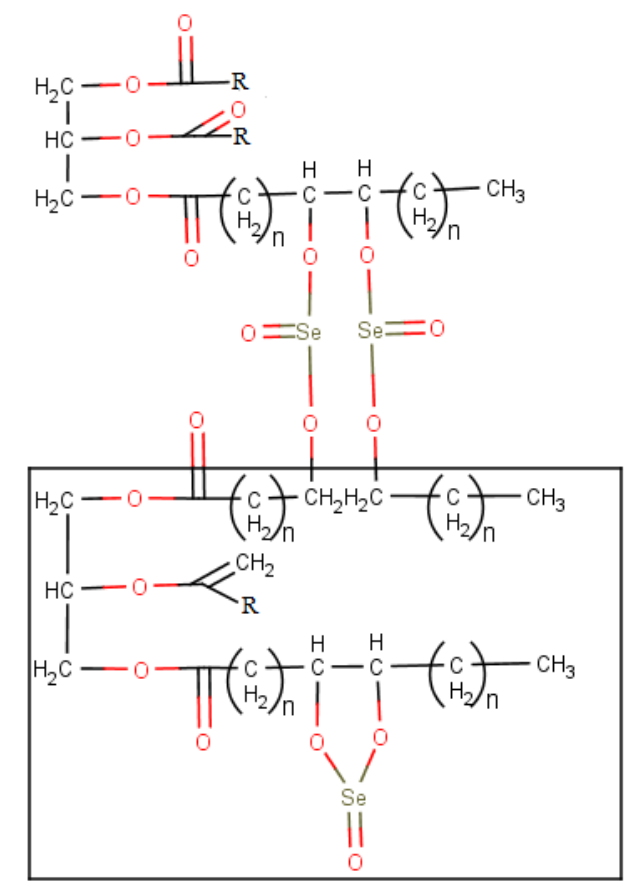

Figura 4.7: Estrutura do Selol.

\subsubsection{Metodologia}

\section{Preparação das amostras}

Os FMs utilizados na realização deste estudo são compostos de nanopartículas magnéticas de magnetita recobertas com bicamada de ácido láurico preparados por Fernando Cruvinel Damasceno, sob orientação da Prof ${ }^{a}$. Dr ${ }^{\mathrm{a}}$. Emília Celma de Oliveira Lima, do Instituto de Química da Universidade Federal de Goiás (UFG).

As nanopartículas de magnetita foram obtidas a partir da co-precipitação dos íons $F e^{+2}$ e $F e^{+3}(0,1$ e $0,05 \mathrm{~mol} / \mathrm{L}$, respectivamente) em meio alcalino (solução aquosa de hidróxido de 
sódio 1,6 mol/L). O precipitado negro de magnetita foi mantido na presença de um imã para que houvesse decantação e em seguida lavado várias vezes com água. Para a funcionalização com a bicamada de ácido láurico, $18 \mathrm{~g}$ do precipitado foram dissolvidos em $90 \mathrm{~mL}$ de água e aquecido de $75-80^{\circ} \mathrm{C}$. Ácido láurico (3 g) foi adicionado lentamente sob agitação contínua, o que causou a dispersão espontânea das nanopartículas no meio aquoso. A suspensão foi resfriada à temperatura ambiente e filtrada para remover o excesso de ácido láurico. A solução foi dialisada com água deionizada, o $\mathrm{pH}$ foi ajustado para 7.0 - 7.2, produzindo uma amostra de FMBL.

Para preparar a amostra de fluido magnético com Selol, 0,3 g de Selol foi dissolvido em $3 \mathrm{~mL}$ de dimetilsufóxido (DMSO) e em seguida essa solução foi adicionada à $70 \mathrm{~mL}$ da amostra FMBL e mantida sob agitação por 48 h. A suspensão foi esterilizada utilizando uma membrana de $0,22 \mu \mathrm{m}$ e a amostra foi denominada FMS. O Selol (5\% de selênio) foi fornecido por pesquisadores da Universidade Médica de Varsóvia, na Polônia [62].

\section{Aquecimento da Amostra FMS por campo magnético alternado.}

Foram realizados testes de aquecimento com as nanopartículas magnéticas submetendo-as a campos magnéticos alternado (CMA). Alíquotas de $1 \mathrm{~mL}$ das amostras FMS e FMBL foram colocadas em microtubos, os quais foram posicionados no centro de uma bobina geradora de campo magnético de frequência alternada (MagneTherm $^{\mathrm{TM}}$ NanoTherics). Estes testes foram realizados pela Dr $^{\mathrm{a}}$. Livia Carneiro Matos Avelino sob orientação da $\operatorname{Prof}^{\mathrm{a}}$.Dr ${ }^{\mathrm{a}}$ Zulmira Guerrero M. Lacava.

Para este experimento foi utilizada uma frequência de $330 \mathrm{kHz}$, onda quadrada e bobina de 17 voltas. Uma alíquota de $1 \mathrm{~mL}$ da amostra FMS foi subtida ao campo magnético alternado por 30 minutos. As temperaturas foram medidas a cada minuto usando o 
termômetro digital MT 525 (Minipa) até atingir a temperatura de $57{ }^{\circ} \mathrm{C}$. Esta amostra foi denominada FMSD. Como controle negativo, uma alíquota de $1 \mathrm{~mL}$ de água foi submetida ao campo magnético alternado.

\subsubsection{Discussões e Resultados}

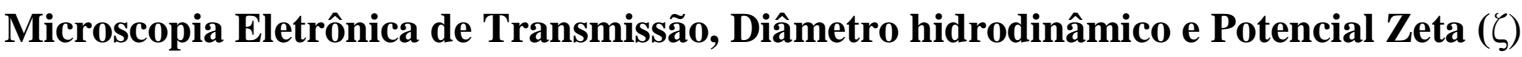

As amostras FMS e FMBL foram diluídos em água milli-Q na proporção 1:400. Em seguida, $3 \mu \mathrm{L}$ dessas soluções foram depositadas sobre telas de cobre cobertas com Formvar 0,5\%. Após a secagem dessa solução na tela, foi feita uma fixação e contrastação com vapor de tetróxido de ósmio $1 \%$ durante 20 minutos. As telas de cobre foram analisadas no microscópio eletrônico (JEOL JEM 1011) do Laboratório de Microscopia Eletrônica do Departamento de Biologia Celular da Universidade de Brasília. Os diâmetros médios obtidos para as amostras FMS e FMBL, utilizando MET, foram de 8,3 e 8,1 nm, respectivamente (veja Fig. 4.8 (a) e (b)). 


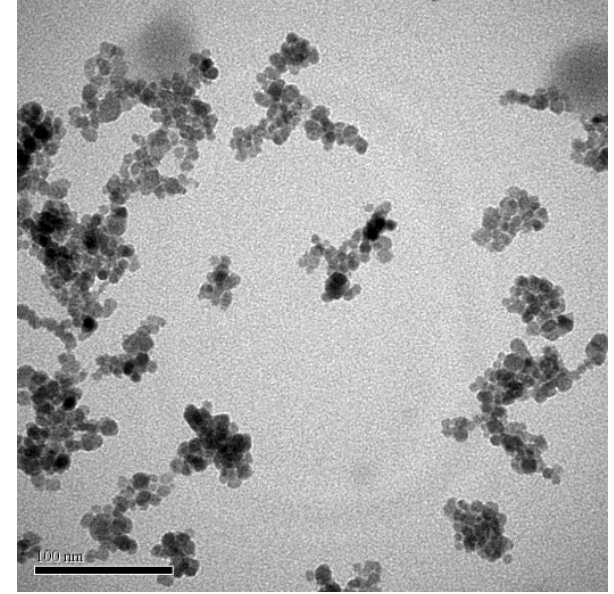

(a)

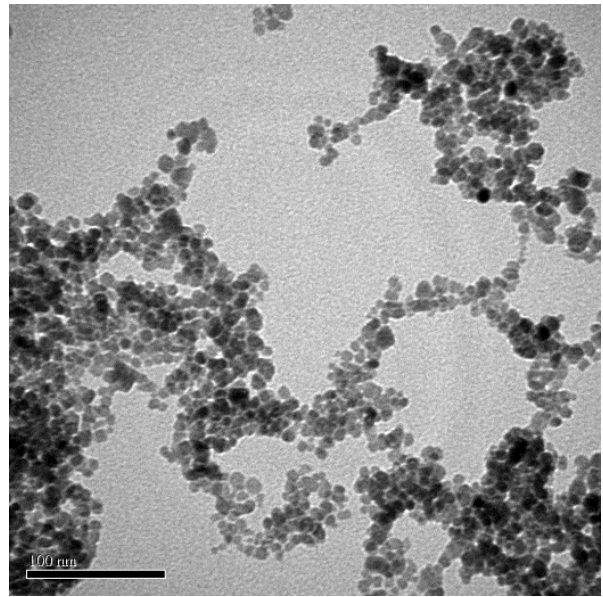

(b)

Figura 4.8: Micrografias MET, das amostras FMS (a) e FMBL (b).

A estabilidade coloidal destas nanopartículas foi avaliada medindo-se o diâmetro hidrodinâmico e o potencial $\zeta$. Por meio destes dados foi verificado que os valores do diâmetro obtidos a partir da micrografia eletrônica de transmissão são menores do que os valores obtidos por meio das medidas de espalhamento de luz dinâmico que foi de 91,7 nm para a amostra FMS e 84,3 nm para a amostra FMBL. E o potencial $\zeta$ encontrado foi de $-46,1$ e -40,1 mV, para as amostras FMS e FMBL, respectivamente.

\section{SERS}

Com o objetivo de estudar o ancoramento e a estabilidade após aquecimento, via campo magnético alternado, os espectros SERS das amostras FMBL, FMS, FMSD foram comparados entre si e com o espectro Raman normal do Selol puro. Estes resultados são mostrados na Fig. 4.9. O espectro SERS da amostra FMBL (Fig. 4.9 (a)) mostra as características de cadeias de hidrocarboneto. As bandas observadas na região de baixas energias $\left(300-800 \mathrm{~cm}^{-1}\right)$ estão associadas com as vibrações $C$ - $C$ do esqueleto da molécula. 
Os picos em 893, 932, 1082 e $1304 \mathrm{~cm}^{-1}$ são assinaturas dos modos $\rho\left(\mathrm{CH}_{3}\right), v(\mathrm{C}-\mathrm{C}), v(\mathrm{C}-\mathrm{OH})$ e $\delta\left(\mathrm{CH}_{2}\right)$, respectivamente (veja Tab. 4.3). Além disso, na região $1400-1650 \mathrm{~cm}^{-1}$, existe a contribuição dos modos $-\mathrm{COO}^{-}\left(v_{s}\left(-\mathrm{COO}^{-}\right)\right.$e $\left.v_{a s}\left(-\mathrm{COO}^{-}\right)\right)$. O significante valor de intensidade dos stretchings do grupo $-\mathrm{COO}^{-}$nos espectros SERS sugere fortemente que o grupo carboxilato se acopla a superfície das nanopartículas de prata, onde o forte campo elétrico sobre a superfície metálica tem ampliado o sinal do espalhamento Raman deste grupo funcional [32].

Os espectros SERS das amostras FMS e FMSD (Fig 4.9 (b) e (c), respectivamente) possuem características muito similares àquelas observadas na amostra FMBL. Contudo, alguns modos adicionais são observados em torno de 800, 1105, 1146 e $1270 \mathrm{~cm}^{-1}$ (picos destacados em vermelho).

Com o intuito de facilitar as análises dos espectros Raman das amostras FMS e FMSD, é mostrado na parte superior da Fig. 4.9 o espectro Raman normal do Selol puro. Devido à alta viscosidade do Selol puro e em solvente não foi possível obter seu espectro SERS. Na literatura não existem estudos envolvendo espectroscopia ótica a respeito do Selol. No entanto, fazendo comparação com as energias vibracionais do dióxido de selênio é possível atribuir as bandas observadas em 866, 753, e $664 \mathrm{~cm}^{-1}$ aos respectivos modos vibracionais $v(S e=O), v_{a s}(S e-O)$ e $v_{s}(S e-O)$ [63]. Na região $1050-1550 \mathrm{~cm}^{-1}$ verifica-se a presença de quatro principais bandas vibracionais. Duas bandas localizadas em 1075 e 1163 $\mathrm{cm}^{-1}$ são devidas ao stretching simétrico e assimétrico $C$ - $C$, respectivamente e as bandas em 1300 e $1508 \mathrm{~cm}^{-1}$ estão relacionadas ao grupo $\mathrm{CH}_{2}$ (twisting e scissoring). Por último, as bandas em 1443 e $1665 \mathrm{~cm}^{-1}$ estão associadas às vibrações dos modos $\delta\left(\mathrm{CH}_{3}\right)$ e $v(\mathrm{C}=\mathrm{O})$, respectivamente. 
Tabela 4.2: Tabela com a posição dos modos vibracionais obtidos a partir da técnica SERS e Raman normal para bicamada de AL, Selol puro e FMS.

\begin{tabular}{|c|c|c|c|}
\hline $\begin{array}{c}\text { Bicamada } \\
\text { AL }\end{array}$ & Selol puro & FMS & Atribuições \\
\hline & 664 & & $v_{\mathrm{s}}(\mathrm{Se}-\mathrm{O})$ \\
\hline & 753 & & $v_{\mathrm{as}}(\mathrm{Se}-\mathrm{O})$ \\
\hline & & 800 & $\mathrm{SeO}^{-}$ \\
\hline & 866 & & $v(\mathrm{Se}=\mathrm{O})$ \\
\hline 893 & & & $\rho\left(\mathrm{CH}_{3}\right)$ \\
\hline \multirow[t]{2}{*}{932} & & & $v(\mathrm{C}-\mathrm{C})$ \\
\hline & 1075 ᄃ & $>1105$ & $v_{\mathrm{s}}(\mathrm{C}-\mathrm{C})$ \\
\hline 1082 & & & $v(\mathrm{C}-\mathrm{OH})$ \\
\hline \multirow[t]{2}{*}{1130} & & 1130 & $v_{\mathrm{s}}(\mathrm{C}-\mathrm{C})$ \\
\hline & 1163 & $>1146$ & $v_{\text {as }}(C-C)$ \\
\hline 1300 & $1304 \sqsubset$ & $>1270$ & $\tau\left(\mathrm{CH}_{2}\right)$ \\
\hline 1404 & & 1404 & $v_{\mathrm{s}}\left(-\mathrm{COO}^{-}\right)$ \\
\hline 1443 & 1443 & 1443 & $\delta\left(\mathrm{CH}_{3}\right)$ \\
\hline 1508 & & & $\varsigma\left(\mathrm{CH}_{2}\right)$ \\
\hline 1600 & & 1600 & $v_{\text {as }}\left(-\mathrm{COO}^{-}\right)$ \\
\hline 1660 & 1665 & & $v(\mathrm{C}=\mathrm{O})$ \\
\hline
\end{tabular}

v: modo stretching; $v_{a s}:$ stretching assimétrico, $v_{a s}:$ stretching simétrico; $\delta$ : modo bending; $\rho$ : modo rocking; $\tau$ : modo twisting; s:modo scissoring. 


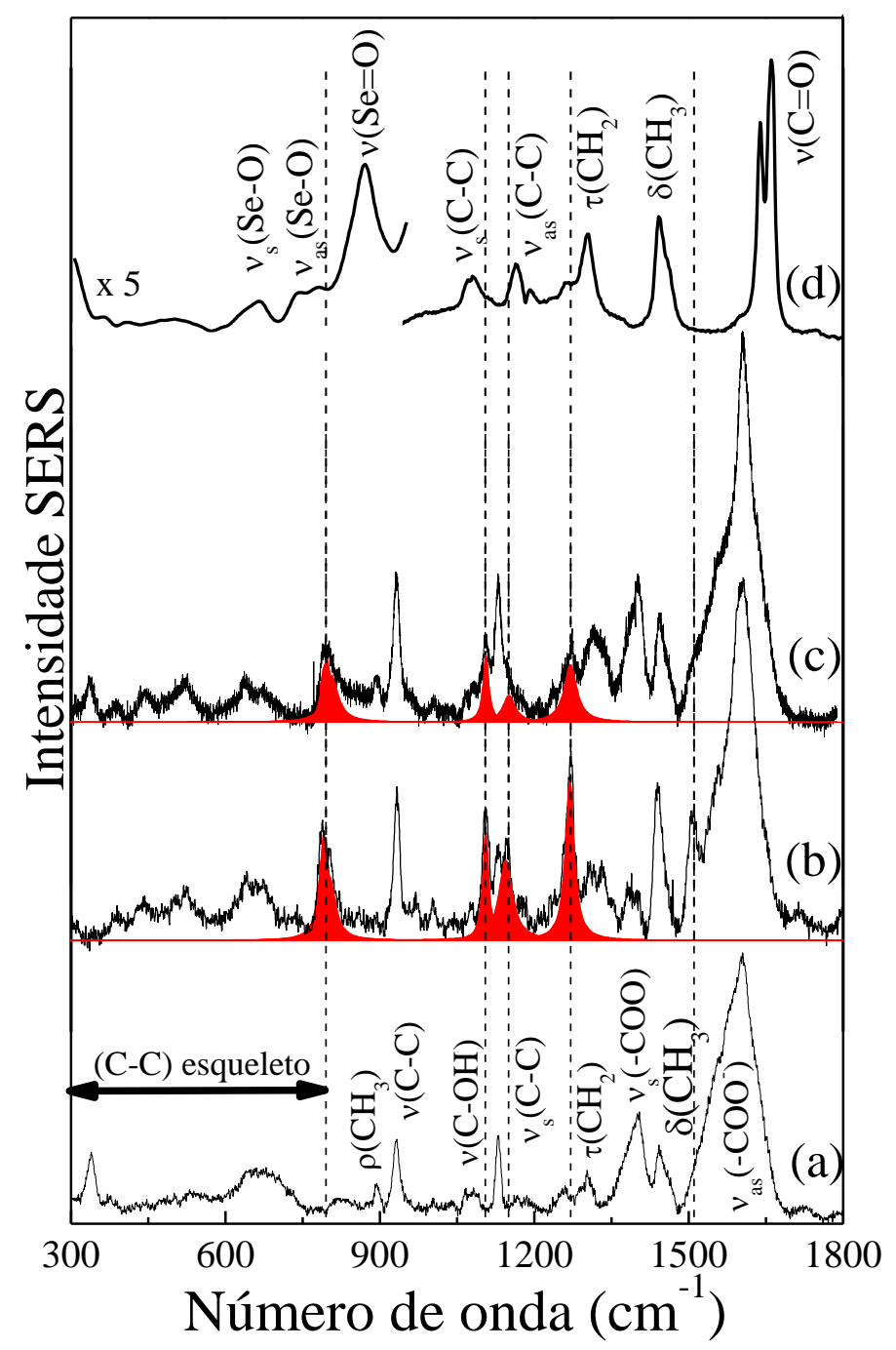

Figura 4.9: Espectros SERS das amostras FMBL (a) FMS (b) FMSD (c). E em (d) tem-se o espectro Raman normal do Selol puro.

Comparando os espectros SERS das amostras FMS e FMSD com o espectro Raman normal do Selol puro, é possível sugerir que as bandas adicionais em 800, 1105, 1146, 1270 $\mathrm{cm}^{-1}$ (picos destacados em vermelho na Fig. 4.9 (b) e (c)) e a banda em $1600 \mathrm{~cm}^{-1}$ são devidas à molécula de Selol que está ancorada sobre a superfície da nanopartícula. O deslocamento da banda em $1665 \mathrm{~cm}^{-1}(C=O)$ para $1600 \mathrm{~cm}^{-1}\left(-C O O^{-}\right)$corresponde ionização do grupo carboxil para o carboxilato. Processo similar ocorre com a ligação $S e=O$. A interação da molécula de Selol com a superfície da nanopartícula, induz a uma delocalização do elétron em torno da 
ligação $\mathrm{Se}=\mathrm{O}$, resultando em $\mathrm{SeO}^{-}$. Como consequência, o comprimento da ligação $\mathrm{Se}=\mathrm{O}$ aumenta e, portanto sua energia vibracional diminui de $866 \mathrm{~cm}^{-1}$ para $800 \mathrm{~cm}^{-1}$. Outra mudança espectral sugere que o efeito de interação da molécula Selol com a superfície da nanopartícula se estende sobre os modos vibracionais da cadeia carbônica do Selol, mas aparentemente não sobre a bicamada de AL. Por exemplo, note na Fig. 4.9 que enquanto as energias vibracionais dos modos em $1130 \mathrm{~cm}^{-1}\left(v_{s}(C-C)\right)$ e $1443 \mathrm{~cm}^{-1}\left(\delta\left(\mathrm{CH}_{3}\right)\right)$ provenientes da bicamada de AL permanecem inalterados em todos os espectros, as energias dos modos Raman $v_{a s}(C-C)$ e $v_{s}(C$ - $C)$, associadas com a molécula de Selol se deslocam de 1075 e 1163 $\mathrm{cm}^{-1}$ (Selol puro) para 1105 e $1146 \mathrm{~cm}^{-1}$, respectivamente. Estes resultados nos levam a acreditar que a molécula de Selol está ancorada à superfície da nanopartícula por meio da interação do grupo $\mathrm{OOSeO}$ com o terminal do grupo carboxil proveniente da bicamada de AL.

Uma estimativa aproximada da concentração relativa de moléculas de Selol ligadas à superfície das nanopartículas, antes (amostra FMS) e depois do aquecimento (amostra FMSD) pode ser determinada medindo-se as áreas sob as bandas vibracionais relacionadas ao Ácido Laurico e ao Selol. Para esta estimativa admitiu-se que apenas o teor de Selol (e não o teor de AL) ligado ao Ácido Láurico possa ser afetado pelo aquecimento da amostra. A razão entre as áreas das bandas 800,1105, 1146 e $1270 \mathrm{~cm}^{-1}$ (associadas à molécula de Selol) com a área sob os modos $v(C-C)$ do esqueleto da bicamada de Ácido Láurico $\left(932 \mathrm{~cm}^{-1}\right)$, para as amostras FMS e FMSD, são mostradas na Tabela 4.3. Verifica-se da Tab.4.3 que a razão FMS/FMSD é igual ou superior 2,0. Comportamento similar é observado para a razão entre as áreas sob os modos vibracionais do Selol e o modo $\delta(\mathrm{CH} 3)$ do Ácido Láurico. O fato de que as razões entre as diferentes áreas associados aos diferentes modos vibracionais observados para as amostras FMS e FMSD serem sempre maiores ou iguais a 2,0 indica que a concentração de moléculas de Selol restante na superfície da nanopartíula (após aquecimento) é da ordem de $50 \%$ do teor de moléculas inicialmente adsorvidas. 
Tabela 4.3: Razão entre as intensidades dos picos de Selol $\left(I_{\text {selol }}\right)$ e da bicamada de $A L\left(I_{A L}\right)$.

\begin{tabular}{cccc}
\hline$I_{\text {selo }} / I_{A L}$ & \multicolumn{2}{c}{ Aquecimento } & $\begin{array}{c}\text { Razão } \\
\text { FMS/FMSD }\end{array}$ \\
\hline & Antes & Depois \\
$\mathrm{SeO}^{-} / v(\mathrm{C}-\mathrm{C})$ & 2.0 & 1.0 & 2.0 \\
$v_{\mathrm{S}}(\mathrm{C}-\mathrm{C}) / v(\mathrm{C}-\mathrm{C})$ & 1.0 & 0.4 & 2.5 \\
$v_{\mathrm{as}}(\mathrm{C}-\mathrm{C}) / v(\mathrm{C}-\mathrm{C})$ & 1.5 & 0.3 & 5.0 \\
$\tau\left(\mathrm{CH}_{2}\right) / v(\mathrm{C}-\mathrm{C})$ & 2.0 & 0.7 & 2.8 \\
\hline stretching; & &
\end{tabular}

$v:$ modo stretching; $v_{s}:$ stretching simétrico; $v_{a s}:$ stretching assimétrico; $\tau$ : twisting.

\subsubsection{Conclusões}

Os espectros SERS das amostras de Selol adsorvidas sobre superfícies de nanopartículas de magnetita foram obtidos com sucesso. Os resultados demonstraram que as nanopartículas magnéticas pré-cobertas com uma bicamada de AL podem ser preparadas e utilizadas para carrear o fármaco Selol. A técnica SERS permitiu estudar o ancoramento do Selol sobre as nanopartículas de magnetita, e os resultados levam a acreditar que a molécula de Selol está ancorada à superfície da nanopartícula através da interação do grupo $O O S e O$ com o terminal do grupo carboxilíco procedente da bicamada de AL. Adicionalmente,estimou-se que $50 \%$ do teor de moléculas inicialmente adsorvidas à superficie das nanopartículas magnéticas permaneceram ancoradas após a amostra FMS ser submetida a aquecimento a $57^{\circ} \mathrm{C}$ por um campo magnético alternado. 


\section{Seção 4.3}

\section{Estudo do carregamento de Itraconazol em Nanopartículas de PLGA.}

O itraconazol (ITZ) é um excelente antifúngico, utilizado no tratamento de infecções superficiais e em algumas infecções sistêmicas. O ITZ tem como mecanismo de ação a inibição da biosíntese do ergosteroal, alterando a permeabilidade da membrana celular fúngica $[64,65,66,67]$. Entretanto, devido a sua baixa solubilidade em meio aquoso (1mg/mL) a absorção do ITZ pelo organismo é altamente variável, dose dependente e incompleta, o que torna sua administração por via oral ou intravenosa limitada [68]. Para contornar este problema sistemas de entregas de drogas baseados em sistemas nanoparticulados têm sido proposto $[69,70]$. Polímeros nanoestruturados baseados em ácido poli (lático-co-glicólico) (do inglês poly(lactic-co-glycolic) acid-PLGA) têm se mostrado um promissor candidato para a veiculação dos mais diversos fármacos, visto que eles são biodegradegradaveis e bio-absorvíveis usados para criar dispositivos farmacêuticos e biomédicos [71]. A biodegradabilidade inerente ao PLGA está relacionada à sua hidrólise no organismo, produzindo metabólicos não tóxicos e toleráveis ao tecido. Por exemplo, o PLGA 50:50 apresenta composição de 50\% de poli (ácido lático) (do inglês poly (lactic acid) - PLA) e 50 $\%$ de poli (ácido glicólico) (do inglês poly (glicolic acid) - PGA). Além disso, ele é um polímero aprovado pela agência americana FDA (US Food and Drug Administration-FDA) e pela Agência de Medicina Europeia (European Medicine Agency) para uso em vários sistemas de entregas de drogas em humanos [72]. Na Fig. 4.10 têm-se as representações das moléculas de Itraconazol e do polímero PLGA, respectivamente.

As características físicas favoráveis de baixa densidade combinada com uma grande área superficial fazem dessas nanoestruturas poliméricas um sistema ideal carreador de 
fármaco [73]. Para que essas nanoestruturas poliméricas sejam aplicadas, é essencial conhecer as suas propriedades físico-químicas.

Nesta seção é realizado o estudo de nanoestruturas baseadas em nanopartículas de PLGA carregando o fármaco Itraconazol. Para obtenção dos espectros SERS, filmes nanoestruturados de prata foram preparados pelo método de eletrólise. Espectros de FTIR, imagens de microscopia eletrônica de varredura, e potencial $\zeta$ foram empregados para caracterização das nanoestruturas.

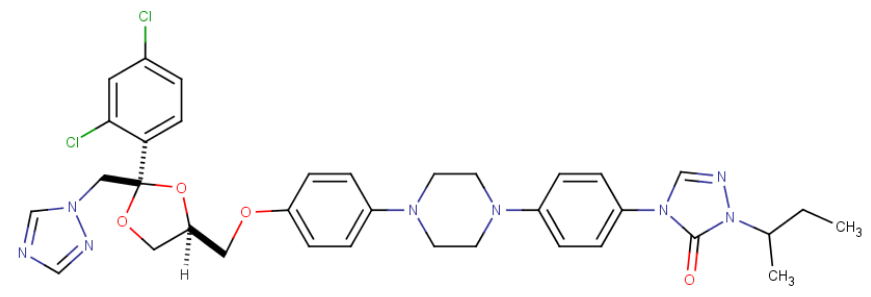

(a)

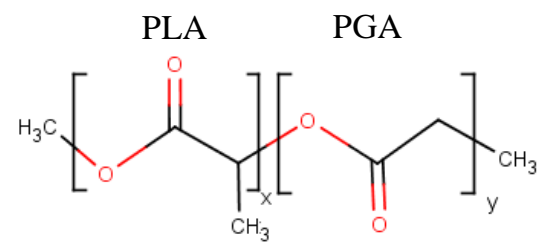

(b)

Figura 4.10: Representação das moléculas de Itraconazol (a) e do polímero PLGA (b), respectivamente. Sendo que o PLGA é composto por outros dois polímeros, o poli (ácido lático) PLA e o poli (ácido glicólico) - PGA.

\subsubsection{Metodologia}

\section{Preparação das Nanopartículas de PLGA}

As nanopartículas de PLGA carregadas com Itraconazol utilizados na realização deste estudo foram preparadas pela $\operatorname{Dr}^{\mathrm{a}}$ Jaqueline Rodrigues da Silva do Instituto de Biologia/UnB. As nanopartículas foram preparadas pela técnica de evaporação/extração de solvente da emulsão de óleo em água $[76,77]$ usando uma mistura de PLGA em diclorometano e Itraconazol em clorofórmio como fase orgânica e uma solução a 1\% (w/v) de PVA (Polyvinyl 
alcohol) como fase aquosa. Após misturar a fase orgânica à fase aquosa, a solução foi homogeneizada em um sonicador (Branson Sonifier ultrasonic) em 2 intervalos de 1 minuto cada em banho de gelo. A emulsão foi dispersada numa solução de PVA a $0,1 \%$ (w/v) mantida sob agitação a $250 \mathrm{rpm}$ (Mikro 22R-HETTICH) por 15 minutos. O solvente foi eliminado utilizando um evaporador rotativo, temperatura de $37^{\circ} \mathrm{C}$. As nanopartículas resultantes foram lavadas 3 vezes com uma solução de PBS, pH 7,2 para retirada do excesso de PVA por centrifugação a $14.000 \mathrm{rpm}$ a $10^{\circ} \mathrm{C}$. Esta amostra foi denominada ITZ@PLGAnano. Com o intuito de verificar a eficiência do carregamento e as possíveis interações químicas entre o ITZ, a matriz polimérica de PLGA e o substrato de prata, amostras da mistura física de ITZ e PLGA (amostra ITZ+PLGA-nano) e a amostra ITZ@PLGA-nano sonicada por 5 minutos, com o objetivo de liberar o fármaco do interior das nanopartículas de PLGA, foram produzidas.

\subsubsection{Resultados e Discussões}

\section{Microscopia Eletrônica de Varredura}

Na Fig. 4.11 são mostradas micrografias MEV representativas das nanopartículas de PLGA pura (a) e da amostra ITZ@PLGA-nano (b). Nota-se que nos dois casos as nanopartículas são quase esféricas. 


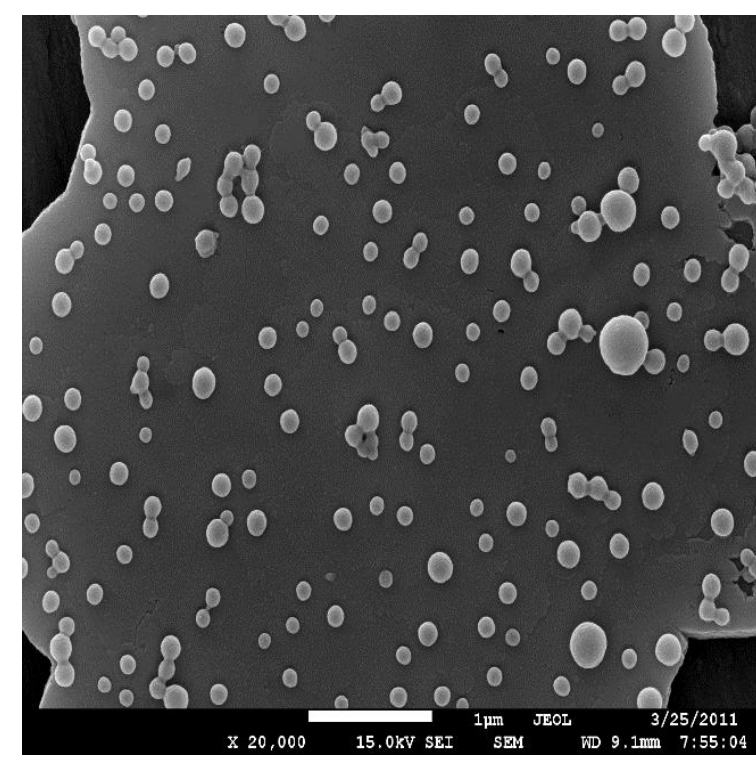

(a)

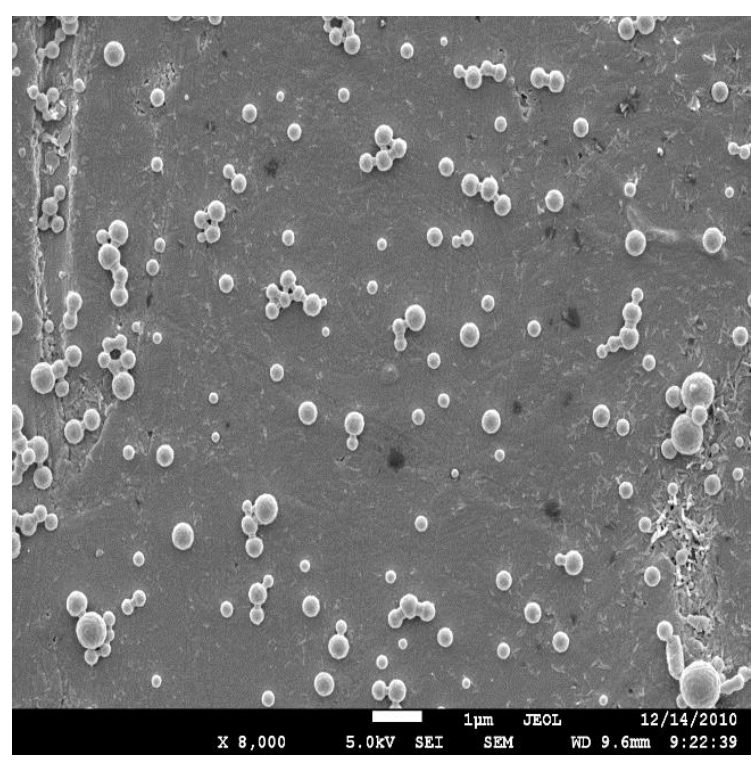

(b)

Figura 4.11: Micrografias MEV para as amostras de nanopartículas de PLGA pura (a) $e$ ITZ@PLGA-nano $(b)$.

Por meio das técnicas de DLS e potencial $\zeta$ foi possível avaliar a estabilidade coloidal das nanopartículas. A partir destes dados foi possível verificar que os valores obtidos para os diâmetros hidrodinâmicos foram de 255,2 e 267,4 nm, para NPs de PLGA e ITZ@PLGAnano, respectivamente. Os valores encontrados para os potenciais $\zeta$ foram $-2,8$ e $-2,7 \mathrm{mV}$, para NPs de PLGA e ITZ@PLGA-nano, respectivamente.

\section{FTIR}

Os dados e análise de FTIR são apresentados nesta subseção. A Fig. 4.12 mostra os espectros de FTIR do ITZ pó (i), da mistura física de ITZ com nanopartícula de PLGA (ITZ+PLGA-nano) (1:20) (ii), das nanopartículas de PLGA carregadas com ITZ (ITZ@PLGA-NANO) (iii) e das nanopartículas de PLGA puras (PLGA-nano) (iv). O 
espectro do ITZ pó mostra bandas características do Itraconazol na região de 2800 - 3200 $\mathrm{cm}^{-1}$ e picos bem definidos entre 800 e $1700 \mathrm{~cm}^{-1}$ [78, 79]. As bandas de mais altas energias são assinaturas do alcano, $C H$ aromático e grupos amina. Os picos observados em 1700, 1609 e $1225 \mathrm{~cm}^{-1}$ podem ser atribuídos às ligações $C=O, C=N$ e éter $C-O$ respectivamente. Os picos em 1510 e $1450 \mathrm{~cm}^{-1}$ são devidos às deformações $C$ - $H$ dos anéis aromáticos. Finalmente o pico em $825 \mathrm{~cm}^{-1}$ é atribuído ao anel triazol [80].

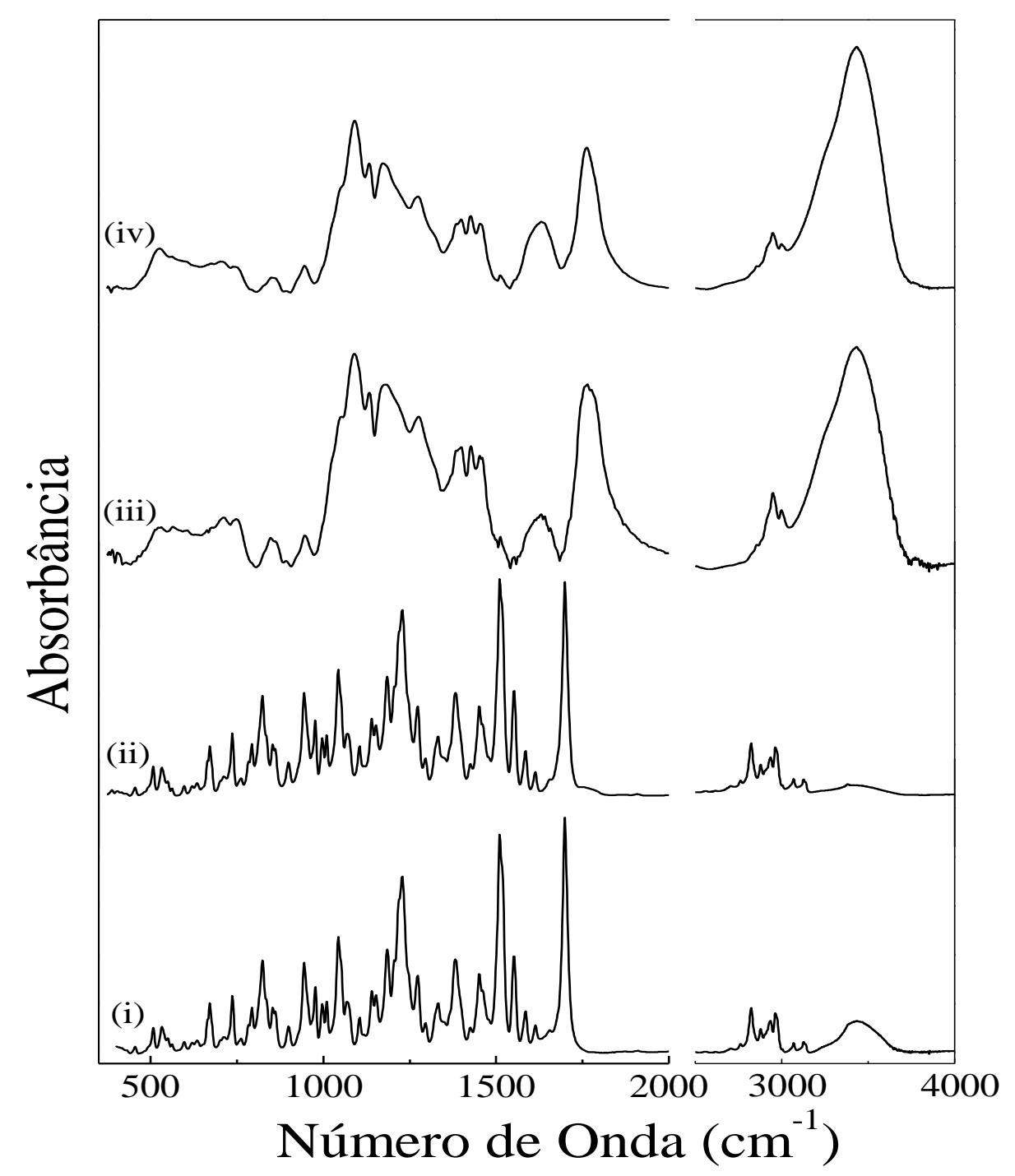

Figura 4.12: Espectro FTIR da amostra ITZ pó (i), mistura física de ITZ com nanopartículas de PLGA (ITZ+PLGA-nano) (ii), nanopartículas de PLGA carregadas com ITZ (ITZ@PLGA-nano) (iii) e nanopartículas de PLGA (iv). 
Embora com baixa relação de peso ITZ:PLGA (1:20) o padrão espectral da mistura física (Fig. 4.12 (ii)) corresponde quase inteiramente ao padrão do espectro de ITZ pó. Um pequeno ombro é observado em $1760 \mathrm{~cm}^{-1}$ o qual corresponde ao stretching $C=O$ da vibração do PLGA. Em contraste, o espectro da amostra ITZ@PLGA-nano (também na relação 1:20) (Fig. 4.12 (iii)) demonstrou uma completa ausência das bandas características de ITZ, presentes no espectro da mistura física (Fig. 4.12 (ii)). Neste espectro foram observadas bandas típicas do polímero PLGA (Fig. 4.12 (iv)), com bandas bending do $\mathrm{CH}_{2}$ e $\mathrm{CH}_{3}$ na região de $1300-1500 \mathrm{~cm}^{-1}$. Na região de $1000-1300 \mathrm{~cm}^{-1}$ observa-se bandas referente ao modo stretching do $\mathrm{COC}$ para o ácido glicólico e vibrações $\mathrm{CH}_{3}$ provenientes do ácido lático. Este resultado indica que para a relação de peso 1:20 (ITZ:PLGA) não foi possível, observar por meio da técnica de FTIR os modos vibracionais do ITZ quando este é carregado pelas nanopartículas de PLGA. Os mesmos resultados foram obtidos para uma relação de ITZ:PLGA menor (1:5).

\section{SERS}

A Fig. 4.13 mostra o espectro de Raman normal da amostra de ITZ pó (i) e os espectros SERS das nanopartículas de PLGA puras (PLGA-nano) (ii), da mistura física de ITZ com nanopartícula de PLGA (ITZ+PLGA-nano) (iii), das nanopartículas de PLGA carregadas com ITZ (ITZ@PLGA-nano) (iv). Para comparação, o espectro SERS da amostra ITZ@PLGA-nano, sonicada por 5 minutos também é mostrado em (v). O processo de sonicação tem como objetivo liberar as moléculas de ITZ do interior das nanopartículas de PLGA, através da quebra das mesmas. Com este processo, espera-se que uma vez livres, as moléculas de ITZ possam interagir com o substrato de prata, gerando intensificação do sinal 
Raman pelo efeito SERS. Em complemento, uma tentativa de se obter um espectro de Raman normal da amostra de ITZ@PLGA-nano foi frustrada devido a presença de uma forte fluorescência, tornado impossível obter um espectro Raman, mesmo de baixa qualidade.

O espectro Raman normal do ITZ pó, mostrado na Fig 4.13 (i), apresenta características típicas dos espectros observados na literatura [80, 81]. Apesar da molécula de ITZ exibir modos vibracionais altamente acoplados, pode-se grosseiramente afirmar que seu espectro Raman é dominado pelas vibrações do anel triazol [80] (com picos em torno de 367, $810,822,1010,1183,1396,1460$ e $1517 \mathrm{~cm}^{-1}$ ) e dos anéis fenil (com picos na região de 400 $1200 \mathrm{~cm}^{-1}$ e em 1583 e $1613 \mathrm{~cm}^{-1}$ ) [82]. Uma tentativa de atribuições para estas bandas é mostrada na Tabela 4.4, a qual é consistente com trabalhos já publicados na literatura $[78,80$, 83]. 


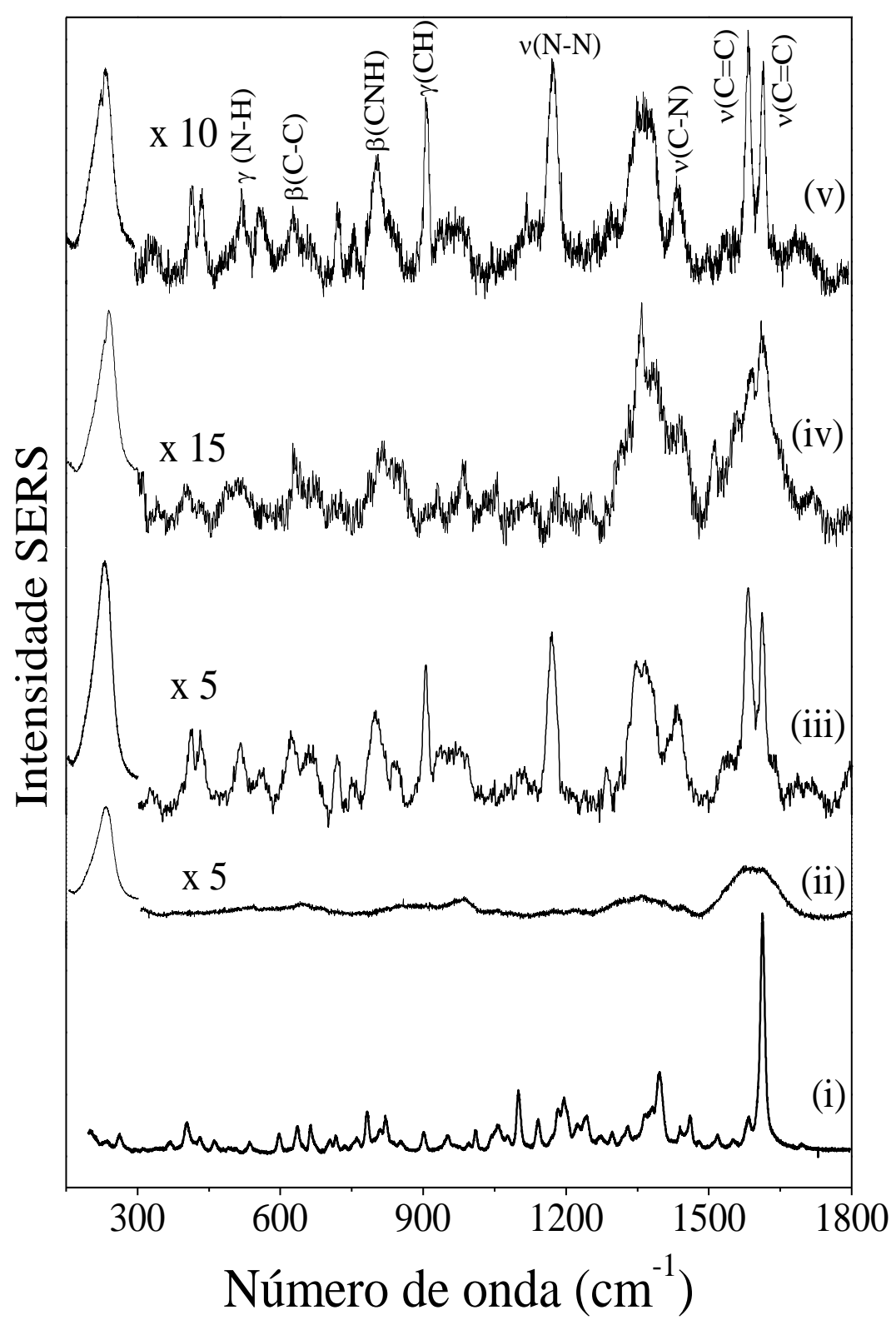

Figura 4.13: Espectro SERS da amostra ITZ pó (i), nanopartículas de PLGA (ii) mistura física de ITZ e nanopartículas de PLGA (iii), nanopartículas de PLGA carregadas com ITZ após sonicação (iv) nanopartículas de PLGA carregadas com ITZ(v). 
Tabela 4.4: Posição dos modos vibracionais obtidos a partir da técnica SERS para o ITZ pó, ITZ+PLGA-nano, ITZ@PLGA-nano e ITZ@PLGA-nano sonicada.

\begin{tabular}{|c|c|c|c|c|}
\hline ITZ pó & $\begin{array}{c}\text { ITZ+PLGA- } \\
\text { nano }\end{array}$ & $\begin{array}{c}\text { ITZ@PLGA- } \\
\text { nano }\end{array}$ & $\begin{array}{c}\text { ITZ@PLGA- } \\
\text { nano } \\
\text { Sonicada } \\
\end{array}$ & Assinaturas \\
\hline Raman & & SERS & & \\
\hline 367 & 330 & & 330 & $\omega(\mathrm{C}-\mathrm{N})$ \\
\hline 404 & 412 & 404 & 412 & $\beta(C-C)$ \\
\hline 430 & 430 & 430 & 430 & $\gamma(\mathrm{C}-\mathrm{H})$ \\
\hline 460 & & & & $\beta(\mathrm{CCC})$ \\
\hline 535 & 516 & 516 & 516 & $\gamma(\mathrm{N}-\mathrm{H})$ \\
\hline 600 & 559 & & 557 & $\tau($ Tri $)$ \\
\hline 636 & 625 & 634 & 625 & $\beta(\mathrm{C}-\mathrm{C})$ \\
\hline 662 & 662 & 663 & 667 & $\beta(\mathrm{C}-\mathrm{C})$ \\
\hline 717 & 719 & & 719 & $\gamma(\mathrm{C}-\mathrm{H})$ \\
\hline 756 & 756 & & 755 & $\theta$ (anel fenil) \\
\hline 783 & & & & $\beta(\mathrm{CCC})$ \\
\hline 810 & 800 & 812 & 802 & $\beta(\mathrm{CNH})$ \\
\hline 822 & 820 & & & $\gamma(\mathrm{C}-\mathrm{H})$ \\
\hline 852 & 840 & 847 & 830 & $\gamma(\mathrm{CNH})$ \\
\hline 902 & 904 & & 904 & $\gamma(\mathrm{C}-\mathrm{H})$ \\
\hline 950 & 935 & & 933 & $\omega(\mathrm{C}-\mathrm{H})$ \\
\hline 1010 & 985 & 985 & & $v(\mathrm{C}-\mathrm{N})$ \\
\hline 1100 & & & 1110 & $\beta(\mathrm{C}-\mathrm{H})$ \\
\hline 1142 & & & & $v(\mathrm{C}-\mathrm{Cl})$ \\
\hline 1183 & 1173 & & 1173 & $v(\mathrm{~N}-\mathrm{N})$ \\
\hline 1242 & & & & $\beta(\mathrm{C}-\mathrm{H})$ \\
\hline 1365 & 1350 & 1357 & 1350 & $v(\mathrm{~N}-\mathrm{N})$ \\
\hline 1396 & 1383 & 1390 & 1383 & $v(\mathrm{C}-\mathrm{N})$ \\
\hline 1460 & 1440 & 1441 & 1439 & $v(\mathrm{C}-\mathrm{N})$ \\
\hline 1517 & & 1512 & & $v(\mathrm{C}=\mathrm{N})$ \\
\hline 1551 & & 1554 & & \\
\hline 1583 & 1583 & 1585 & 1586 & $v(\mathrm{C}=\mathrm{C})$ \\
\hline 1613 & 1613 & 1613 & 1613 & $v(\mathrm{C}=\mathrm{C})$ \\
\hline 1696 & 1720 & 1720 & 1705 & $v(\mathrm{C}=\mathrm{O})$ \\
\hline
\end{tabular}

v: modo stretching; $\beta$ : bending no plano; $\gamma$ : bending fora do plano; $\omega:$ modo wagging; $\theta:$ modo respiração; $\tau$ : modo twisting. 
O espectro SERS da amostra PLGA-nano, mostrado na Fig. 4.13 (ii), apresenta sinal Raman fraco, com bandas largas centradas em 980, 1350 e $1600 \mathrm{~cm}^{-1}$, muito similar ao espectro obtido na referência [84], onde foram estudadas nanopartículas de PLGA dopadas com Ag e Au. Adicionalmente, nota-se que o espectro SERS da amostra ITZ+PLGA-nano (Fig. 4.13 (iii)) é dominado pelos modos vibracionais do itraconazol, não mostrando evidências apreciáveis da presença das nanopartículas de PLGA.

Uma cuidadosa comparação entre os espectros SERS do ITZ pó e o da amostra de ITZ+PLGA-nano, evidencia que os modos vibracionais do anel triazol (deste último) sofrem consideráveis deslocamentos para menores energias (redshift) (ver bandas em 367/330 ( $\omega$ (CN)), 535/516 ( $(\mathrm{N}-\mathrm{H})), 600 / 559(\tau(\mathrm{Tri})), 810 / 800(\beta(\mathrm{CNH})), 852 / 840(\gamma(\mathrm{CNH})), 1010 / 985$ $(v(C-N)), 1183 / 1173(v(N-N)), 1365 / 1350(v(N-N), 1396 / 1383(v(C-N))$ e $1460 / 1440(v(C-N))$ $\left.\mathrm{cm}^{-1}\right)$. Por sua vez, verifica-se também que as bandas associadas ao grupo fenil $(430(\gamma(C-H))$, $662 \beta(C-C), 717 \gamma(C-H), 902 \gamma(C-H), 1583 v(C=C)$ e $\left.1613 v(C=C) \mathrm{cm}^{-1}\right)$ permanecem com suas energias vibracionais inalteradas em relação ao ITZ pó. Além do mais, observa-se que as bandas em $460(\beta(C C C)), 783(\beta(C C C)), 1100(\beta(C-H)), 1142(v(C-C l)), 1242(\beta(C-H)), 1517$ $(v(C=N))$ e $1551 \mathrm{~cm}^{-1}$ estão ausentes no espectro SERS da mistura física. Note que, com exceção dos modos $v(C=N)$ e $v(C$ - $C l)$ ) os demais modos ausentes, assim como os modos vibracionais que permanecem com as mesmas energias são atribuídos ao grupo fenil. Note ainda que os modos ausentes estão associados com vibrações no plano enquanto os modos energeticamente inalterados são modos vibracionais fora do plano. Este comportamento pode ser explicado levando-se em conta as regras de seleção de superfície as quais sugerem que quando uma molécula está adsorvida horizontalmente à superfície do metal, os modos vibracionais fora do plano serão intensificados quando comparados com seus modos vibracionais no plano e vice versa quando esta molécula está adsorvida perpendicularmente à superfície [54]. 
Por outro lado, os deslocamentos para menores energias observados para os modos vibracionais associados ao anel triazol, podem ser explicados considerando a interação do nitrogênio heterocíclico da molécula de ITZ com o substrato de prata. Como resultado desta interação, há uma delocalização do elétron em torno da ligação $C=N$, formando a ligação $C-N-A g$, com modo vibracional em torno de $245 \mathrm{~cm}^{-1}$ [85] (ver Fig. 4.13). Como consequência, há um aumento do comprimento da ligação $C=N$, levando ao decréscimo das energias vibracionais observadas para o grupo triazol, ao desaparecimento do pico em 1517 $\mathrm{cm}^{-1}(C=N)$ e ao alargamento dos picos em 1383 e $1440 \mathrm{~cm}^{-1}$, ambos associados às vibrações da ligação $C-N$.

As mudanças espectrais descritas acima sugerem que as moléculas de ITZ presentes na mistura física (ITZ+PLGA-nano) estão adsorvidas na superfície do filme de prata nanoestruturado por meio do anel triazol, o qual estaria orientado perpendicularmente a superfície do filme. Além disso, devido à geometria da molécula é verificado que os anéis fenil (localizados no centro da molécula de ITZ) estão preferencialmente orientados paralelamente à superfície do filme de prata. Um esquema do arranjo espacial proposto para a adsorção do ITZ é mostrado na Fig. 4.14.

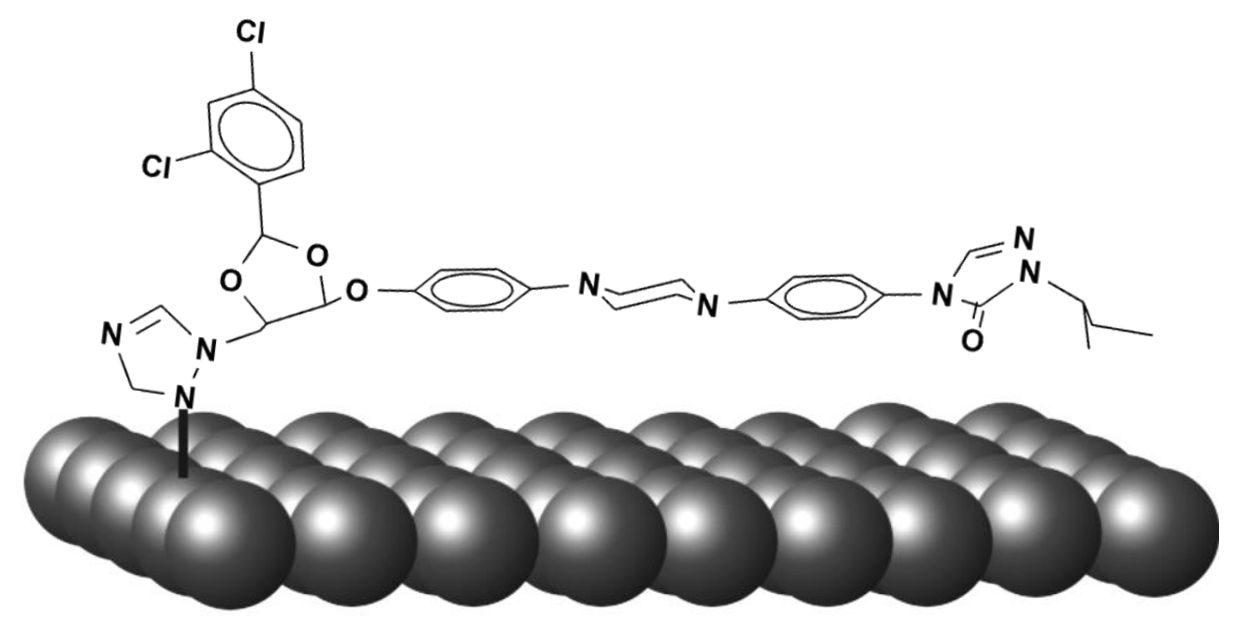

Figura 4.14: Esquema do arranjo espacial proposto para a adsorção do ITZ sobre a superfície de prata. 
A Fig 4.13 (iv) mostra o espectro SERS da amostra de ITZ carregada pelas nanopartículas de PLGA (ITZ@PLGA-nano). Verifica-se que este espectro apresenta características muito diferentes daquelas observadas para a amostra de ITZ+PLGA-nano (Fig. 4.13 (iii)). A diferença mais evidente é a presença de duas estruturas largas em torno de 1350 e $1600 \mathrm{~cm}^{-1}$, as quais podem estar associadas ao sinal Raman das nanopartículas de PLGA. Contudo, é possível observar que sobrepostos a estas bandas estão presentes os modos vibracionais do triazol e do fenil, com frequências muito próximas às observadas no ITZ pó. Outra importante diferença é a presença do pico em $1512 \mathrm{~cm}^{-1}$, atribuído à ligação $C=N$ e a ausência dos picos em 904 e $1173 \mathrm{~cm}^{-1}$, atribuídos aos modos vibracionais $\gamma(C-H)$ e $v(N-N)$, os quais foram fortemente intensificados na amostra de mistura física em virtude da adsorção da molécula de ITZ com a superfície de prata. Devido a estas evidências, é possível constatar que o efeito estérico provocado pelo carregamento do ITZ pelas NPs de PLGA impede a adsorção do ITZ com a superfície de prata. Contudo a presença dos modos vibracionais do ITZ no espectro SERS evidencia, que mesmo não havendo adsorção química, o efeito SERS ocorre em virtude do mecanismo eletromagnético. Este resultado é corroborado pelos os dados de FTIR mostrados na Fig. 4.12 (iii), onde não foi verificada a presença dos modos vibracionais do ITZ.

Finalmente, uma comparação entre os espectros SERS da amostra de IZT+PLGAnano (Fig. 4.13 (iii)) com a amostra de IZT@PLGA-nano sonicada por 5 min (Fig. 4.13 (v)), mostra que ambos os espectros apresentam as mesmas características. Ou seja, praticamente com as mesmas energias vibracionais, as mesmas intensidades relativas, bem como as mesmas larguras de linhas. É verificado somente um decréscimo na relação sinal/ruído. Provavelmente relacionado com a diminuição do teor de RIF disponível para adsorção na superfície do filme de prata. Este comportamento, mostra claramente que a discussão 
realizada anteriormente a respeito da amostra de mistura física de ITZ com nanopartículas de PLGA-nano pode ser aplicada para a amostra de ITZ@PLGA-nano sonicada por 5 minutos. Em outras palavras, pode-se concluir que o processo de sonicação quebrou as nanopartículas de PLGA, liberando as moléculas de itraconazol para serem adsorvidas na superfície do filme de prata.

\subsubsection{Conclusões}

Este estudo reporta o uso bem sucedido do espalhamento Raman intensificado por superfície (SERS) no estudo do carregamento de moléculas de Itraconazol (ITZ) em nanopartícula de PLGA (ITZ@PLGA-nano). Para comparação, o espectro Raman normal do ITZ pó assim como o espectro SERS da mistura física de ITZ com nanopartícula de PLGA (ITZ+PLGA-nano) foram também investigados. Os dados SERS mostraram que, diferentemente do observado para a mistura física de ITZ com nanopartículas de PLGA, as energias vibracionais do ITZ carregadas pelas nanopartículas de PLGA são iguais às encontradas para o ITZ pó. Estes resultados evidenciam que há adsorção das moléculas de ITZ à superfície do filme de prata para o caso do ITZ na mistura física, e que esta adsorção é suprimida pelo impedimento estérico provocado pelo PLGA, para o caso da amostra ITZ@PLGA. Com base nas alterações espectrais encontradas entre as moléculas de ITZ na mistura física e o ITZ pó foi possível propor um arranjo espacial esquemático para o processo de adsorção do ITZ à superfície do filme de prata. 


\section{Capítulo 5}

\subsection{Conclusões Gerais}

Este trabalho teve como objetivo principal utilizar a técnica SERS, na caracterização de complexos magnéticos e poliméricos nanoestruturados destinados a vetores de drogas. Para isso foram utilizados substratos SERS ativos, obtidos por eletrodeposição de íons prata. Estes substratos foram utilizados para estudar a adsorção de moléculas de Rifampicina (RIF) e SELOL à superfície de nanopartículas magnéticas à base de óxido de ferro e do fármaco Itraconazol (ITZ) carregado em nanopartículas de PLGA.

Do estudo das moléculas de RIF adsorvidas à superfície de nanopartículas magnéticas (NPMs), verificou-se que NPMs recobertas com uma bicamada de Ácido Laurico (AL) podem ser preparadas e utilizadas com sucesso no carreamento do fármaco Rifampicina. Com base nos resultados SERS, foi proposto que o ancoramento da RIF à superfície das NPMs 
ocorre por meio da ligação do grupo carboxilato proveniente da bicamada de AL com o nitrogênio piperazina adjacente ao nitrogênio imina da RIF.

Adicionalmente, foi também estudado o efeito da luz branca nas propriedades físicoquímicas da RIF livre e após sua adsorção à superfície de NPMs. Verificou-se que o espectro SERS da RIF livre, antes da exposição à luz branca, apresenta um modo $v(C=N)$ em 1623 $\mathrm{cm}^{-1}$, o qual indica a não existência de interação entre este grupo e o substrato de prata. Como resultado deste comportamento, foi também verificada a presença de modos vibracionais totalmente simétricos $\left(A_{1 \mathrm{~g}}\right.$ em $\left.1586 \mathrm{~cm}^{-1}\right)$ e de modos vibracionais proibidos $\left(\mathrm{B}_{1 \mathrm{u}}\right.$ e $\mathrm{B}_{2 \mathrm{u}}$ em 1435 e $1509 \mathrm{~cm}^{-1}$, respectivamente). Consideráveis alterações espectrais foram observadas após a exposição à luz branca. Neste caso, observou-se o quase desaparecimento do modo com simetria $A_{1 g}$ e a intensificação dos modos com simetria $B_{1 u}$ e $B_{2 u}$. Este comportamento sugere que a exposição à luz leva a uma redução na simetria do anel naftohidroquinona, o qual distorce a ligação $C=N$, explicando assim, tanto o decréscimo da intensidade como o alargamento do pico em $1623 \mathrm{~cm}^{-1}$. Verificou-se ainda que não há alterações significativas no espectro SERS do sistema onde a molécula de RIF está adsorvida à superfície da NP. Este resultado sugere que, quando adsorvida à superfície da NPMs, as moleculas de RIF são menos susceptíveis à degradação química do que a molécula livre.

No segundo caso foi estudada a adsorção da molécula de SELOL à superfície de NPMs, assim como a estabilidade desta adsorção quando este sistema é submetido a aquecimento por campo magnético alternado. Esta condição foi criada com o objetivo de simular o tratamento por magnetohipertemia. Comparando os espectros SERS das amostras FMS (antes do aquecimento) e FMSD (após aquecimento) com o espectro Raman normal do Selol puro, foi possível sugerir que as moléculas de Selol se ancoram à superfície da NPMs por meio da interação do grupo $O O S e O$ da molécula de Selol com o terminal do grupo carboxilato proveniente da bicamada de AL. Esta interação induz uma delocalização do 
elétron em torno da ligação $\mathrm{Se}=\mathrm{O}$, resultando em $\mathrm{SeO}^{-}$, o qual se liga ao terminal do grupo carboxilato procedente da bicamada de AL. Adicionalmente, estimou-se que cerca de $50 \%$ do das moléculas inicialmente adsorvidas à superfície das nanopartículas magnéticas permaneceram ancoradas após a amostra FMS ser submetida a aquecimento por um campo magnético alternado.

Por último, o carregamento do fármaco Itraconazol por nanopartículas de PLGA (ITZ@PLGA-nano) foi investigado com sucesso pela técnica SERS. Os dados Raman referentes às amostras de ITZ pó e ITZ@PLGA-nano revelaram que as energias vibracionais são iguais em ambos os casos. Somando-se a este fato, a presença do pico em $1512 \mathrm{~cm}^{-1}$ $(v(C=N))$ evidencia que, quando carregada pelas NPMs de PLGA, a molécula de ITZ não se adsorve à superfície do filme de prata em virtude do impedimento estérico provocado pelo PLGA. Por outro lado, as mudanças espectrais observadas entre o espectro Raman do ITZ pó e espectro SERS da amostra ITZ+PLGA-nano estão associadas com a adsorção do ITZ à superfície do filme de prata nanoestruturado por meio da interação do nitrogênio heterocíclico da molécula de ITZ com os átomos de Ag do substrato. Esta conclusão é suportada pela supressão do pico $1512 \mathrm{~cm}^{-1}$, referente ao modo vibracional da ligação $C=N$ e pelos deslocamentos para menores energias dos modos vibracionais provenientes do anel triazol. Além do mais, a constatação de que os modos vibracionais fora do plano, associados ao grupo fenil, assim como a ausência de modos vibracionais no plano do mesmo grupo molecular sugerem que os anéis fenil estão preferencialmente orientados paralelamente à superfície do filme de prata. Como consequência foi proposto um arranjo espacial esquemático para o processo de adsorção. 


\subsection{Perspectivas Futuras.}

- Estudar pela técnica SERS a eficácia dos sistemas FMBL/RIF, FMBL/Selol e ITZ@PLGAnano no tratamento de infecções fúngicas e câncer em sistemas in vitro e in vivo.

- Estudar pela técnica SERS sistemas nanoestruturados baseados em nanopartículas metálicas e de nanoemulsões. 


\section{Bibliografia}

[1] K. Guze, M. Short, H. Zeng, M. Lerman and S. Sonis, "Comparison of molecular images as defined by Raman spectra between normal mucosa and squamous cell carcinoma in the oral cavity," J. Raman Spectrosc., vol. 42, p. 1232-1239, 2011.

[2] M. Si, Y. Kang and Z. Zhang, "Surface-enhanced Raman scattering (SERS) spectra of Methyl Orange in Ag colloids prepared by electrolysis method," Appl. Surf. Sci., vol. 255, p. 6007-6010, 2009.

[3] S. Feng, R. Chen, J. Lin, J. Pan, Y. Wu, Y. Li, J. Chen and H. Zeng, "Gastric cancer detection based on blood plasma surface-enhanced Raman spectroscopy excited by polarized laser light," Biosens. Bioelectron., vol. 26, p. 3167-3174, 2011.

[4] D. L. de Faria, M. L. A. Temperini and O. Sala, "Vinte anos de efeito SERS," Quím. Nova, vol. 22, 1999.

[5] S. Nie and S. R. Emory, "Probing Single Molecules and Single Nanoparticles by SurfaceEnhanced Raman Scattering," Science, vol. 275, pp. 1102-1106, 1997. 
[6] W. Hayes and R. Loudon, Scattering of light by crystals, Nova Jersey: John Wiley \& Sons, 1978.

[7] C. V. Raman and K. S. Krisman, "A new type of secondary radiation," Nature, vol. 121, pp. 501-502, 1928.

[8] O. Sala, Fundamentos da espectroscopia Raman e no infravermelho, $2^{a}$ ed., São Paulo: Unesp, 2008.

[9] D. A. Long, The Raman Effect: A Unified Treatment of the Theory of Raman Scattering by Molecules, England: John Wiley \& Sons Ltd., 2002.

[10] E. Smith and G. Dent, Modern Raman spectroscopy - A practical approach, England: Wiley, 2005.

[11] A. J. McQuillan, "The discovery of surface-enhanced Raman scattering," The Royal Society, vol. 63, pp. 105-109, 2009.

[12] M. Fleischmann, P. J. Hendra and A. J. McQuillan, "Raman spectra of pyridine adsorbed at a silver electrode," Chem. Phys. Lett., vol. 26, pp. 163-166, 1974.

[13] D. L. Jeanmaire and R. P. V. Duyne, "Surface Raman spectroelectrochemistry: Part I. heterocyclic, aromatic, and aliphatic amines adsorbed on the anodized silver electrode," J. Electroanal. Chem., vol. 84, pp. 1-20, 1977.

[14] M. G. Albrecht and J. A. Creighton, "Anomalously intense Raman spectra of pyridine at a silver electrode," JACS, vol. 99, pp. 5215-5217, 1977.

[15] M. Z. Si, Y. P. Kang and R. M. Liu, "Surface-enhanced Raman scattering (SERS) spectra of three kinds of azo-dye molecules on silver nanoparticles prepared by electrolysis," Appl. Surf. Sci., vol. 258, pp. 5533-5537, 2012.

[16] C. H. Munro, W. E. Smith, M. Garner, J. Clarkson and P. C. White, "Characterization of the surface of a citrate-reduced colloid optimized for use as a substrate for surfaceenhanced resonance Raman scattering," Langmuir, vol. 11, pp. 3712-3720, 1995.

[17] J. A. Creighton, C. G. Blatchford and M. G. Albrecht, "Plasma resonance enhancement 
of Raman scattering by pyridine adsorbed on silver or gold sol particles of size comparable to the excitation wavelength," J. Chem. Soc., vol. 75, pp. 790-798, 1978.

[18] P. C. Lee and D. Meisel, "Adsorption and surface-enhanced Raman of dyes on silver and gold sols," J.l Phys. Chem., vol. 86, pp. 3391-3395, 1982.

[19] B. Palpant, B. Prével, J. Lerme, E. Cottancin, M. Pellarin, M. Treilleux, A. Perez, J. L. Vialle and M. Broyer, "Optical properties of gold clusters in the size range 2-4 nm," Phys. Rev. B, vol. 57, pp. 1963-1970, 1998.

[20] A. Campion and P. Kambhampati, "Surface-enhanced Raman Scattering," Chem. Soc., vol. 27, pp. 241-250, 1998.

[21] K. Kneipp, "Surface-enhanced Raman scattering," Phys. Today, pp. 40-46, 2007.

[22] C. M. B. Santos, Estudo pela técnica SERS do arranjo de moléculas bioativas adsorvidas em nanopartículas de óxido de ferro e de suas aplicações em sistemas biológicos, Tese de doutorado: UnB, 2012.

[23] V. O. dos S. Júnior, Estudos SERS (Surface-Enhanced Raman Scattering) em meio de líquido iônico BMIPF6 usando eletrodo de prata, Dissertação de mestrado: UnB, 2007.

[24] P. C. Morais, S. W. Silva, M. A. G. Soler, M. H. Sousa and F. A. Tourinho, "Raman study of ionic water-based copper and zinc ferrite magnetic fluids," J. Magn. Magn. Mater., vol. 201, pp. 105-109, 1999.

[25] S. W. Silva, R. C. Pedroza, P. P. C. Sartoratto, D. R. Rezende, A. V. d. S. Neto, M. A. G. Soler and P. C. Morais, "Raman spectroscopy of cobalto ferrite nanocomposite in silica matrix prepared by sol-gel method," J. Non-Cryst. Solids, vol. 352, pp. 1602-1606, 2006.

[26] J. C. Rubim, M. H. Sousa, J. C. O. Silva and F. A. Tourinho, "Raman spectroscopy as a powerful technique in the caracterization of ferrofluids," Braz. J. Phys., vol. 31, pp. 402408, 2001.

[27] L. Slavov, M. V. Abrashev, T. Merodiiska, C. Gelev, R. E. Vandenberghe, I. MarkovaDeneva and I. Nedkov, "Raman spectroscopy investigation of magnetite nanoparticles in 
ferrofluids," J.Magn.Magn. Mat., vol. 322, pp. 1904-1911, 2010.

[28] S. W. d. Silva, T. F. O. Melo, M. A. G. Soler, E. C. D. Lima, M. F. d. Silva and P. C. Morais, "Stability of citrate-coated magnetite and cobalto-ferrite nanoparticles under laser irradiation: a Raman spectroscopy investigation," IEEE T. Magn., vol. 39, pp. 26452647, 2003.

[29] P. C. Morais, S. W. d. Silva, M. A. G. Soler and N. Buske, "Raman spectroscopy in oleoylsarcosine-coated magnetic fluids: a surface grafting investigation," IEEE T. Magn., vol. 36, pp. 3712-3714, 2000.

[30] M. A. G. Soler, G. B. Alcantara, F. Q. Soares, W. R. Viali, P. P. C. Sartoratto, J. R. L. Fernandez, S. W. da Silva, V. K. Garg, A. C. Oliveira and P. C. Morais, "Study of molecular surface coating on the stability of maghemite nanoparticles," Surf. Sci., vol. 601, pp. 3921-3925, 2007.

[31] M. C. da Paz, M. F. M. A. Santos, C. M. B. Santos, S. W. da Silva, L. B. d. Souza, E. C. Lima, R. C. Silva, C. M. Lucci, P. C. Morais, R. B. Azevedo and Z. G. M. Lacava, "AntiCEA loaded maghemite nanoparticles as a theragnostic device for colorectal cancer," Int. J. Nanomedicine, 2012 (Aceito).

[32] C. M. B. Santos, S. W. da Silva, L. R. Guilherme and P. C. Morais, "SERRS Study of Molecular Arrangement of Amphotericin B Adsorbed onto Iron Oxide Nanoparticles Precoated with a Bilayer of Lauric Acid," J. Phys. Chem. C, vol. 115, pp. 20442 - 20448, 2011.

[33] S. R. Schaffazick, S. S. Guterres, L. d. L. Freitas and A. R. Pohlmann, "Caracterização e estabilidade físico-química de sistemas poliméricos nanoparticulados para administração de fármacos," Quím. Nova, vol. 26, no. 5, pp. 726 - 737, 2003.

[34] N. Durán, P. D. Marcato, O. L. Alves, G. I. D. Souza and E. Esposito, "Mechanistic aspects of biosynthesis of silver nanoparticles by several Fusarium oxysporum strains," $J$. Nanobiotechnol., vol. 3, no. 8, 2005.

[35] B. D. Howes, S. Scatragli, M. P. Marzocchi and G. Smulevich, "Surface-enhanced resonance Raman spectroscopy of rifamycins on silver nanoparticles: insight into their 
adsorption mechanisms," J. Raman Spectrosc., vol. 37, pp. 900-909, 2006.

[36] S. Mizuno, H. Yamazaki, K. Nitta and H. Umezawa, "Inhibition of DNA-dependent RNA polymerase reaction of Escherichia Coli by an antimicrobial antibiotic, streptovaricin," Biochim. Biophys. Acta, vol. 157, pp. 322 - 332, 1968.

[37] E. Hershfield, "Tuberculosis: 9. Treatment," in Clinical Basics, 4 ed., vol. 161, Manitoba, Canadian Medical Association, 1999, pp. 405 - 411.

[38] R. R. Reisbig, A.-Y. M. Woody and R. W. Woody, "Rifampicin as a spectroscopy probe of the mechanism of RNA polymerase from Escherichia coli," Biochemistry, vol. 21, pp. $196-200,1982$.

[39] R. S. Johnson, "A resonance Raman study on the interaction of rifampicin with Escherichia coli RNA polymerase," Biochim. Biophys. Acta, vol. 839, pp. 16 - 25, 1985.

[40] A. Sosnik, Á. M. Carcaboso, R. J. Glisoni and D. A. C. Marcela A. Moretton, "New old challenges in tuberculosis: Potentially effective nanotechnologies in drug delivery," $A d v$. Drug Delivery Rev., vol. 62, pp. 547 - 559, 2010.

[41] H. T. T. Thuy and T. T. C. Loan, "Degradation of Selected Pharmaceuticals in Coastal Wetland Water and Sediments," Water Air Soil Pollut, vol. 225, pp. 1940 - 1949, 2014.

[42] N. Changsa, A. Nilkaeo, P. Pungrassami and T. Srichana, "Monitoring safety of liposomes containing rifampicin on respiratory cell lines and in vitro efficacy against Mycobacterium bovis in alveolar macrophages.," J. Drug. Target., vol. 17, no. 10, pp. $751-762,2009$.

[43] J. Chuan, Y. Li, L. Yang, X. Sun, Q. Zhang, T. Gong and Z. Zhang, "Enhanced rifampicin delivery to alveolar macrophages by solid lipid nanoparticles," J. Nanopart. Res., vol. 15, pp. 1634 - 1643, 2013.

[44] H. A. A. Wab, K. A. Razak and N. D. Zakaria, "Properties of amorphous silica nanoparticles colloid drug delivery system synthesized using the micelle formation method," J. Nanopar.t Res., vol. 16, pp. 2256 - 2270, 2014. 
[45] C. M. B. Santos, S. W. da Silva, C. A. Saldanha, M. F. M. A. Santos, M. P. Garcia, R. B. Azevedo and P. C. Morais, "SERS as a valuable tool for detection and treatment followup of fungal infection in mice lungs: use of Amphotericin B and its nanoencapsulation onto magnetic nanoparticles," J. Raman Spectrosc., vol. 44, p. 695 - 702, 2013.

[46] B. D. Howes, L. Guerrini, S. Sanchez-Cortes and M. P. Marzocchi, "The influence of pH and anions on the adsorption mechanism of rifampicin on silver colloids," J. Raman Spectrosc., vol. 38, p. 859-864, 2007.

[47] S. Khalafalla and G. Reimers, "Preparation of dilution-stable aqueous magnetic fluids," IEEE Transactions on Magnetics, vol. 16, pp. 178-183, 1980.

[48] S. Agrawal, Y. Ashokraj, P. Bharatam, O. Pillai and R. Panchagnula., "Solid statecharacterization of rifampicin samples and its biopharmaceutic relevance," Eur. J. Pharm. Sci., vol. 22, pp. 127 - 144, 2014.

[49] A. Favila, M. Gallo and D. Glossman-Mitnik, "CHIH-DFT determination of the molecular structure infrared spectra, UV spectra and chemical reactivity of three antitubercular compounds: Rifampicin, Isoniazid and Pyrazinamide.," J. Mol. Model., vol. 13 , p. 505-518, 2007.

[50] C. Vora, R. Patadia, K. Mittal and R. Mashru, "Risk based approach for design and optimization of stomach specific delivery of rifampicin," Int. J. Pharm., vol. 455, p. 169$181,2013$.

[51] L. Angeloni, M. P. Marzocchi and G. Smulevich, "Resonance Raman Spectra and Excitation Profiles of Some Rifamycins," J. Raman Spectrosc., vol. 15, no. 2, pp. 90 - 96, 1984.

[52] E. Campbell, N. Korzheva, A. Mustaev, K. Murakami, S. Nair, A. Goldfarb and S. Darst., "Structural mechanism for rifampicin inhibition of bacterial rna polymerase.," Cell., vol. 104, no. 6, pp. 901 - 912, 2001.

[53] H. H. Abdullah, R. M. Kubba and M. Shanshal, "Vibration Frequencies Shifts of Naphthalene and Anthracene as Caused by Different Molecular Charges," $Z$. Naturforsch., vol. 58a, p. 645 - 655, 2003. 
[54] X. Gao, J. P. Davies and M. J. Weaver, "Test of surface selection rules for surfaceenhanced Raman scattering: the orientation of adsorbed benzene and monosubstituted benzenes on gold," J. Phys. Chem., vol. 94, no. 17, p. 6858-6864, 1990.

[55] A. Flis, P. Suchocki, M. A. Królikowska, Z. Suchocka, M. Remiszewska, L. Sliwka, I. Ksiazek, K. Sitarz, M. Sochacka, G. Hoser, E. Anuszewska, P. Wroczynski and Z. Iastrzebski, "Selenitetriglycerides - Redox - active agents," Pharmacol. Rep., vol. 67, pp. $1-8,2015$.

[56] B. Fitak, M. Grabowski and P.Suchocki.Polôna Patent Pol. Pl 176530 Cl. A61K31/095, 30 junho 1999.

[57] P. Suchocki, I. Misiewicz, K. Skupinska, K. Waclawek, Z. Fijalek and T. KasprzyckaGuttman, "The activity of Selol in multidrug-resistant and sensitive human leukemia cells.," Oncol. Rep., vol. 18, pp. 893 - 899, 2007.

[58] L. L. Estevanato, J. R. D. Silva, A. M. Falqueiro, E. M. Szablewska, P. Suchocki, A. C. Tedesco, P. C. Morais and Z. G. Lacava, "Co-nanoencapsulation of magnetic nanoparticles and selol for breast tumor treatment: in vitro evaluation of cytotoxicity and magnetohyperthermia efficacy.," Int. J. Nanomedicine, vol. 7, pp. 5285 - 5299, 2012.

[59] A. M. Falqueiro, M. P. Siqueira-Moura, D. R. Jardim, P. C. Morais, E. MosiniewiczSzablewska, P. Suchocki and A. C. Tedesco, "In vitro cytotoxicity of Selol-loaded magnetic nanocapsules against neoplastic cell lines under AC magnetic field activation.," J. Appl. Phys., vol. 111, p. 07B335, 2012.

[60] D. K. Chatterjee, P. Diagaradjane and S. Krishnan., "Nanoparticle-mediated hyperthermia in cancer therapy.," Ther. Deliv. , vol. 2, no. 8, pp. 1001 - 1014, 2011.

[61] S. Laurent, S. Dutzb, U. O. Häfeli and M. Mahmoudi., "Magnetic fluid hyperthermia: Focus on superparamagnetic iron oxide nanoparticles.," Adv. Colloid Interface Sci., vol. 166, no. 1 - 2, p. 8 - 23, 2011.

[62] Z. Jastrzebski, H. Czyzewska-Szafran, Z. Fijatek, P. Suchocki and B. A. Fitak, "Toxicity studies of a new selenium compound, Selol, in rats.," Drugs. Exp. Clin. Res., vol. 21, pp. $217-220,1995$. 
[63] R. A. Burley, "The Infrared Spectrum and Structure of Selenium Dioxide.," Mat. Res. Bull. , vol. 3, pp. 735 - 744, 1968.

[64] M. Ahuja, P. Verma and M. Bhatia, "Preparation and evaluation of chitosan-itraconazole co-precipitated," J. Exp. Nanosci., vol. 8, pp. 209 - 221, 2013.

[65] W. Hu, Y. Ran, K. Zhuang, J. Lama and C. Zhang, "Alternaria arborescens Infection in a Healthy Individual and Literature Review of Cutaneous Alternariosis," Mycopathologia, vol. 179, p. 147-152, 2015.

[66] Y. Zhu, Y. Shan, S. Fan, J. Li and X. Liu, "Candida parapsilosis Sensu Stricto and the Closely Related Species Candida orthopsilosis and Candida metapsilosis in Vulvovaginal Candidiasis," Mycopathologia, vol. 179, pp. 111 - 118, 2015.

[67] J. R. P. M. Strating et al., "Itraconazole Inhibits Enterovirus Replication by Targeting the Oxysterol-Binding Protein," Cell Rep., vol. 10, p. 600 - 615, 2015.

[68] T. Tao, Y. Zhao, J. Wu and B. Zhou, "Preparation and evaluation of itraconazole dihydrochloride for the solubility and dissolution rate enhancement," Int. J. Pharm., vol. 367, pp. 109 - 114, 2009.

[69] L. Qiu, B. Hu, H. Chen, S. Li, Y. Hu, Y. Zheng and X. Wu, "Antifungal efficacy of itraconazole-loaded TPGS-b-(PCL-ran-PGA) nanoparticles," Int. J. Nanomedicine, vol. 10, pp. 1415 - 1423, 2015.

[70] N. Kumar, S. Goindi, B. Saini and G. Bansa, "Thermal chacacterization and compatibility studies of itraconazole and excipients for development of solid lipid nanoparticles," j. Therm. Anal. Calorim., vol. 115, pp. 2375 - 2383, 2014.

[71] G. Kister, G. Cassanas and M. Vert, "Structure and morphology of solid lactide-glycolide copolymers from 13C n.m.r., infra-red and Raman spectroscopy," Polymer, vol. 39, no. 15, pp. 3335 - 3340, 1997.

[72] F. Danhier, E. Ansorena, J. M. Silva, R. Coco and V. P. Aude Le Breton, "PLGA-basead nanoparticles: An overview of biomedical applications," J. Controlled Release, vol. 161, pp. $505-522,2012$. 
[73] A. J. Wang, Y.-P. Lu and R.-X. Sun, "Recent progress on the fabrication of hollow microspheres," Mater. Sci. Eng. : A, Vols. 460 - 461, pp. 1 - 6, 2007.

[74] M. Muniz-Miranda, "SERS monitoring of the catalytic reduction of 4-nitrophenol on Agdoped titania nanoparticles," Appl. Catal. B: Environ., vol. 146, pp. 147 - 150, 2014.

[75] B. S. Zolnik and D. J. Burgess, "Effect of acidic pH on PLGA microsphere degradation and release," Journal of Controlled Release, vol. 122, p. 338 - 344, 2007.

[76] Y. Tang, T. Lei, R. Manchanda, A. Nagesetti, A. Fernandez-Fernandez and A. McGoron, "Simultaneous delivery of chemotherapeutic and thermal-optical agents to cancer cells by a polymeric (PLGA) nanocarrier: an in vitro study.," Pharm. Res., vol. 27, no. 10, pp. $2242-2253,2010$.

[77] D. I. Nesseem, "Formulation and evaluation of itraconazole via liquid crystal for topical delivery system," J. Pharm. Biomed. Anal., vol. 26, p. 387 - 399, 2001.

[78] G. M. E. Maghraby and A. H. Alomrani, "Synergistic Enhancement of Itraconazole Dissolution by Ternary System Formation with Pluronic F68 and Hydroxypropylmethylcellulose," Sci. Pharm. , vol. 77, pp. 401 - 417, 2009.

[79] L. De Smet, L. Saerens, T. D. Beer, R. Carleer, P. Adriaensens, J. V. Bocxlaer, C. Vervaet and J. P. Remon., "Formulation of itraconazole nanococrystals and evaluation of their bioavailability in dogs.," Eur. J. Pharm. Biopharm., vol. 87, pp. 107 - 113, 2014.

[80] Y. Wang, Y.-H. Luo, J. Zhao and B.-W. Sun, "Selection of excipients for dispersible tablets of itraconazole through the application of thermal techniques and Raman spectroscopy," J. Therm. Anal. Calorim., vol. 115, pp. 2391 - 2400, 2014.

[81] K. Bahgat and S. Fraihat, "Normal coordinate analysis, molecular structure, vibrational, electronic spectra and NMR investigation of 4-Amino-3-phenyl-1H-1,2,4-triazole-5(4H)thione by ab initio HF and DFT method," Spectrochim. Acta A, vol. 135, pp. 1145-1155, 2015.

[82] A. H. Al-Marzouqi, H. M. Elwy, I. Shehadi and A. Adem, "Physicochemical properties of antifungal drug-cyclodextrin complexes prepared by supercritical carbon dioxide and 
by conventional techniques," J. Pharm. Biomed. Anal., vol. 49, p. 227 - 233, 2009.

[83] S. Y. Li and M. Wang, "Novel core-shell structured Paclitaxel-loaded PLGA@Ag-Au nanoparticles," Mater. Lett., vol. 92, pp. 350 - 353, 2013.

[84] B. Pergolese, M. Muniz-Miranda and A. Bigotto., "Study of the Adsorption of 1,2,3Triazole on Silver and Gold Colloidal Nanoparticles by Means of Surface Enhanced Raman Scattering," J. Phys. Chem. B., vol. 108, no. 18, pp. 5698 - 5702, 2004.

[85] J. Grdadolnik, "ATR-FTIR spectroscopy: Its advantages and limitations," Acta Chim. Slov., vol. 49, pp. 631 - 642, 2002.

[86] S. Wartewiga and R. H. Neuber, "Pharmaceutical applications of Mid-IR and Raman spectroscopy," Adv. Drug Delivery Rev., vol. 57, pp. 1144 - 1170, 2005. 